\title{
Präparation und röntgenkristallographische Untersuchungen an archaebakteriellen Box C/D sRNPs und einer neuartigen Glukosyltransferase aus Thermotoga maritima MSB8
}

\section{Dissertation}

\author{
zur \\ Erlangung des Doktorgrades \\ der Mathematisch-Naturwissenschaftlichen Fakultäten \\ der Georg-August-Universität zu Göttingen
}

vorgelegt von

Carmen Steinke

aus Attendorn

Göttingen, 2004 
D7

Referent: Prof. Dr. Ralf Ficner

Korreferent: Prof. Dr. Oliver Einsle

Tag der mündlichen Prüfung: 03 November 2004 
Meinen Eltern 
Die Natur ist uneshitterlich und unverändeslich, and es ist iles gleichgilltif, ol die verbargenen Gründe und Arten ibses Handeless dem Menschen verständlich sind oder nicht.

Galilea Galilei 


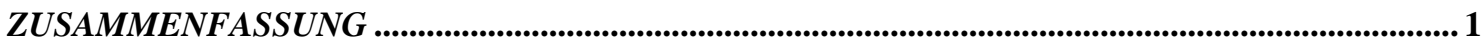

1. EINLEITUNG

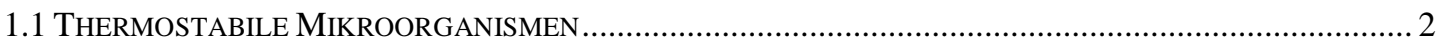

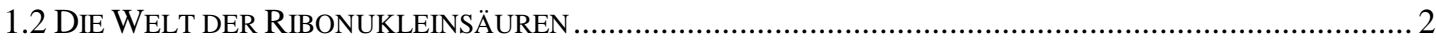

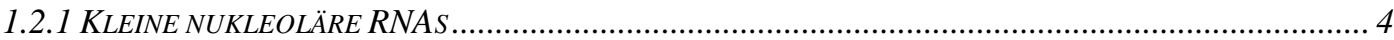

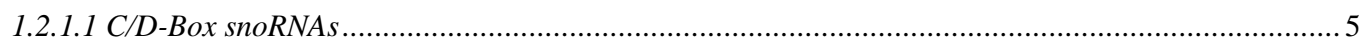

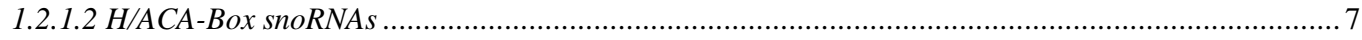

1.2.1.3 Die Endoribonukleasen RNase MRP und RNase P ....................................................... 8

1.2.1.4 Modifizierung zellulärer RNAs durch snoRNPs .................................................................. 9

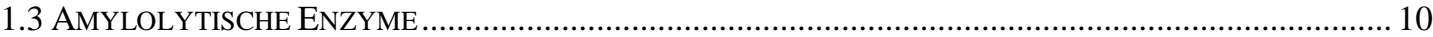

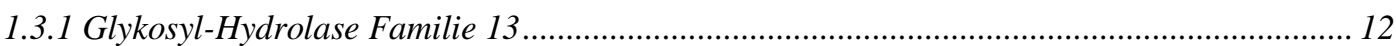

1.3.1.1 Sequenzeigenheiten und strukturelle Besonderheiten der GHF 13 .......................................... 13

1.3.1.2 Die Bindung von $\mathrm{Ca}^{2+}$ an GHF $13 \alpha$-Amylasen ....................................................................... 17

1.3.1.3 Thermostabile $\alpha$-Amylasen: Strukturelle Voraussetzungen zum Überleben an extremen Standorten

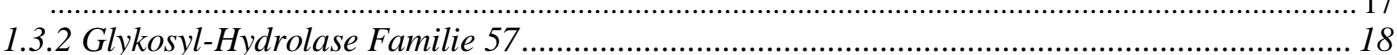

1.3.2.1 Glykosyl-Hydrolase Familien 13 und 57: Besitz eines gemeinsamen Ursprungs? ........................ 19

1.3.2.2 Amylase B aus Thermotoga maritima MSB8: ein Mitglied der GHF 57 ...................................... 19

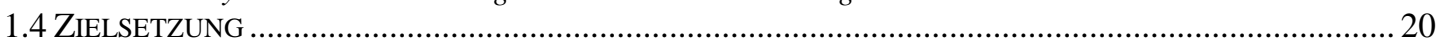

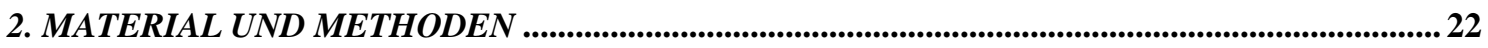

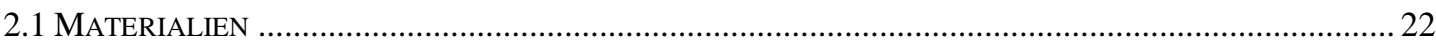

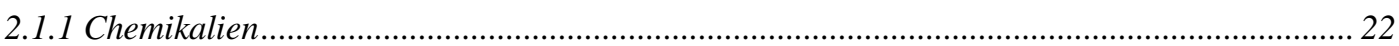

2.1.2 Kulturmedien, Antibiotika und Medienzusätze ............................................................... 22

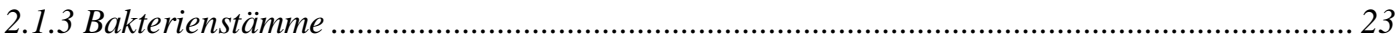

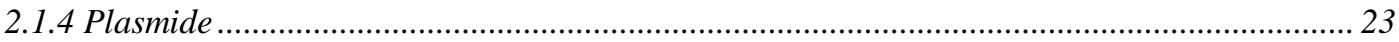

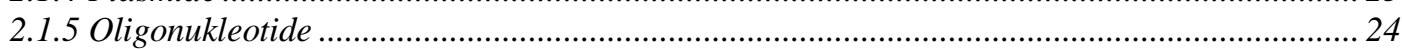

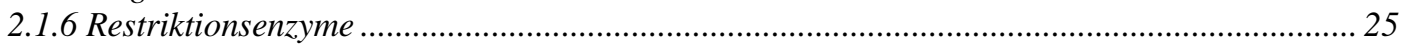

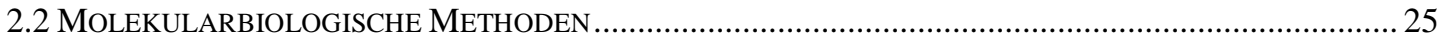

2.2.1 Isolierung von DNA aus Bakterien (Plasmidpräparation) ............................................... 25

2.2.2 Konzentrationsbestimmung von Nukleinsäuren................................................................. 26

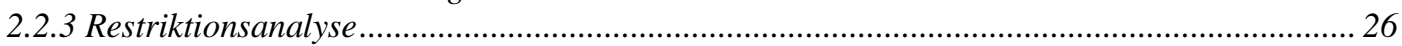

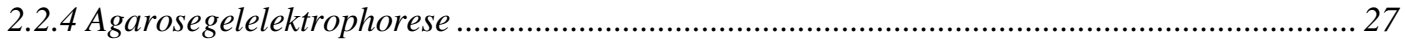

2.2.5 Herstellung kompetenter Zellen........................................................................................... 28

2.2.6 Transformation von Plasmid-DNA in E. coli-Zellen ........................................................... 28

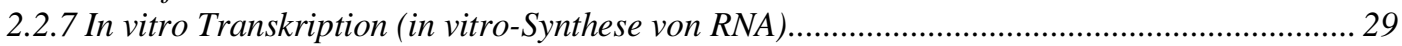

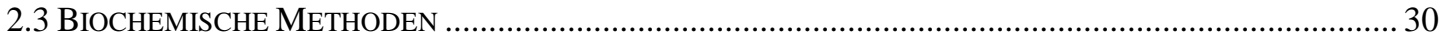

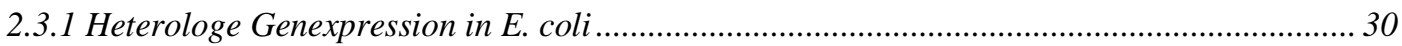

2.3.2 Reinigung der exprimierten Proteine aus E. coli-Zellen ....................................................... 31

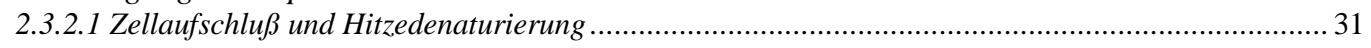

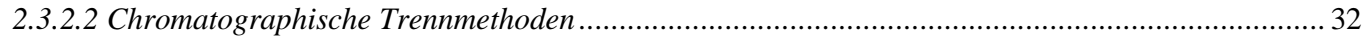

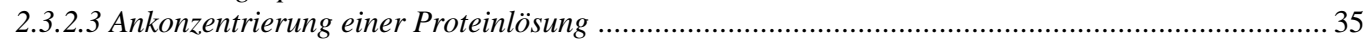

2.3.3 Proteinbestimmung nach BRADFORD (1979)................................................................. 37

2.3.4 Diskontinuierliche SDS-Polyacrylamid-Gelelektrophorese nach LAEMMLI (1970)................ 37

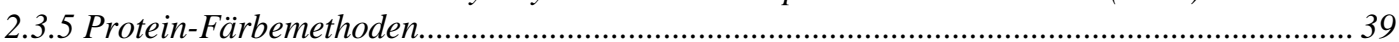

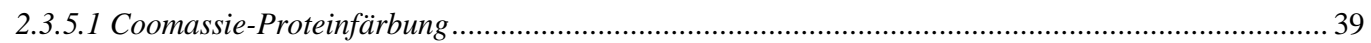

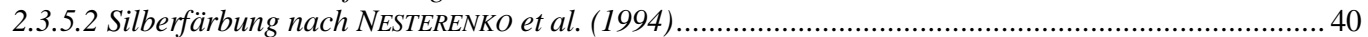

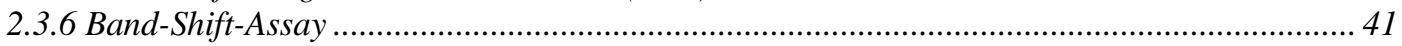

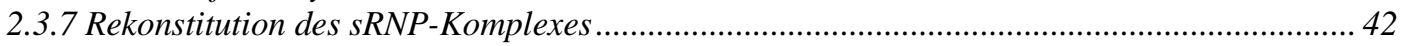

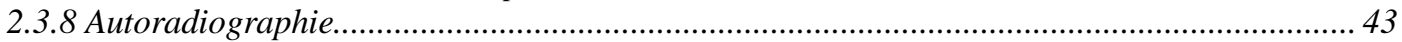

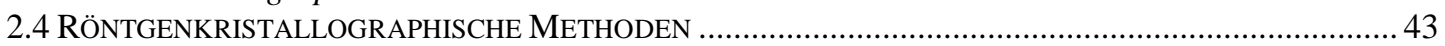

2.4.1 Kristallisation biologischer Makromoleküle ................................................................... 44

2.4.2 Co-Kristallisation und Derivatisierung durch Diffusion (Soaking)..................................... 45

2.4.2.1 Co-Kristallisation von RNA-Protein- und Protein-Protein-Komplexen ....................................... 45

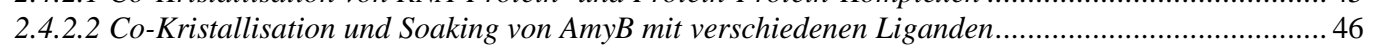

2.4.3 Kryo-Konservierung und Montage der Kristalle zur Datensammlung ................................. 47

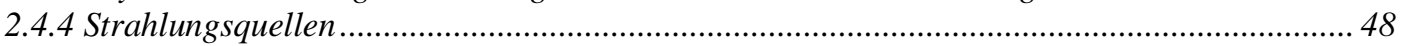

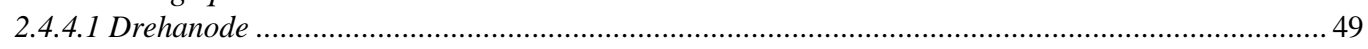

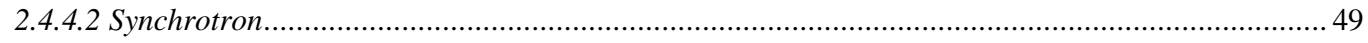




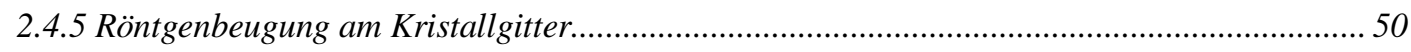

2.4.6 Prozessierung der Meßdaten .................................................................................................. 51

2.4.7 Vergleich der AmyB-Struktur mit bekannten Strukturen ..................................................... 52

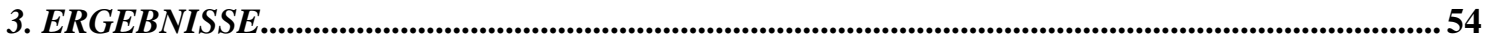

3.1 EXPRESSION UND REINIGUNG DER SRNP-PROTEINE AL7, ANOP56 UND AFIB ...............................5 54

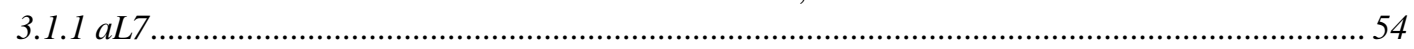

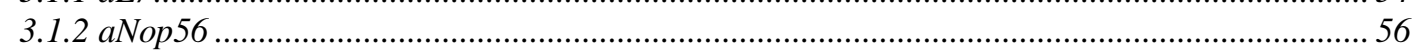

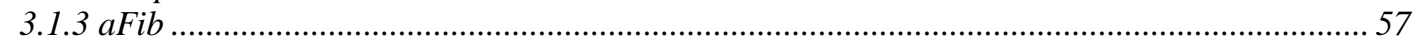

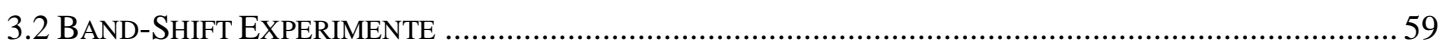

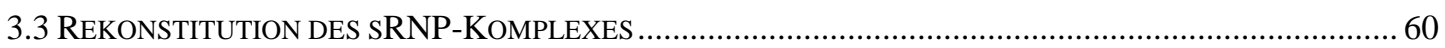

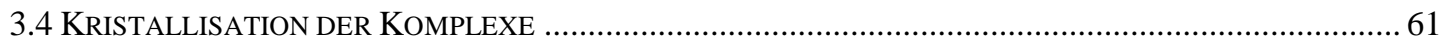

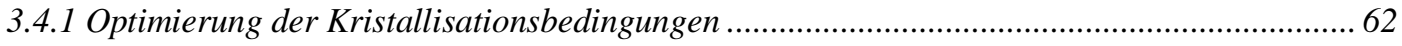

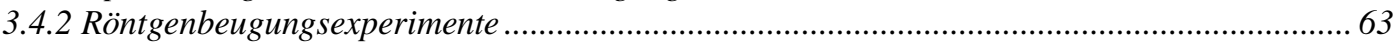

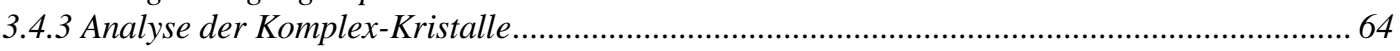

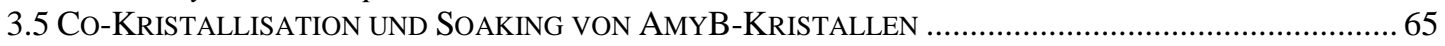

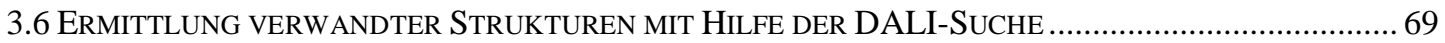

3.6.1 Vergleich von AmyB mit der 4- $\alpha$-Glukanotransferase ........................................................... 71

3.6.2 Vergleich von AmyB mit IUFA aus Thermus thermophilus Hb8 .......................................... 75

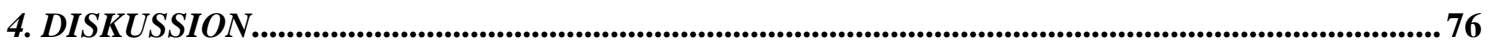

4.1 REKONSTITUTION UND KRISTALLISATIONSVERSUCHE EINES SRNP-KOMPLEXES ............................ 76

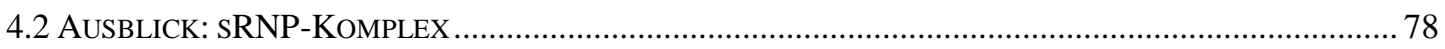

4.3 VERGLEICHENDE UNTERSUCHUNGEN VON AMYB MIT VERWANDTEN STRUKTUREN ....................... 79

4.3.1 Charakteristische Sequenz- und Strukturelemente von AmyB, einem Mitglied der Glykosyl-

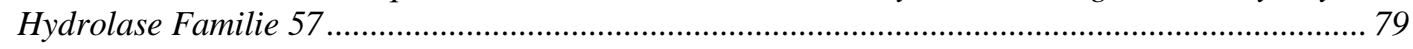

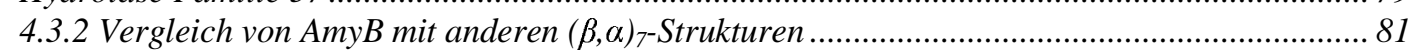

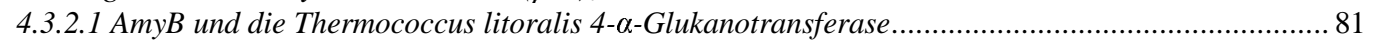

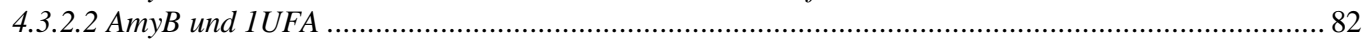

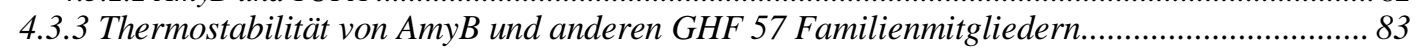

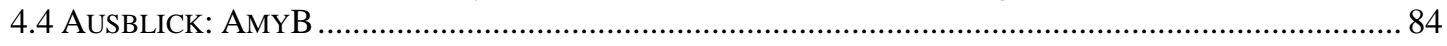

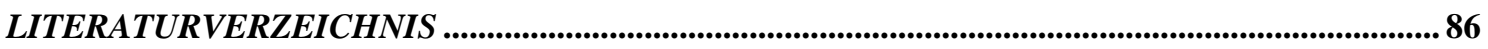

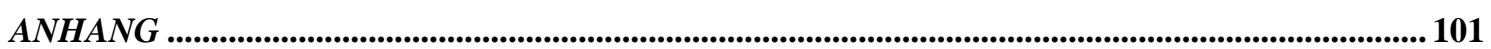

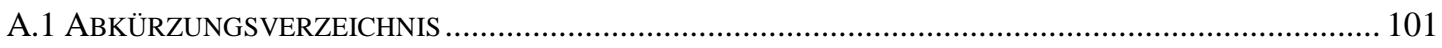

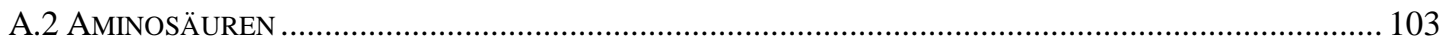

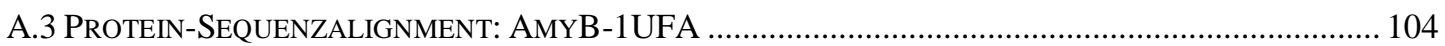

A.4 PRoteINSEQUENZEN DER SRNP PROTEINE AL7, ANOP56 UND AFIB .......................................... 106

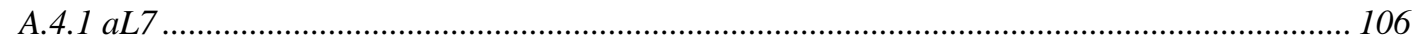

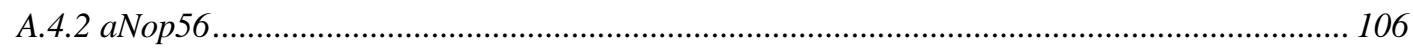

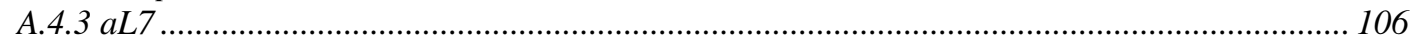




\section{ZUSAMMENFASSUNG}

Ribosomale RNAs werden posttranskriptional durch kleine nukleoläre RNAs (snoRNAs) modifiziert. Dabei kommt es zum einen zur Umwandlung von Uridin in Pseudouridin durch die H/ACA-Box snoRNAs und zum anderen zur 2'-O-Methylierung von Ribose durch Box C/D snoRNAs, wobei beide snoRNA-Familien mit spezifischen Proteinen zu kleinen nukleolären Ribonukleoprotein Partikeln (snoRNPs) assembliert sind. In zellkernlosen Prokaryonten konnten homologe RNAs (sRNAs) und Proteine identifiziert werden, die ebenfalls an der Modifizierung von ribosomalen RNAs beteiligt sind.

Ein Komplex aus einer C/D-Box sRNA und den Proteinen aL7, aNop56 und aFibrillarin aus Sulfolobus solfataricus konnte rekonstituiert werden. Die Kristallisation des rekonstituierten Komplexes lieferte jedoch nur Kristalle, die aufgrund ihrer geringen Auflösung ( $14 \AA$ Å) nicht für eine Strukturaufklärung verwertbar waren. Eine Analyse der Kristalle zeigte des weiteren, daß der rekonstituierte Komplex wieder dissoziierte und nur ein Komplex aus aFibrillarin und einem degradierten aNop56 gebildet worden war.

Das im Jahr 1998 identifizierte Enzym Amylase B aus Thermotoga maritima MSB8 wurde aufgrund seiner Fähigkeit, Stärke und deren Abbauprodukte Amylose und Amylopektin an den $\alpha$-1,4-glykosidischen Bindungen zu spalten, als $\alpha$-Amylase deklariert. Eine Einordnung der Amylase B in die Glykosyl-Hydrolase Familie 57 wird zum einen durch die fehlenden, für die Glykosyl-Hydrolase Familie 13 (typische $\alpha$-Amylasen) charakteristischen Konsensus-Sequenzen in Amylase B und zum anderen durch geringe Sequenzähnlichkeiten und einem gleichen Hydrolysemuster zu einem Mitglied der Glykosyl-Hydrolase Familie 57 gestützt. Die Aufklärung der Amylase BStruktur, in der das strukturell konservierte $(\beta, \alpha)_{8}$-Barrel in einer verzerrten und verkürzten Variante das katalytische Zentrum bildet, festigen die Eingliederung. Ein struktureller Vergleich der katalytischen Domäne von Amylase B mit einer verwandten Struktur aus Thermococcus litoralis, der 4- $\alpha$-Glukanotransferase, konnte eine Blockierung der Bindungsstelle durch mehrere Aminosäurereste in Amylase B zeigen. 


\section{EINLEITUNG}

\subsection{THERMOSTABILE MIKROORGANISMEN}

Mikroorganismen haben sich im Laufe der Evolution perfekt an die verschiedensten Umweltbedingungen angepaßt. So wurden Mikroorganismen identifiziert, die an den extremsten Standorten, wie z.B. Salzlaken, schwefelhaltigen und/oder heißen Quellen, überleben. Dies ist den Mikroorganismen nur möglich, da ihr Stoffwechsel enorm anpassungsfähig und von aerober Autotrophie bis zur anaeroben Heterotrophie alles zu finden ist (DELONG, 2001).

Thermostabile Mikroorganismen, die unterteilt werden können in thermophil $\left(55-80^{\circ} \mathrm{C}\right)$ und hyperthermophil $\left(>80^{\circ} \mathrm{C}\right)$, kommen dabei sowohl in den Eubakterien als auch in den Archaebakterien (Archaea) vor (HougH \& DANSON, 1999).

Interessanterweise finden sich sowohl bei Eubakterien als auch bei Archaebakterien Proteine, die neben charakteristischen Sequenzmotiven auch in ihrer Wirkung zu Proteinen in höheren Organismen homolog sind. Da sich archae- und eubakterielle Proteine, im Gegensatz zu Proteinen aus höheren Organismen, leicht in dem gut untersuchten Organismus Escherichia coli heterolog exprimieren und anschließend gut und in ausreichender Menge reinigen lassen, wird dieses System häufig verwendet, um Proteine rekombinant herzustellen und anschließend z.B. durch Mutagenesestudien und enzymkinetischen Untersuchungen die funktionellen Mechanismen aufzuklären. Neben der Verwendung biochemischer und molekularbiologischer Methoden wird zur weiteren Klärung von Funktion und Auftreten eines Proteins in einer Zelle oft auch die Struktur der Proteine benötigt. Diese kann z.B. mit Hilfe der Röntgenkristallographie aufgeklärt werden.

\subsection{DIE WELT DER RIBONUKLEINSÄUREN}

Betrachtet man die heutigen Organismen, stellt man fest, daß sie aus Proteinen bestehen, die aus nur 20 verschiedenen Aminosäuren aufgebaut sind. Die Information, die zum Bau und zur Vervielfältigung der Proteine benötigt wird, ist in den Nuklein- 
säuren, die aus 4 Basen bestehen, codiert. Sowohl Proteine als auch Nukleinsäuren leben in einem gegenseitigen Abhängigkeitsverhältnis, d.h. Nukleinsäuren werden zum Aufbau der Proteine benötigt und die Nukleinsäuren werden mit Hilfe der Proteine synthetisiert.

Man ist sich heute jedoch einig, das zu Beginn Information und Funktion in einem Molekül entstanden ist (RNA-Welt Hypothese). Am Anfang war wahrscheinlich eine einfach strukturierte prä-RNA (Ribonukleinsäure; engl.: ribonucleic acid), die später in die heute bekannte, komplexere RNA-Struktur übergegangen ist, als Informationsträger aktiv. Dabei wird angenommen, daß einzelsträngige Nukleinsäure, bestehend aus ca. 50-100 Nukleotiden, in einer primitiven Zelle in der Lage ist, sich durch Ausbilden einer Sekundärstruktur selbst zu stabilisieren, zu replizieren und chemische Reaktionen zu katalysieren. Gestützt wird diese Annahme durch die heute noch existierenden tRNA (Transfer-RNA) Kleeblattstrukturen und durch die Entdekkung der Ribozyme, die eine Selbstreplikation der RNA vorstellbar machte.

Auf die RNA-Welt folgte die DNA-Welt, bei der es gelang, die Gene eines Organismus auf einer stabileren, doppelsträngigen DNA (Desoxyribonukleinsäure; engl.: desoxyribonucleic acid) unterzubringen. Die Replikation der DNA ist mit weniger Kopierfehlern behaftet und kann autonom reguliert werden. Ein vollständiger Übergang von der RNA-Welt zur DNA-Welt hat jedoch nie stattgefunden, da noch heute grundlegende Reaktionen von RNAs katalysiert werden (s. Abb. 1.1).

Während die DNA als Informationsträger im Organismus vorliegt, ist die RNA heute überwiegend in der Proteinbiosynthese von Bedeutung. Bei der Herstellung von Proteinen aus der genetischen Information werden hauptsächlich drei Arten von RNA benötigt. Dabei werden zuerst die Strukturgene, die auf der DNA liegen, auf einen komplementären Strang Messenger-RNA (mRNA) überschrieben. Anschließend wird die mRNA am Ribosom, das aus ribosomaler RNA (rRNA) und Proteinen aufgebaut ist, mit Hilfe der Transfer-RNA (tRNA) in Peptide übersetzt.

Bei $\sim 80 \%$ der in der sich teilenden Zelle vorkommenden RNA handelt es sich um rRNA. Sie bilden den Kern des Ribosoms und werden im Unterschied zu mRNAs durch die im Nukleolus enthaltene Polymerase I und nicht durch die nukleoplasmatische Polymerase II in eukaryontischen Zellen synthetisiert. Der Unterschied besteht in einem Schwanz, den die Polymerase I im Gegensatz zur Polymerase II nicht besitzt, und daher 
weder ein Cap noch einen PolyA-Schwanz an die rRNA anhängt. Es existieren vier verschiedene Arten von rRNAs, wobei jede nur einmal im Ribosom vorhanden ist. Während die rRNAs 18S, 5,8S und 28S aus einem großen Vorläufer-rRNA-Molekül, der sogenannten 45S rRNA, hervorgehen, wird die 5S rRNA direkt durch die Polymerase III synthetisiert. Die 13000 Nukleotide lange 45S rRNA wird an ca. 120 2'-OH-Gruppen der Nukleotidzucker methyliert und ca. 100 Uridine werden zu Pseudouridin isomerisiert (MADEN, 1990).

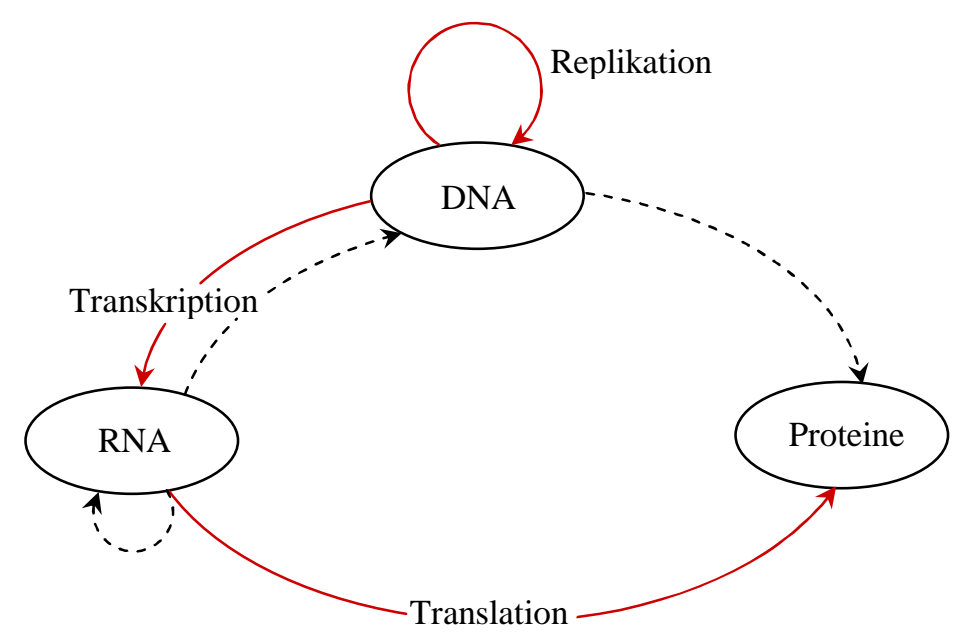

Abbildung 1.1: Dogma der Molekularbiologie. Durchgehende Pfeile zeigen den Transfer genetischer Informationen, wie sie in allen Zellen zu finden sind. Gestrichelte Pfeile stellen spezielle Übertragungen dar. Eine direkte Translation von DNA zu Protein ist bislang nicht bekannt, ist aber nicht unmöglich. Proteine hingegen können nur Empfänger genetischer Informationen sein (aus VOET \& VOET, 1994: nach CRICK (1970))

\subsubsection{KLEINE NUKLEOLÄRE RNAS}

Bei der nukleolären Biogenese von cytoplasmatischen Ribosomen in eukaryontischen Zellen werden in komplexen Vorgängen die ribosomalen Ribonukleinsäuren (ribosomal ribonucleic acids: rRNAs) aus Vorläufer-RNAs (precursor-rRNAs: prärRNAs) prozessiert, indem innere (ITS1 und ITS2) und äußere (5' ETS und 3' ETS) 
Spacer-Sequenzen endo- beziehungsweise exonukleolytisch entfernt werden. Daneben ist eine Vielzahl von kleinen metabolisch stabilen RNAs (ㅍmall nucleolar ribonucleic acids: snoRNAs) bekannt, durch die die rRNAs posttranskriptional modifiziert werden, indem jede prä-rRNA mit ungefähr 150-200 verschiedenen snoRNAs während ihrer Entwicklung in Kontakt kommt.

Die beiden am häufigsten auftretenden Modifikationen durch snoRNAs sind die 2'-O-Methylierung bestimmter Ribose-Gruppen und die Umwandlung von Uridin in Pseudouridin. Von anderen snoRNAs ist bekannt, daß sie die korrekte Faltung oder das Spalten der prä-rRNA steuern. In der Zelle kommen die snoRNAs nur in mit nukleolären Proteinen (nnucleolar proteins: Nop's) assoziierter Form als kleine nukleoläre Ribonukleoprotein Partikel (small nucleolar ribonucleoprotein particle: snoRNP) vor (Filipowicz ET AL., 1999; WeInSTEIN \& SteITZ, 1999). Durch konservierte Sequenzabschnitte, die als Bindungsstellen für die Proteine dienen, können die snoRNAs in drei große Klassen unterteilt werden. Es handelt sich dabei um die C/D-Box snoRNAs, die H/ACA-Box snoRNAs und die Endoribonukleasen RNase MRP und RNase P, die vielleicht als Ribozyme an der prä-rRNA Spaltung beteiligt sind.

\subsubsection{C/D-Box snoRNAs}

Die Mitglieder der C/D-Box snoRNA-Familie werden nach ihren zwei kurzen konservierten Sequenzmotiven, der C-Box (RUGAUGA, wobei das R für ein Purin steht) und der D-Box (CUGA) benannt (BALAKIN ET AL., 1994). Die beiden Enden der RNA sind durch eine kurze komplementäre Sequenz miteinander verbunden. Zwischen der C-Box am 5'-Ende und der D-Box am 3'-Ende der snoRNA liegt eine unstrukturierte Schleife, die homologe aber oft unvollständige Kopien der Boxen C und D (C'und D’-Box) enthält (BALAKIN ET AL., 1994; BACHELlERIE ET AL., 1995). Der Abstand zwischen den Boxen C' und D' ist auf 3-9 Nukleotide beschränkt. Häufig werden dabei die beiden Boxen durch eine Stammbildung näher zusammen gebracht (KISS, 2001). Eine oder manchmal auch zwei 10-22 Nukleotid lange Sequenzen, die komplementär zu Abschnitten einer reifen rRNA sind, liegen in der Schleife stromaufwärts vor der Doder D'-Box (Abb. 1.2 A) (BACHELlERIE ET AL., 1995). In der rRNA, die an dieser Sequenz bindet, wird das Nukleotid methyliert, das mit exakt dem fünften Nukleotid 
vor dem Start des D- oder D'-Motives basenpaart (TYCOWSKI ET AL, 1996; KISSLÁSZLó ET AL., 1998). Die Boxen C und D sind essentielle Stabilisierungsfaktoren bei der Prozessierung der prä-snoRNA und bei der Bindung des snoRNP-Komplexproteins Fibrillarin (BASERGA ET AL., 1991).

Um rRNAs methylieren zu können, binden die snoRNAs an nukleoläre Proteine und bilden snoRNPs. Als allgemein in humanen Box C/D snoRNPs vorkommende Proteine konnten dabei Fibrillarin (Ortholog in Saccharomyces cerevisiae: Nop1p), Nop56 (Nop56p), Nop58 (Nop58p) und 15,5 kDa (Snu13p) identifiziert werden (KISSLÁSZló ET AL., 1996; GAUTIER ET AL., 1997; WATKINS ET AL., 2000). In Fibrillarin wurde ein für Methyltransferasen charakteristisches S-Adenosylmethionin- (Adomet) bindendes Motiv entdeckt (Tollervey ET AL., 1993; WANG ET AL., 2000; AiTTALEB ET AL., 2003). Bei Versuchen, in denen eine Aminosäure dieses Motivs substituiert wurde, konnte gezeigt werden, daß es zu einem temperatur-sensitven Defekt bei der rRNA Methylierung kommt. Eine Funktion der Paraloge Nop56 und Nop58 ist bislang nicht bekannt, sie sind jedoch für den gesamten Ablauf der Methylierung ebenso wichtig wie das Fibrillarin. Das 15,5 kDa Protein kommt sowohl in C/D-Box snoRNPs als auch in spleißosomalen U4/U6.U5 tri-snRNPs (ㅍmall nuclear RNPs) vor und gehört zu einer Familie RNA-bindender Proteine (NotTROTT ET AL., 1999; WATKINS ET AL., 2000). Die Proteine binden an eine interne purinreiche $5+2$ Schleife (s. Abb. 1.2 B), deren Faltung durch zwei Tandem G•A Basenpaare und einer Base, die aus der Schleife herausragt, charakterisiert wird (VIDOVIC ET AL., 2000). Die 5+2 Schleife findet sich auch in dem U3-spezifischen B/C-Box Motiv und bindet ebenfalls das 15,5 kDa Protein (WATKINS ET AL., 2000).

In dem Archaebakterium Sulfolobus solfataricus, das als Prokaryont keinen Zellkern und somit auch keine snoRNAs besitzt, konnten sRNAs identifiziert werden, die zu den snoRNAs homolog sind. Die sRNAs formen mit den archaebakteriellen Proteinen aL7 (Ortholog in Homo sapiens: 15,5 kDa), aNop56 (Nop56/Nop58) und aFibrillarin (Fibrillarin) einen sRNP-Komplex, der homolog zu den snoRNPs an der 2'-O-Methylierung der rRNAs beteiligt ist (OMER ET AL., 2002). 
A
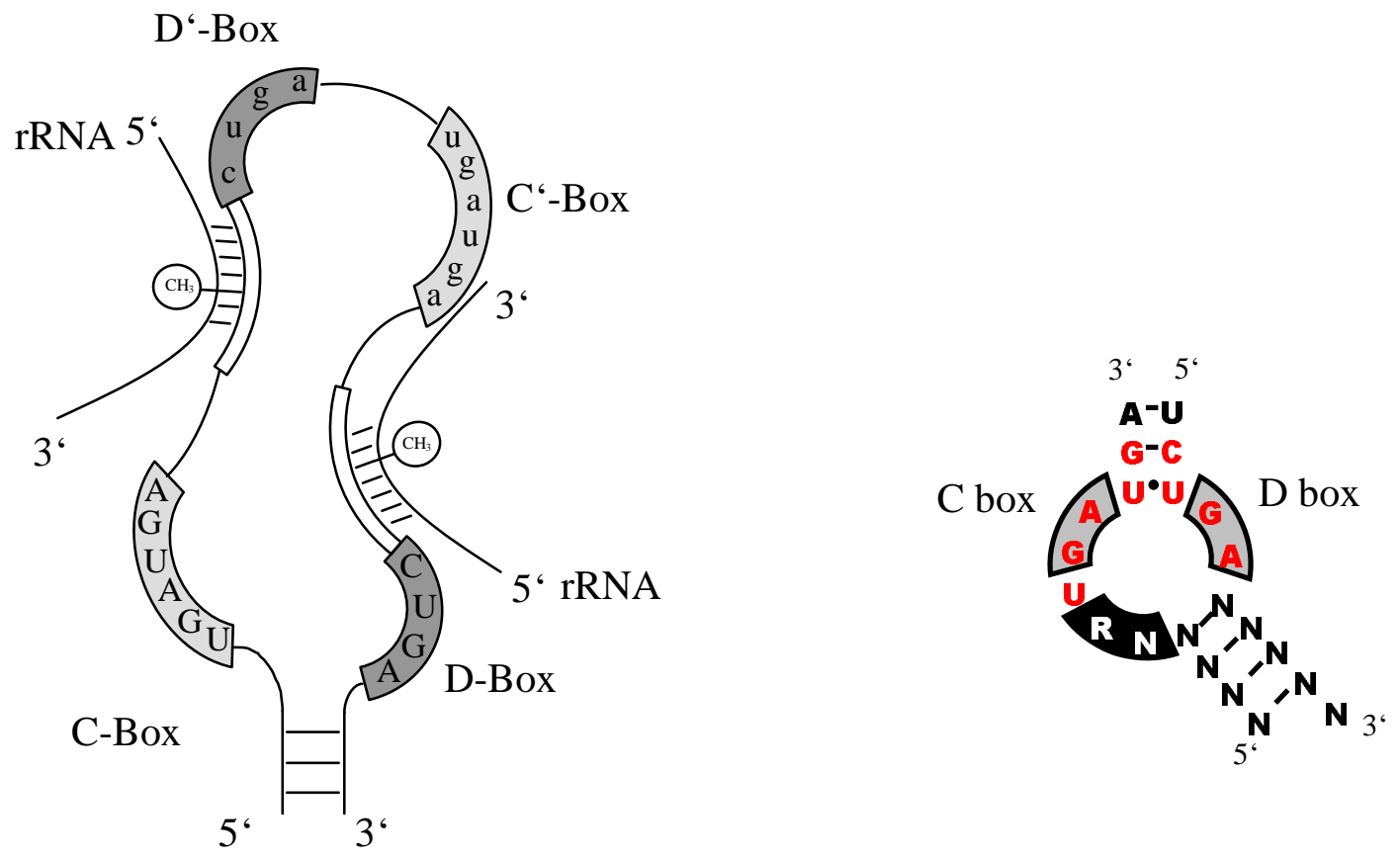

Abbildung 1.2: A. Schematische Struktur einer Box C/D snoRNA. Die kleinen Buchstaben in den C'- und D'-Boxen sollen darstellen, daß es sich um evtl. veränderte Kopien der Orginalsequenzen handelt. B. 5+2 Schleife, die an die Proteine bindet

\subsubsection{H/ACA-Box SnoRNAs}

Die evolutionär gut erhaltene H/ACA-Struktur besteht aus zwei Haarnadelschleifen, einer dazwischen liegenden H-Box-Sequenz (ANANNA) und einer konservierten ACA-Box (ACA) nahe des 3'-Endes (BALAKIN ET AL., 1996; GANOT ET AL., 1997a). Die Schleifen liegen in den Regionen der snoRNA, in der diese komplementär zu der zu modifizierenden rRNAs ist. In Hefe konnte gezeigt werden, daß viele der H/ACA snoRNAs an eine bestimmte Sequenz in der prä-rRNA binden und die Umwandlung von Uridin in Pseudouridin lenken. Die beiden Boxen $\mathrm{H}$ und ACA liegen ca. 14-16 Nukleotide in Richtung 3'-Ende hinter dem Uridin, das zu Pseudouridin umgewandelt wird (s. Abb. 1.3) (NI ET AL., 1997; BORTOLIN ET AL., 1999). Ebenso wie die C/D-Box snoRNAs binden auch die H/ACA-Box snoRNAs Proteine, die für die Pseudouridinilierung wichtig sind. Bisher konnten in Eukaryonten die vier Proteine, 
Cbf5p (Nap57p in Säugern), Gar1p, Nhp2p und Nop10p, identifiziert werden, die an der Bildung von snoRNPs beteiligt sind (BALAKIN ET AL., 1996, GANOT ET AL., 1997b; HENRAS ET AL., 1998). Das zur E. coli tRNA:Y55 Pseudouridin Synthase homologe Cbf5p, stellt die Pseudouridin Synthase Aktivität für die snoRNA-gerichtete Pseudouridinylierungsreaktion bereit (LAFONTAINE ET AL., 1998, ZEBARJADIAN ET AL., 1999). Die Funktion der anderen Proteine ist weitestgehend unklar (BOUSQUET-ANTONELLI ET AL., 1997, HENRAS ET AL., 1998).

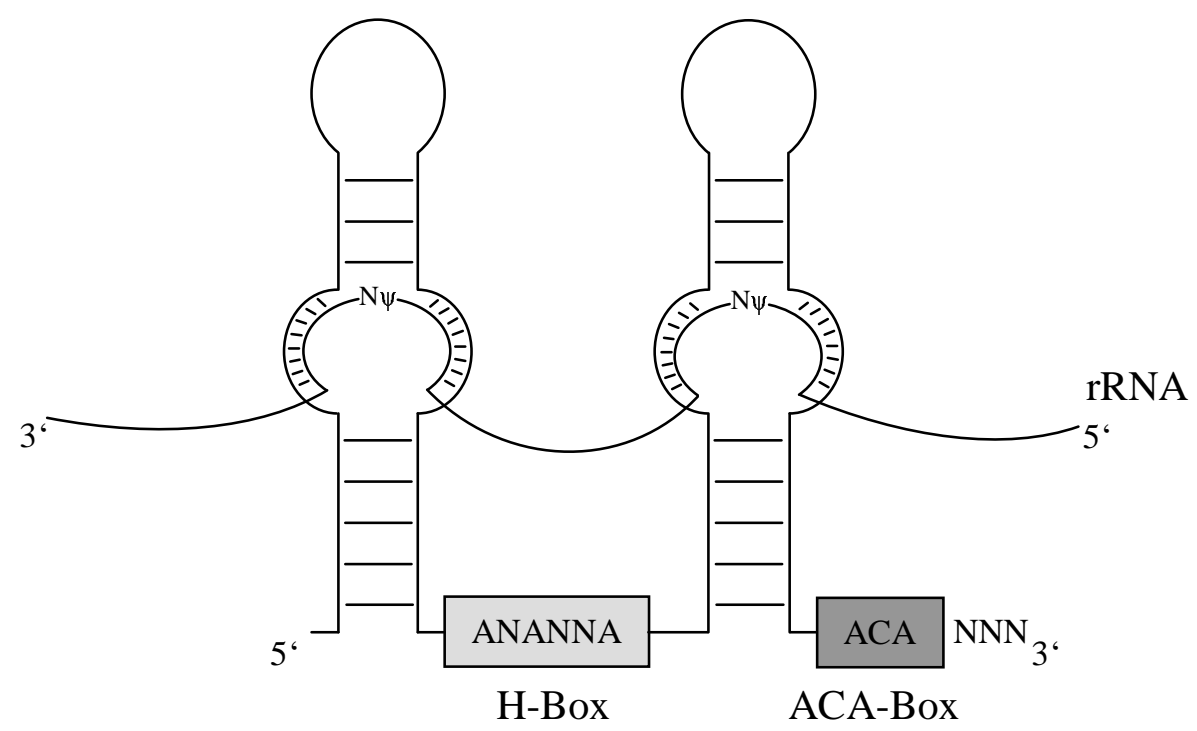

Abbildung 1.3: Schematischer Aufbau einer H/ACA-Box snoRNA

\subsubsection{Die Endoribonukleasen RNase MRP und RNase P}

Die RNase MRP (Mitochondrial $\underline{R} N A$ Processing) ist strukturell und funktionell mit der RNase P verwandt. Neben ähnlichen Sekundärstrukturvorhersagen, teilen sich die Endonukleasen in Hefe mindestens drei der Proteinuntereinheiten (Pop1p, Pop3p und Pop4p), die sowohl für die Stabilität als auch für die Funktion der Enzyme essentiell sind (LyGEROU ET AL., 1994, CHU ET AL., 1997; DichtL \& TOlLERVEY, 1997). RNase MRP spielt eine entscheidende Rolle bei der prä-rRNA Prozessierung, aber die Hauptfunktion ist noch immer ungeklärt. In eukaryontischen Zellen besitzen weder die RNAs der RNase $\mathrm{P}$ noch der RNase MRP in Abwesenheit der Proteine eine 
enzymatische Aktivität, während in bakteriellen Zellen die RNA der RNase P in der Lage ist, prä-tRNA in vitro sequenzspezifisch zu spalten (GUERRIER-TAKADA ET AL., 1983).

\subsubsection{Modifizierung zellulärer RNAs durch snoRNPs}

Neben den erwähnten nukleolären Modifikationen sind die snoRNPs ferner in der Lage, sowohl spleißosomale Proteine (REDDY \& BUSCH, 1988; TYCOWSKI ET AL., 1998) als auch tRNAs (OMER ET AL., 2000; KISS, 2001) zu modifizieren. So befinden sich z.B. in den fünf bedeutenden spleißosomalen snRNAs U1, U2, U4, U5 \& U6 der Säugetiere 30 2'-O-Methylierungen und 24 Pseudouridine. Zehn Jahre nach dieser Entdeckung konnten die ersten C/D-Box snoRNAs beobachtet werden, die bei der Polymerase III-transkribierten U6 snRNA Modifizierung beteiligt sind und im Nukleolus vorkamen (TYCOWSKI ET AL., 1998; GANOT ET AL., 1999). Neben den bekannten C/D und H/ACA Boxen wurde 2001 U85 in humanen und Drosophila Zellen entdeckt, eine ,Hybrid'-snoRNA, die beide Boxen enthält (JÁDY \& KISS, 2001). Diese U85 enthält nicht nur beide Modifizierungs-Boxen, sondern führt auch beide Reaktionen an der Polymerase II-transkribierten U5 snRNA durch.

Die posttranskriptionale Modifizierung von nukleoplasmatischen und cytoplasmatischen RNAs durch nukleoläre snoRNPs zeigte neue Wege des intrazellulären Transports von RNAs auf. Die Identifizierung von U6 snRNA-modifizierenden Faktoren im Nukleolus ließ darauf schließen, daß die U6 snRNAs vom Nukleoplasma in den Nukleolus transportiert werden, bevor sie dort methyliert beziehungsweise pseudouridinyliert werden (TYCOWSKI ET AL., 1998; GANOT ET AL, 1999). An Xenopus Oocyten-Kernen konnten LANGE \& GERBI (2000) letztendlich das vorübergehende Auftreten von U6 snRNAs im Nukleolus nachweisen. Bei verschiedenen anderen RNAs konnte ein solches Wanderungsverhalten in den Nukleolus zu Modifikationszwecken ebenfalls beobachtet werden. Im Gegensatz zu den U6 snRNAs werden die U1, U2, U4 und U5 snRNAs temporär ins Cytoplasma transportiert, wo ihre 5'-Caps hypermethyliert werden. Zurück im Nukleoplasma werden die snRNAs in Cajal Körperchen (engl. cajal bodies) methyliert und pseudouridinyliert (CARVALHO ET AL., 1999). Mit in situ 
Hybridisierungs-Experimenten wurde belegt, daß in HeLa-Zellen diese Cajal Körperchen mit snoRNAs assoziiert sind (KISS, 2001; DARZACQ ET AL., 2002).

\subsection{AMYLOLYTISCHE ENZYME}

Eine der wichtigsten Energiequellen neben Cellulose für alle Lebewesen, insbesondere für Mikroorganismen, ist Stärke (JANEČEK, 1997). Mit ihrer komplexen Struktur aus $\alpha$-Amylose, einem ausschließlich $\alpha$-1,4-glykosidisch verknüpften linearen Glukosepolymer, und Amylopektin, einem verzweigten Polymer, das ebenfalls aus $\alpha$-1,4-glykosidisch verknüpften Glukoseresten besteht, aber alle 24-30 GlukoseEinheiten mit einer weiteren Glukosekette $\alpha$-1,6-glykosidisch verbunden ist. Um diese komplex verzweigte Struktur in Glukose und kleine Oligosaccharide zu spalten, wird in den Zellen ein kompletter Satz hydrolysierender Enzyme benötigt (JANEČEK, 1997). Am besten untersucht sind das endo-spaltende Enzym $\alpha$-Amylase und die exo-spaltenden Enzyme $\beta$-Amylase und Glukoamylase. Obwohl diese drei Enzyme ähnliche Funktionen besitzen, sind sie sowohl strukturell als auch evolutionär weit voneinander entfernt (JANEČEK, 1994). $\alpha$-Amylase spaltet die Stärke an zufällig ausgewählten $\alpha$-1,4-glykosidischen Verknüpfungen im Inneren der Zelle und es entstehen lineare und verzweigte Oligosaccharide mit $\alpha$-konfigurierten Hydroxylgruppen. Die exo-spaltenden Enzyme hydrolysieren das nicht-reduzierende Ende der Stärke und setzen definierte Oligosaccharide und Glukose mit der anomeren $\beta$-Konfiguration frei (JANEČEK, 1997). Daneben werden die $\alpha$-1,6-glykosidischen Bindungen in Amylopektin von Isoamylasen gespalten. Thermophile amylolytische Enzyme, besonders $\alpha$-Amylasen gewinnen in der Biotechnologie immer mehr an Bedeutung. So werden sie bei der Produktion von Sirup, Dextrose, der Brot- und Bierherstellung verwendet (COWAN, 1996; BERTOLDO \& ANTRANIKIAN, 2001).

Stärke Hydrolasen und die mit ihnen verwandten Enzyme werden zusammen mit anderen O-Glykosyl-Hydrolasen in mittlerweile 95 Glykosyl-Hydrolase Familien (GHF) eingeteilt (HENRISSAT, 1991; HENRISSAT \& BAIROCH, 1993 \& 1996; COUTINHO \& HenRISSAT, 1999). Aufgrund ihrer Aminosäure-Sequenz-Ähnlichkeit und ihrer Glykosyl-Hydrolase/Transferase Aktivität mit einigen Transferasen (z.B. Cyclodextrin Glykosyltransferasen: CGTasen) können alle $\alpha$-Amylasen in die drei Glykosyl- 
Hydrolase Familien 13 (typische $\alpha$-Amylasen), 70 (Glykan Sucrase-Typ Glykosyltransferasen) und 77 (Amylomaltasen), die den Glykosyl-Hydrolase Stamm H (GH-H; COUTINHO \& HENRISSAT, 1999: http://afmb.cnrs-mrs.fr/ cazy/CAZY/index.html) bilden, eingeteilt werden (JANEČEK, 1997; HENRISSAT, 1998; ROUJEINIKOVA ET AL., 2002). Die $\beta$-Amylasen und die Glukoamylasen werden in die Familien 14 und 15 eingegliedert. Das katalytische Zentrum aller $\alpha$-Amylase Familien ist das $(\beta, \alpha)_{8}$-Faß $\left((\beta, \alpha)_{8}\right.$-Barrel), das einen konservierten Glutamat- und zwei konservierte Aspartat-Reste enthält. Das als Domäne A bezeichnete $(\beta, \alpha)_{8}$-Faß wird bei den $\alpha$-Amylasen durch die Domäne B zwischen dem dritten $\beta$-Strang und der dritten $\alpha$-Helix unterbrochen (KLEIN \& SCHULZ, 1991; QIAN ET AL., 1993; JANEČEK, 1997).

A

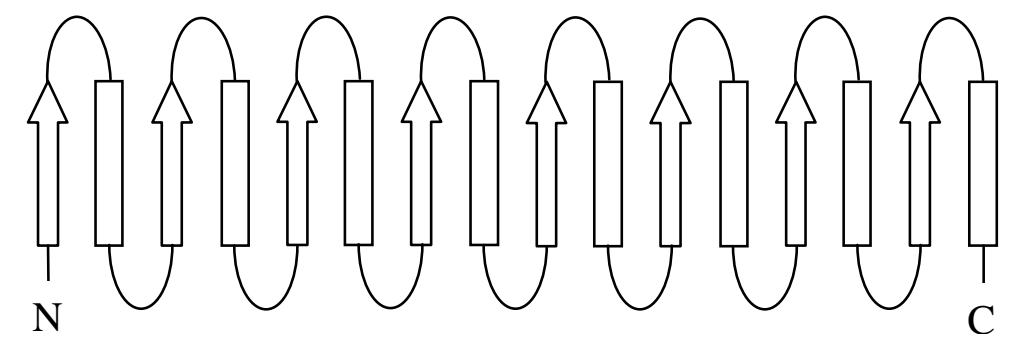

B

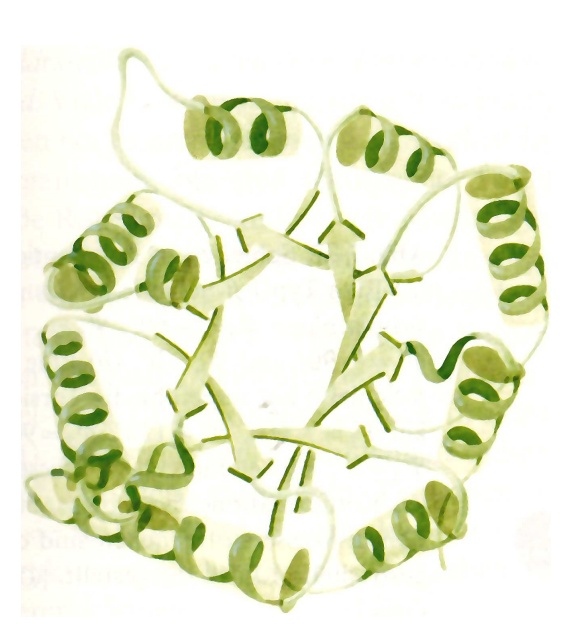

C

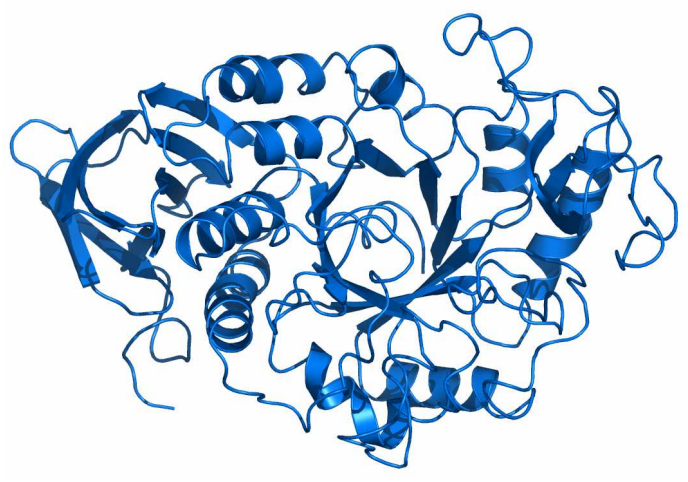

Abbildung 1.4: A. Topologisches Diagramm eines $(\beta, \alpha)_{8}$-Fasses. B. Aufsicht auf die Struktur der Triosephosphatisomerase aus Gallus gallus. Die acht parallelen $\beta$-Faltblätter bilden eine zylindrische Struktur ( $\beta$-Faß) (aus VOET \& VOET, 1994). C. Typisches $\alpha$-Amylase $(\beta, \alpha)_{8}$-Fa $\beta$ der TAKA-Amylase A (PDB: 2TAA) (Matsuura et AL., 1984) 


\subsubsection{Glykosyl-Hydrolase Familie 13}

Das markanteste Merkmal der Mitglieder der $\alpha$-Amylase Familien ist das funktionell wichtige $(\beta, \alpha)_{8}$-Faß, das zuerst bei der Struktur der Triosephosphatisomerase aus Gallus gallus beschrieben wurde und deshalb auch unter dem Namen TIM-Barrel bekannt ist (BANNER ET AL., 1975). Als $(\beta, \alpha)_{8}$-Faß wird es aufgrund seiner alternierenden Folge von $8 \beta$-Strängen und $8 \alpha$-Helices bezeichnet (vgl. Abb. $1.4 \mathbf{A}$ ), wobei die $\beta$-Stränge ein inneres $\mathrm{Fa} ß$ mit hydrophoben Kern und die $\alpha$-Helices ein äußere Hülle bilden (vgl. Abb. 1.4 B). Es ist unter röntgenkristallographisch aufgeklärten Strukturen die variantenreichste Proteindomänenstruktur, die in über 10\% aller Fälle auftritt. 1980 wurde bei einer $\alpha$-Amylase (TAKA-Amylase A: TAA) aus Aspergillus oryzae zum erstenmal das $(\beta, \alpha)_{8}$-Faß identifiziert (MATsuURA ET AL., 1980) (vgl. Abb. 1.4 C). Mittlerweile sind fast 30 verschiedene Enzyme mit einem $(\beta, \alpha)_{8}-\mathrm{Fa} \beta$ in den $\alpha$-Amylase Familien mit Wirkungen als Hydrolasen, Transglukosidasen und Isomerasen, jedoch nicht als Ligase geläufig (MACGREGOR ET AL., 2001; JANEČEK ET AL., 2003).

Durch die geringen Gesamtsequenz-Ähnlichkeiten und den verschiedensten Funktionen der $\alpha$-Amylase Familienmitgliedern ist immer wieder die Frage nach einer gemeinsamen Herkunft aufgeworfen worden. Eine eindeutige Antwort auf den Ursprung des $(\beta, \alpha)_{8}$-Fasses konnte bisher nicht gefunden werden. Daher konnte bislang auch noch keine der zwei folgenden Evolutionstheorien völlig ausgeschlossen beziehungsweise bestätigt werden:

1. Konvergente Evolution

Entwicklung desselben Motivs mit einer hoch geordneten und stabilen Faltung aus unterschiedlichen Ursprüngen. Gegen diese Theorie spricht allerdings die Arbeit von BRÄNDÉN \& TOOZE (1991), welche davon ausgeht, daß die $(\beta, \alpha)_{8}$-Fässer miteinander verwandt sind.

2. Divergente Evolution

Alle $(\beta, \alpha)_{8}$-Fässer sind aus einem gemeinsamen Ursprung hervorgegangen und haben sich im Laufe der Evolution in Sequenz und Form den jeweiligen Gegebenheiten angepaßt. Die funktionellen und strukturellen Ähnlichkeiten der $\alpha$-Amylase Familienmitgliedern deuten darauf 
hin, daß diese Entwicklungstheorie als die wahrscheinlichere angenommen wird (JANEČEK, 1997).

\subsubsection{Sequenzeigenheiten und strukturelle Besonderheiten der GHF 13}

Die in allen Bereichen von Tieren über höhere Pflanzen bis zu den Mikroorganismen vorkommenden Mitglieder der $\alpha$-Amylase Familie besitzen in ihrer Gesamtsequenz nur eine Ähnlichkeit von 10\% (NAKAJIMA ET AL., 1986; JANEČEK, 1997; PUJADAS \& PALAU, 2001), aber 10 hoch konservierte Aminosäure-Reste, die in allen $\alpha$-Amylasen zu finden sind. Die Familienzugehörigkeit zur GHF 13 wird dennoch durch einige hoch konservierte Aminosäure-Sequenzmotive (I-VII) deutlich. In den zuerst beschriebenen Regionen II, IV, VI und V (FrIEDBERG, 1983; ROGERS, 1985; NAKAJIMA, 1986) konnten die drei Aminosäuren Aspartat 206 (Asp206), Glutamat 230 (Glu230) und Aspartat 297 (Asp297; diese und alle folgenden Numerierungen beziehen sich auf TAA) experimentell durch Röntgenkristallographie und Mutagenesestudien und theoretisch durch Sequenzhomologien als wichtige Reste bei der Katalyse identifiziert werden. Neben diesen drei katalytischen Aminosäure-Resten sind ein weiteres Aspartat (Asp117), zwei Histidine (His122 \& His296) und ein Arginin (Arg204) in der katalytischen Region der Enzyme konserviert. Zwei weitere Aminosäuren, Glycin (Gly56) und Prolin (Pro64), schließen eine acht bis neun Aminosäuren lange Sequenz am C-terminalen Ende des zweiten $\beta$-Faltblattes ein. Als letzte konservierte Aminosäure ist das Glycin (Gly323) zu nennen, daß eine entscheidende Rolle bei der Stabilisierung des $(\beta, \alpha)_{8}$-Fasses spielt (MACGREGOR, 1988; Holm ET AL., 1990; JESPERSEN ET AL., 1993; JANEČEK, 1994, JANEČEK \& TÓTH, 1994, SVENSSON, 1994). Von diesen zehn invariablen Aminosäuren sind sieben im aktiven Zentrum zu finden.

Alle Enzyme der $\alpha$-Amylase Familien sind Multidomänen Proteine mit charakteristischen Bereichen (MACGREGOR ET AL., 2001). Die wichtigste und auffälligste Domäne ist das $(\beta, \alpha)_{8}-\mathrm{Fa}$, das auch als Domäne A bekannt ist. Das $\alpha$-Amylase Faß unterscheidet sich vom klassischen Beispiel des TIM-Barrels hauptsichtlich durch eine Schleife, die zwischen $\beta$-Faltblatt 3 und $\alpha$-Helix 3 herausragt; diese Schleife wird als Domäne B bezeichnet (KLEIN \& SchUlZ, 1991; QIAN ET AL., 1993, JESPERSEN ET AL., 
1993; JANEČEK ET AL., 1997). In ihrer Form, Länge und Sequenz variiert die Domäne stark, so ist z.B. die Schleife in dem in E. coli vorkommende Glucan Branching Enzyme nur 40 Aminosäuren lang (BAECKER ET AL, 1986) während sie in dem Glucan Debranching Enzyme aus dem Hasenmuskel aus etwa 250 Aminosäuren besteht (LIU ET AL, 1993). Diese Diskrepanz macht ein Alignment der verschiedenen B-Domänen Sequenzen unmöglich (JANEČEK ET AL., 1997). Einzig eine kurze konservierte Region (Region III) ist bei allen $\alpha$-Amylasen am C-terminalen Ende zu erkennen (JANEČEK, $1992 \& 1995)$.

An die Domäne A schließt sich die Domäne C an, deren Funktion wahrscheinlich die Stabilisierung des katalytischen Fasses ist, indem es die hydrophoben Reste schützt. Da die Domäne in manchen $\alpha$-Amylase Enzymen fehlt, ist sie aber weder für die Aktivität noch für die Stabilität des Enzyms zwingend notwendig (PRZYLAS ET AL., 2000; MACGREGOR ET AL., 2001). Die Unklarheit über die Funktion wird durch das Fehlen der Domäne C in der Familie 77 und einer von dem typischen $\beta$-Sandwich abweichenden Struktur in Familie 70 weiter untermauert (JANEČEK, 1997). Einige Mitglieder der Familie 13 besitzen am N-terminalen Ende noch eine oder mehrere Domänen, die normalerweise als Domäne N bezeichnet werden, strukturell aber nicht miteinander verwandt sind. Andere Mitglieder der GHF 13 besitzen nur am C-terminalen Ende weitere Domänen. Die Domänen D und E bestehen ausschließlich aus $\beta$-Faltblättern (JANEČEK ET AL, 2003). Die Aufgabe von Domäne D ist noch ungeklärt (JESPERSEN ET AL., 1991; JANEČEK, 2002), es wird jedoch spekuliert, daß die Domäne D in die Carbohydrat-Bindung involviert sein könnte (BORK ET AL., 1994). Während die Domäne D nur im Zusammenhang mit der Domäne E auftritt, findet man die ansonsten als Stärke-bindende Domäne (SBD: Starch Binding Domain) bekannte Domäne E auch alleine vor.

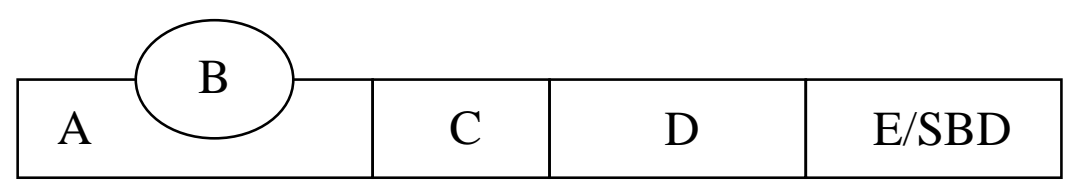

Abbildung 1.5: Domänenstruktur der $\alpha$-Amylasen, wobei die Domänen C-E nicht in allen $\alpha$-Amylasen auftreten. D.h. während der Evolution unterlag die katalytische $\mathrm{N}$-terminale Seite deutlich weniger Veränderungen als die C-terminale Seite 
Das zentrale Element der $\alpha$-Amylasen ist das katalytische $(\beta, \alpha)_{8}$-Faß. Während die $\beta$-Faltblätter des Fasses in ihrer Länge und Sequenz konserviert sind, findet man bei den $\alpha$-Helices eine große Variabilität (JESPERSEN ET AL., 1993). Sowohl die Variabilität der Aminosäuren in den $\alpha$-Helices und den Schleifen und die nicht so stark konservierten Reste der $\beta$-Faltblätter, als auch die Geometrie und die Ausrichtung der Seitenketten bieten zum einen genügend Platz für die Bindung des Substrats und die Katalyse und zum anderen für die unterschiedlichsten Enzymaktivitäten (LESK ET AL., 1989; PICKETT ET AL., 1992; JESPERSEN ET AL., 1993).

Trotz der bereits erwähnten Unterschiede, z.B. der Domäne $B$, zwischen den $\alpha$-Amylase $(\beta, \alpha)_{8}$-Fässern und allen anderen bekannten $(\beta, \alpha)_{8}$-Faß-Strukturen konnte gezeigt werden, daß das aktive Zentrum in allen Fällen am C-terminalen Ende des Fasses lokalisiert ist (FARBER \& PETSKO, 1990; BRÄNDÉN \& TOOZE, 1991). Im aktiven Zentrum konnten die Aminosäurereste Asp206 und Glu230 als die Reste identifiziert werden, die eine tragende Rolle als agierende Base und Säure tragen (QIAN ET AL., 1994; STROKOPYTOV ET AL., 1995). Während der Katalyse wird an der zu spaltenden glykosidischen Bindung der Sauerstoff von der allgemeinen Säure Glu230 protoniert und der Kohlenstoff C1 durch die Base Asp206 angegriffen (SVENSSON \& SøRGAARD, 1993; SVENSSON, 1994). Aufgrund von Wasserstoffbrückenbindungslängen in AmylaseÄquivalenten zu TAA konnte das Asp297 als Säurerest ausgeschlossen werden (QIAN ET AL., 1994). Das Asp297 spielt indessen bei einigen Amylasen (z.B. Bacillus circulans Stamm 251) eine wichtige Rolle bei der Substratbindung und es schützt die protonierte Carboxylategruppe des Glu230 bei höheren pH-Werten (STROKOPYTOV ET AL., 1995).

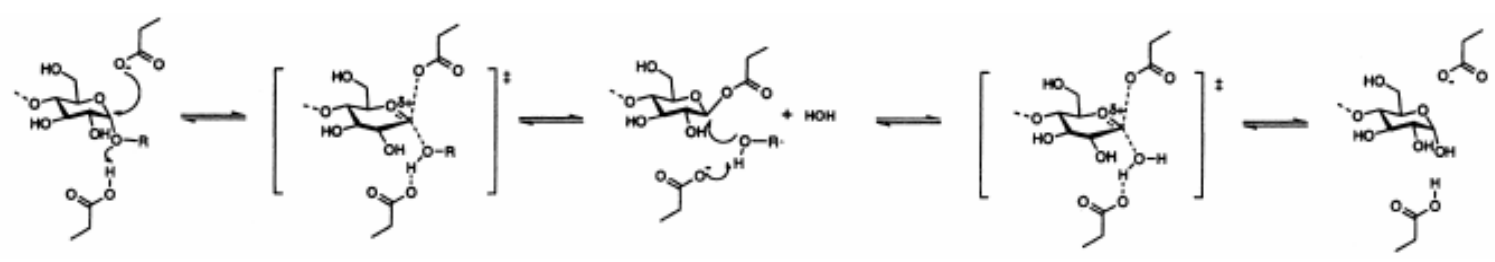

Abbildung 1.6: Katalytischer Reaktionsmechanismus einer glykosidischen Spaltung (aus MACGREGOR ET AL., 2003) 
Im aktiven Zentrum befinden sich weitere Aminosäure-Reste, die in ihrer Familie oder nur für eine bestimmte Enzymspezifität stark konserviert sind. So ist z.B. für die bereits erwähnten invariablen Histidine, His122 und His296, bekannt, daß sie z.B. der Substraterkennung (ISHIKAWA ET AL., 1992 \& 1993) beziehungsweise zur Stabilisierung des Übergangszustandes (SøRGAARD ET AL., 1993) dienen. Auch alle anderen in Mutagenesestudien identifizierten, funktionell wichtigen Aminosäuren liegen in den bekannten konservierten Regionen (JANEČEK, 1997).

Das aktive Zentrum der $\alpha$-Amylase Familienmitglieder besteht aus einer Reihe von Bindungstaschen, von denen jede in der Lage, ist einen Glukoserest des Substrates zu binden (MACGREGOR ET AL., 2001). Die Bindungstaschen bestehen aus Aminosäure Seitenketten, lokalisiert in den Schleifen, die das C-terminale Ende der $\beta$-Faltblätter mit den N-terminalen Enden der $\alpha$-Helices verbinden. Es wird postuliert, daß die Bindungstasche -1 fünf der zehn hoch konservierten Aminosäuren enthält (SvENSSON, 1994; MaCGREGOR ET AL., 1996; JANEČEK, 1997). Mit den Aminosäuren Asp206 und Glu230 enthält die Bindungstasche -1 die beiden katalytischen Reste, die für die Spaltung verantwortlich sind. Für alle Enzyme der $\alpha$-Amylase Familie gilt, daß an Bindungstasche -1 immer eine Glukoseeinheit gebunden wird, während die Zuckerreste, die an die Bindungstaschen +1 und +2 binden, mit der Enzymspezifität variieren. Das inhibitorische Substrat Acarbose bindet im $(\beta, \alpha)_{8}-\mathrm{Fa} \beta$ an die Bindungstaschen -1 bis +3 (Bindungstaschen-Nomenklatur nach DAVIES ET AL., 1997), wobei die inhibitorische Disaccharid-Gruppe Acarviosin die Bindungstaschen -1 und +1 besetzt und somit eine Spaltung an den katalytischen Resten Asp206 und Glu230 blockiert.

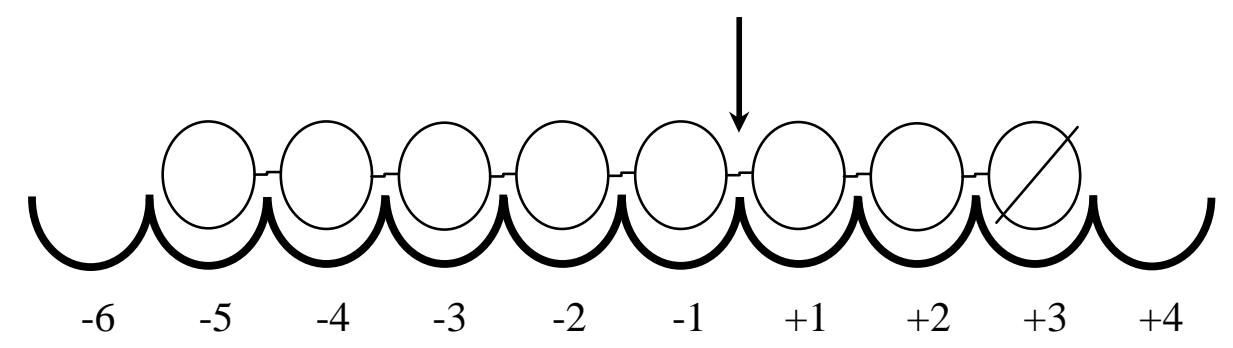

Abbildung 1.7: Schematische Darstellung der Bindungstaschen, wobei die Bindungstaschen -5 bis +3 von einem Oligosaccharid besetzt sind. Die Spaltstelle ist durch einen Pfeil zwischen -1 und +1 gekennzeichnet. Das reduzierende Ende des Zuckers ist an Bindungstasche +3 gebunden (nach MACGREGOR ET AL., 2001) 


\subsubsection{Die Bindung von $\mathrm{Ca}^{2+}$ an GHF $13 \alpha$-Amylasen}

Bei vielen $\alpha$-Amylasen können, unabhängig von ihrer Enzymspezifität, eine oder mehrere Kalziumionen gebunden werden. So postulierten BUISSON ET AL. (1987), daß das $\mathrm{Ca}^{2+}$ die Struktur des aktiven Zentrums durch die Verbindung der Domänen A und B stabilisiert. Im Jahr 1990 konnten BOEL ET AL. bei der $\alpha$-Amylase aus Aspergillus niger zeigen, daß zwei $\mathrm{Ca}^{2+}$-Bindungsstellen pro Proteinmolekül vorhanden sind. An der primären Bindungsstelle wird das Kalziumion fest gebunden und sorgt für die Erhaltung der korrekten Faltung des aktiven Zentrums, während bei der Bindung des zweiten Kalziumions an die sekundäre Bindungsstelle die katalytischen Reste Asp206 und Glu230 mit einbezogen werden, was eine inhibitorische Wirkung von hohen Kalziumkonzentrationen erklärt (BOEL ET EL., 1990).

\subsubsection{Thermostabile a-Amylasen: Strukturelle Voraussetzungen zum Überleben an extremen Standorten}

Die Thermostabilität von vielen $\alpha$-Amylasen wird auf zwei strukturelle Begebenheiten zurückgeführt. WATANABE ET AL. (1991, 1994 \& 1996) konnten anhand der Oligo-1,6-Glukosidasen verschiedener Bacillus Stämme die 1987 von SUZUKI ET AL. postulierte Protein-Regel zur Thermostabilisierung von Proteinen untermauern. Mit einer ansteigenden Anzahl von Prolin-Resten erhöhte sich die Thermostabilität, wobei Proline an der zweiten Stelle der $\beta$-Schleife und in der ersten Windung von $\alpha$-Helices die größte Bedeutung für die Hitzestabilität besitzen (WATANABE ET AL., 1996).

Die Ausrichtung der Aminosäure-Reste ist ebenfalls für eine erhöhte Hitzestabilität verantwortlich. Dabei steigt die Thermostabilität, je höher der Anteil an hydrophoben Resten im Innern des Proteins oder respektive des $(\beta, \alpha)_{8}$-Fasses und je höher der Anteil an hydrophilen Aminosäure-Resten auf der Außenseite ist (JANEČEK, 1993). 


\subsubsection{Glykosyl-Hydrolase Familie 57}

Bei dem hyperthermophilen Bakterium Dictyoglomus thermophilum und bei dem thermophilen Archaebakterium Pyrococcus furiosus konnten als erstes zwei Enzyme identifiziert werden, die zwar eine $\alpha$-Amylase-Aktivität aufwiesen, jedoch nicht in die Glykosyl-Hydrolase Familie 13 einzuordnen waren (FUKUSUMI ET AL., 1988; LADERMAN ET AL., 1993). Bei Sequenzvergleichen der neuen $\alpha$-Amylasen mit den GHF $13 \alpha$-Amylasen wurden weder die charakteristischen Sequenzmotive noch die drei katalytischen Aminosäuren der GHF 13 gefunden. Aufgrund ihrer 40\%-igen Sequenzähnlichkeiten untereinander, wurden die $\alpha$-Amylasen aus Dictyoglomus thermophilum und Pyrococcus furiosus in einer neuen Glykosyl-Hydrolase Familie mit a-Amylase-Aktivität, der Familie 57, zusammengefaßt (HENRISSAT \& BAIROCH, 1996). Trotz der $\alpha$-amylolytischen Aktivität, die in beiden Glykosyl-Hydrolase Familien aufzufinden ist, konnte zunächst kein gemeinsamer Ursprung identifiziert werden. Erst durch die Entdeckung einer $\alpha$-Amylase-Sequenz im Methanococcus jannaschii Genom (BULT ET AL., 1996) konnte von JANEČEK (1998) durch den Vergleich einiger charakteristischer $\alpha$-Amylasen aus den Familien 13 und 57 mit Hilfe der Hydrophoben Cluster Analyse (HCA: Hydrophobic Cluster Analysis; GABORIAUd ET AL., 1987) gezeigt werden, daß eine Verwandtschaft zwischen beiden Familien besteht.

Mitglieder der Glykosyl-Hydrolase Familie 57 katalysieren ähnliche Reaktionen wie die $\alpha$-Amylase Familien, sind in ihrer Sequenz-Ähnlichkeit jedoch weit von diesen entfernt (IMAMURA ET AL., 2003). Im Gegensatz zu den $\alpha$-Amylase-Familien 13, 70 und 77 ist die GHF 57 bisher nur unzureichend untersucht (SVENSSON, 1994; JANEČEK, 1998; IMAMURA ET AL., 2003), die katalytische Domäne A der $\alpha$-Amylasen, das $(\beta, \alpha)_{8}-\mathrm{Fa} \beta$, kann verändert aber auch in den Strukturen der GHF 57 wiedergefunden werden. 


\subsubsection{Glykosyl-Hydrolase Familien 13 und 57: Besitz eines gemeinsamen Ur- sprungs?}

Klassische Sequenz-Alignments (ClustalW; THOMPSON ET AL., 1994) der $\alpha$-Amylasen aus Methanococcus jannaschii und Pyrococcus furiosus wiesen eine Sequenz-Identität unter Berücksichtigung mehrerer Lücken in beiden Sequenzen von $27,1 \%$ auf (nur 21,8\% ohne Lücken mit der HCA-Methode) und ließen somit die $\alpha$-Amylase von Methanococcus jannaschii eindeutig in die Glykosyl-Hydrolase Familie 57 einordnen (BULT ET AL., 1996).

Durch die Anwendung der HCA-Methode konnte von JANEČEK (1998) gezeigt werden, daß die $\alpha$-Amylase aus Methanococcus jannaschii neben den SequenzÄhnlichkeiten zur GHF 57 auch einige der charakteristischen Merkmale der GHF 13 besitzt. So konnten zwei von den drei katalytischen Aminosäuren, die $\beta$-Stränge 2, 3, 4 , 5 \& 7 (leicht verändert) und die C-terminal konservierte Sequenz der Domäne B identifiziert werden.

Die eindeutige Zuordnung in die GHF 57 und das Vorkommen der SequenzCharakteristika der GHF 13 in der Methanococcus jannaschii $\alpha$-Amylase, führte bei JANEČEK (1998) zu dem Schluß, daß beide Glykosyl-Hydrolase Familien einen gemeinsamen, wenn auch sehr entfernten Ursprung haben könnten. Neben dieser Theorie eines gemeinsamen Ursprungs, gibt JANEČEK aber noch eine weitere Erklärung für die Gemeinsamkeiten der Methanococcus jannaschii $\alpha$-Amylase mit beiden GlykosylHydrolase Familien. In dieser nimmt er an, daß die $\alpha$-Amylase nur als ein Intermediat bei der Entwicklung von Familie 13 zu 57 beziehungsweise 57 zu 13 entstanden sein könnte.

\subsubsection{Amylase B aus Thermotoga maritima MSB8: ein Mitglied der GHF 57}

Das Enzym Amylase B (AmyB) konnte bei einer Genbank Analyse als drittes amylolytisches Enzym im Thermotoga maritima MSB8 Genom identifiziert werden (LIEBL, 1998). Es konnte gezeigt werden, daß AmyB, ebenso wie die $\alpha$-Amylase A aus Thermotoga maritima MSB8, neben Stärke auch deren polymere Komponenten Amylose und Amylopektin als Substrate bevorzugt und diese zu Maltooligosacchariden 
abbaut. Da in dünnschichtchromatographischen Untersuchungen außer den $\alpha$-1,4-glykosidischen Bindungen keine anderen glykosidischen Bindungen gespalten wurden, wurde das Enzym AmyB als $\alpha$-Amylase klassifiziert.

Die in der Glykosyl-Hydrolase Familie 13 charakteristisch vorkommenden vier Konsensus-Sequenzen konnten in einer Datenbank-Analyse nicht in AmyB nachgewiesen werden, während geringe Sequenzähnlichkeiten zur GHF 57 zu beobachten sind, wie z.B. zur $\alpha$-Amylase A aus Dictyoglomus thermophilum (FüTTERER, 2001), bei der auch ein gleiches Hydrolysemuster bekannt ist (FUKUSUMI ET AL., 1988; FÜTTERER, 2001). Daneben spricht die Inhibition von AmyB durch geringe Konzentrationen $(2 \mathrm{mM})$ zweiwertiger Metallionen (Ausnahme: $\mathrm{Ca}^{2+}$ ) ebenfalls gegen eine Einordnung in die GHF 13, bei der im Gegensatz zu Mitgliedern der GHF 57 kein Aktivitätsverlust beobachtet werden konnte (LADERMAN ET AL., 1993; DONG ET AL., 1997; FÜTTERER, 2001). Trotz einer geringen Sequenzähnlichkeit von AmyB zu den Enzymen der GHF 57, wird sie aufgrund ihrer enzymatischen und physikochemischen Ähnlichkeiten in diese Familie eingeordnet (FÜTTERER, 2001).

\subsection{ZIELSETZUNG}

Von den Komponenten des sRNP-Komplexes in Sulfolobus solfataricus ist bekannt, daß aL7 benötigt wird, um die anderen Proteine an die sRNA zu binden. Daher sollte mit einer möglichst kurzen sRNA, die aber die zur Assemblierung wichtigen Boxen $\mathrm{C}$ und $\mathrm{D}$ enthält, und den notwendigen Proteinen aL7, aNop56 und aFib der sRNP-Komplex in vitro rekonstituiert werden. Zur näheren Verifizierung der RNAProtein- und Protein-Protein-Bindungen sollte der Komplex dazu kristallisiert und strukturell aufgeklärt werden.

Die seit einigen Jahren bekannte intrazelluläre $\alpha$-Amylase AmyB wurde unter enzymatischen und biochemischen Aspekten untersucht, eine eindeutige Aussage über die funktionelle Bedeutung des Enzyms im Kohlenhydratstoffwechsel konnte jedoch nicht getroffen werden (FÜTTERER, 2001). Darum sollte mit Hilfe der Kristallisation von AmyB mit bekannten Inhibitoren (z.B. Acarbose, ATP), Produkten (Glukose \& Maltose) und Aktivatoren (z.B. $\mathrm{Ca}^{2+}$ ) versucht werden, weitere Einblicke in die 
Funktion von AmyB im Stoffwechsel zu ermöglichen. Ein besonderes Augenmerk wurde dabei auf die Kristallisation mit dem Pseudotetrasaccharid Acarbose gelegt. Bei Acarbose handelt es sich um eine Maltotetraose mit Maltose als reduzierendem Ende und Acarviosin, einem inhibitorischen Disaccharid, als nicht-reduzierendem Ende. Es ist bekannt, daß Acarbose die Aktivität von Enzymen der $\alpha$-Amylase Familien, $\beta$-Amylasen und Glukoamylasen inhibiert (PARK ET AL., 2000; MACGREGOR ET AL., 2001; IMAMURA ET AL., 2003).<smiles>CC1OC(OC2C(CO)OC(OC3C(CO)OC(O)C(O)C3O)C(O)C2O)C(O)C(O)C1NC1CC(CO)C(O)C(O)C1O</smiles>

Maltose

Acarviosin

Abbildung 1.8: Acarbose $=\mathrm{C}_{25} \mathrm{H}_{43} \mathrm{NO}_{18}$

O-4,6-dideoxy-4[[(1S,4R,5S,6S)-4,5,6-trihydroxy-3-(hydroxymethyl)-2-

cyclohexen1-yl]-a-D-glukanopyranosyl-(1,4)-O-a-D-glukanopyranosyl-(1,4)-

D-Glukose 


\section{MATERIAL UND METHODEN}

\subsection{MATERIALIEN}

\subsubsection{Chemikalien}

Die verwendeten Chemikalien wurden, soweit nicht anders erwähnt, von den Firmen AppliChem (Darmstadt), Fluka (Buchs, Schweiz), Merck (Darmstadt), Oxoid (Basingstoke, Hampshire, England), Roth (Karlsruhe), Serva (Heidelberg) und SigmaAldrich (Steinheim) bezogen. Alle Chemikalien besaßen den Reinheitsgrad ,p. a.“ (zur Analyse). Die verwendeten Puffer wurden mit sterilem $\mathrm{H}_{2} \mathrm{O}_{\text {bidest }}$ (SG Wasseraufbereitung und Regenerierstation $\mathrm{GmbH}$, Barsbüttel) angesetzt.

\subsubsection{Kulturmedien, Antibiotika und Medienzusätze}

- Luria Bertani (LB)-Medium: 1\% (w/v) Trypton, 0,5\% (w/v) Hefeextrakt, $1 \%$ (w/v) $\mathrm{NaCl}$, ad $11 \mathrm{H}_{2} \mathrm{O}$, autoklaviert

- LB-Agar: $1 \%$ (w/v) Agar, ad 11 LB-Medium, autoklaviert

- ECPM1 Medium: 0,4\% (w/v) $\mathrm{K}_{2} \mathrm{HPO}_{4}, 0,1 \%$ (w/v) $\mathrm{KH}_{2} \mathrm{PO}_{4}, 0,1 \%$ (w/v) $\mathrm{NH}_{4} \mathrm{Cl}$, 0,24\% (w/v) $\mathrm{K}_{2} \mathrm{SO}_{4}, 0,0132 \%(\mathrm{w} / \mathrm{v}) \mathrm{CaCl}_{2} \times 2 \mathrm{H}_{2} \mathrm{O}, 10 \mathrm{ml}$ Trace Elements Solution 1, 2\% (w/v) Casein, 0,3\% (w/v) Hefeextrakt, 4\% (v/v) Glycerin, ad 11 $\mathrm{H}_{2} \mathrm{O}$, autoklaviert, nach dem Abkühlen wurden $2 \mathrm{ml} 1 \mathrm{M} \mathrm{MgCl}_{2} \times 6 \mathrm{H}_{2} \mathrm{O}$ (sterilfiltriert) zugegeben (SAMBROOK ET AL., 1989)

- Trace Elements Solution: 0,5\% (w/v) EDTA, 0,05\% (w/v) $\mathrm{FeCl}_{3} \times 6 \mathrm{H}_{2} \mathrm{O}, 0,005 \%$ (w/v) $\mathrm{ZnO}, 0,001 \%$ (w/v) $\mathrm{CuCl}_{2} \times 2 \mathrm{H}_{2} \mathrm{O}, 0,001 \%$ (w/v) $\mathrm{Co}\left(\mathrm{NO}_{3}\right)_{2} \times 6 \mathrm{H}_{2} \mathrm{O}, 0,001 \%$ (w/v) $\left(\mathrm{NH}_{4}\right)_{6} \mathrm{Mo}_{7} \mathrm{O}_{24} \times 4 \mathrm{H}_{2} \mathrm{O}$; das EDTA wurde in $700 \mathrm{ml} \mathrm{H}_{2} \mathrm{O}$ gelöst. Die anderen Komponenten wurden einzeln in möglichst wenig $10 \mathrm{~N} \mathrm{HCl}$ gelöst und zur EDTA-Lösung gegeben. Der $\mathrm{pH}-$ Wert wurde mit konzentrierter $\mathrm{NaOH}$ auf 7,0 eingestellt. Die Lösung wurde mit $\mathrm{H}_{2} \mathrm{O}$ auf 11 aufgefüllt und sterilisiert (SAMBROOK ET AL., 1989) 
- Ampicillin: $100 \mathrm{mg} / \mathrm{ml}$ in $\mathrm{H}_{2} \mathrm{O}$ gelöst und sterilfiltriert, verwendete Arbeitskonzentration $100 \mu \mathrm{g} / \mathrm{ml}$

- Kanamycin: $50 \mathrm{mg} / \mathrm{ml}$ in $\mathrm{H}_{2} \mathrm{O}$ gelöst und sterilfiltriert, verwendete Arbeitskonzentration $50 \mu \mathrm{g} / \mathrm{ml}$

- Chloramphenicol: $35 \mathrm{mg} / \mathrm{ml}$ in Ethanol gelöst und sterilfiltriert, verwendete Arbeitskonzentration $35 \mathrm{mg} / \mathrm{ml}$

\subsubsection{Bakterienstämme}

Alle zur Transformation verwendeten kompetenten Bakterienstämme wurden bei Novagen (Schwalbach) erworben.

- Escherichia coli BL21(DE3)

- Escherichia coli BL21(DE3)pLysE

- Escherichia coli BL21(DE3)pLysS

- Escherichia coli XL-1 blue

\subsubsection{Plasmide}

Die Plasmide für die Proteinexpressionen von aL7, aNop56 und aFibrillarin wurden freundlicherweise von Arina D. Omer, Universität Britisch Columbia, Institut für Biochemie und Molekularbiologie, Vancouver, Kanada zur Verfügung gestellt. Die verwendeten pET-Vektoren sind von der Firma Novagen. Die Gene, die für aL7 und aFib kodieren, waren als NcoI/BamHI-Fragmente in den Vektor pET3d, und das Gen für aNop56 war als NcoI/EcoRI-Fragment in den Vektor pET28a einkloniert worden (OMER ET AL., 2002).

- $\quad$ pET-3d-aL7

- $\quad$ EET-3d-aFib

- $\quad$ pET-28a-aNop56 


\subsubsection{Oligonukleotide}

Die DNA-Oligonukleotide wurden von MWG Biotech (Ebersberg) synthetisiert. Da alle Oligonukleotide zur Synthese einzelsträngiger RNA mittels T7 in vitroTranskription (s. 2.2.7) eingesetzt wurden, mußte am 3'-Ende die T7-Promotorsequenz ergänzt werden. Zur Kristallisation des rekonstituierten RNA-Protein-Komplexes wurde eine möglichst kurze synthetische RNA benötigt. Um diese zu finden, wurden als Ausgangssequenzen für die verkürzten RNAs die sRNA-Sequenzen sR1 und sR13 aus Sulfolobus acidocaldarius verwendet. Diese hatten in vorangegangenen Band-ShiftExperimenten am Besten mit den drei Proteinen (aL7, aNop56, aFib) interagiert (OMER ET AL., 2002).

sR1del1:

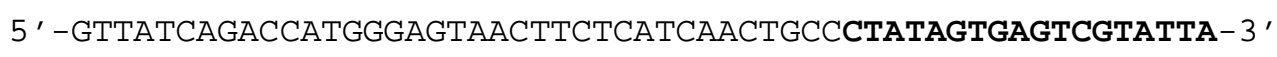

sR1del2:

5' -GTTATCAGACCATGGGAGTCTCATCAACTGCCCTATAGTGAGTCGTATTA-3'

sR1del3:

5' -GTtATCAGACCATGGTCATCAACTGCCCTATAGTGAGTCGTATTA-3'

SR13del1:

5' -TtGATCAGACTtTTtGGCGGCCGTCACCAGACATCATtTCAACCCTATAGTGAGTCGTATTA-3'

sR13del2:

5' -TTGATCAGACTtTtTGGTGACATCATtTCAACCCTATAGTGAGTCGTATTA-3'

sR13del3:

5' -TTGATCAGACTTTTTCATCATTTCAACCCTATAGTGAGTCGTATTA-3' 
Die RNA für die Kristallisationsansätze wurde von den Firmen Dharmacon Research (Lafayette, USA) und Purimex (Staufenberg) synthetisiert.

sR13-28a: 5' -GGCAGUUGAUGUCAAAAAGUCUGAUCAA-3'

sR13-28b: 5' -GGCAGUUGAUGUCAAAAAGUCUGAUGCC-3'

sR1/U4-22: $\quad$ 5'-GCAGUUGAUGUUUUUCUGAUGC-3'

\subsubsection{Restriktionsenzyme}

Die Restriktionsenzyme wurden von New England Biolabs (Frankfurt a. M.) bezogen.

Tabelle 2.1: Restriktionsenzyme und ihre Herkunft

\begin{tabular}{|c|c|c|}
\hline Restriktionsenzym & Ursprungsorganismus & Erkennungssequenz \\
\hline \multirow{2}{*}{ Bam $\mathrm{HI}$} & Bacillus amyloliquefaciens $\mathrm{H}$ & $\begin{array}{l}\text { 5' G } \downarrow \text { GATC C 3, } \\
\text { 3' C CATG } \uparrow \mathrm{G} \mathrm{5}\end{array}$ \\
\hline \multirow{2}{*}{ EcoRI } & Escherichia coli $\mathrm{RY} 13$ & $\begin{array}{l}\text { 5' G } \downarrow \text { AATT C 3, } \\
\text { 3, C TTAA } \uparrow \mathrm{G} \mathrm{5}\end{array}$ \\
\hline \multirow{2}{*}{ NcoI } & Nocardia corallina & $\begin{array}{l}\text { 5' C } \downarrow \text { CATG G 3, } \\
\text { 3' G GTAC } \uparrow \text { C 5, }\end{array}$ \\
\hline
\end{tabular}

\subsection{MolekULARBIOLOGISCHE METHODEN}

\subsubsection{Isolierung von DNA aus Bakterien (Plasmidpräparation)}

Zur Plasmidpräparation wurden QIAGEN Plasmid Purification Kits (Qiagen, Hilden) verwendet. Das Prinzip, auf dem die Kits beruhen, ist die alkalische Lyse der Bakterienzellen (BIRNBOIM \& DOLY, 1979). Anschließend wird die Plasmid-DNA unter Niedrig-Salz Konditionen an einen Anionaustauscher gebunden. Verunreinigungen, wie z.B. RNA oder Proteine, werden durch mehrere Waschschritte entfernt, und unter Hoch- 
Salz wird die DNA eluiert. Um die DNA-Lösung zu entsalzen und anzukonzentrieren, wird sie zuletzt mit Isopropanol gefällt und in sterilem $\mathrm{H}_{2} \mathrm{O}$ resuspendiert.

Die gewonnene Plasmid-DNA wurde zur Insert-Kontrolle und zur Transformation in $E$. coli-Zellen verwendet.

\subsubsection{Konzentrationsbestimmung von Nukleinsäuren}

Die Konzentration von Nukleinsäuren kann photometrisch bei einer Wellenlänge von $260 \mathrm{~nm}$ bestimmt werden (SAMBROOK ET AL., 1989), da dort das Absorptionsmaximum aromatischer Basen liegt. Aus der gemessenen Absorption (optische Dichte: $\mathrm{OD}_{260 \mathrm{~nm}}$ ), der Verdünnung (V) und einem spezifischen Multiplikationsfaktor (F) wurde die Konzentration berechnet.

$$
c[\mu g / m l]=O D_{260 n m} \times V \times F
$$

Die Multiplikationsfaktoren hängen davon $a b$, ob es sich um einzelsträngige oder doppelsträngige DNA, RNA oder Oligonukleotide handelt.

\subsubsection{Restriktionsanalyse}

Restriktionsendonukleasen können anhand von spezifischen Methylierungsmustern die bakterieneigene DNA von fremder DNA unterscheiden. Die Enzyme schneiden spezifisch vier bis acht Basenpaare des DNA-Strangs. In den meisten Fällen werden Fragmente mit 5'-Phosphat- und 3'-OH-Enden erzeugt, was wichtig für die Ligation ist. Die Enden können entweder glatt (blunt ends) oder überhängend (sticky ends) geschnitten sein.

Zur Analyse wurde die bei der Plasmidpräparation erhaltene DNA durch Restriktionsenzyme verdaut. Die verwendeten Restriktionsenzyme schnitten vor und hinter dem Insert in der multiplen Klonierungskassette (Multiple Cloning Site) und dienten so zur Größenbestimmung der vorhandenen Fremdgene. 
Die Ansätze (Tabelle 2.2) wurden bei $37^{\circ} \mathrm{C}$ für 1 Stunde inkubiert. Um die Restriktionsenzyme zu inaktivieren, wurden die Ansätze anschließend für 10 Minuten bei $65^{\circ} \mathrm{C}$ erhitzt. Die so geschnittenen Proben wurden auf ein 1\%-iges Agarosegel geladen.

Tabelle 2.2: Restriktionsansatz

\begin{tabular}{|c|c|}
\hline Komponenten & Eingesetzte Volumina $[\boldsymbol{\mu l}]$ \\
\hline 10X Puffer & 2 \\
\hline steriles $\mathrm{H}_{2} \mathrm{O}_{\text {bidest }}$ & 15 \\
\hline Enzym 1 (5 Units) & 1 \\
\hline Enzym 2 (5 Units) & 1 \\
\hline DNA & 1 \\
\hline
\end{tabular}

\subsubsection{Agarosegelelektrophorese}

Die negative Ladung des Zucker-Phosphat-Rückgrats läßt Nukleinsäuren im elektrischen Feld zum positiven Pol wandern. In einem bestimmten Größenbereich ist die Wanderungsgeschwindigkeit umgekehrt proportional zum dekadischen Logarithmus ihres Molekulargewichts.

Zur Analyse der Restriktionsfragmente wurde eine 1\%-ige Agaroselösung mit 1X TAE-Puffer (Tris-Acetat-EDTA) hergestellt (AUSUBEL ET AL., 1992). Die mit Probenpuffer vermischten Proben wurden auf das Gel geladen und mit einer Stromstärke von 12 mA/cm Gellänge aufgetrennt. Im Anschluß wurden die Gele in Ethidiumbromidlösung, die mit der DNA interkaliert, für ca. 30 min inkubiert, mit Wasser abgespült und unter UV-Licht (256 nm) ausgewertet und dokumentiert. Als Größenstandart wurde ein $1 \mathrm{~kb}$ Marker verwendet. 
Benötigte Lösungen:

- 50X TAE-Puffer: 2 M Tris/HCl, 0,1 M EDTA, mit Eisessig auf pH 8.5 einstellen

- 10X Probenpuffer: 0,02\% (w/v) Bromphenolblau, 50\% (v/v) Glycerin, 0,1\% 1 M EDTA

- Ethidiumbromidlösung: 5\% (v/v) Ethidiumbromid $(10 \mathrm{mg} / \mathrm{ml})$ in $1 \mathrm{X}$ TAEPuffer

- Marker: GeneRuler ${ }^{\mathrm{TM}} 1$ kb DNA Ladder, MBI Fermentas (St. Leon-Rot)

\subsubsection{Herstellung kompetenter Zellen}

Kompetente Zellen zeichnen sich dadurch aus, daß ihre Zellwand in der logarithmischen Wachstumsphase z.B. durch Chemikalien für DNA aufnahmefähig gemacht wird. Die fremde zirkuläre DNA kann dann von den kompetenten Zellen z.B. durch Hitzeschock aufgenommen werden.

Zur Herstellung von kompetenten Zellen wurde die Calciumchlorid-Methode verwendet:

400-500 ml LB-Medium, ohne Antibiotikum, wurden mit $1 \mathrm{ml}$ frischer Übernachtkultur angeimpft, bei $37^{\circ} \mathrm{C}$ inkubiert und bei einer $\mathrm{OD}_{600} \mathrm{~nm}$ von $0,4-0,5$ abzentrifugiert (4000 g, $10 \mathrm{~min}$ ). Das Pellet wurde in $100 \mathrm{ml}$ eiskaltem 0,1 $\mathrm{M} \mathrm{MgCl}_{2}$ aufgenommen, $20 \mathrm{~min}$ auf Eis inkubiert und zentrifugiert (2500 g, $10 \mathrm{~min})$. Der Schritt wurde mit $200 \mathrm{ml}$ eiskaltem 0,1 $\mathrm{M} \mathrm{CaCl}_{2}$ wiederholt. Das Pellet wurde dann in $5 \mathrm{ml} \mathrm{CaCl}$-Lösung (85\% 0,1 $\mathrm{M} \mathrm{CaCl}_{2}, 15 \%$ (v/v) Glycerin) aufgenommen und aliquotiert. Die Zellen wurden anschließend direkt verwendet oder schockgefroren und bei $-80^{\circ} \mathrm{C}$ gelagert.

\subsubsection{Transformation von Plasmid-DNA in E. coli-Zellen}

Bei der Transformation wird Fremd-DNA in Zellen eingeschleust. Zu diesem Zweck wurden $100 \mu$ l kompetente Zellen mit 1 ng Plasmid-DNA vermischt und für $10 \mathrm{~min}$ auf Eis inkubiert. Nach einem Hitzeschock $\left(42^{\circ} \mathrm{C}, 45 \mathrm{~s}\right)$ wurden die Zellen 
weitere $10 \mathrm{~min}$ auf Eis inkubiert. Anschließend wurde der Ansatz mit $1 \mathrm{ml}$ LB-Medium versetzt und für $30-60$ min bei $37^{\circ} \mathrm{C}$ kultiviert. Um ausschließlich transformierte Bakterien, die eine plasmid-codierte Antibiotikaresistenz tragen, zu selektieren, wurden $100 \mu 1$ des Ansatzes auf entsprechenden LB-Agarplatten ausgestrichen.

\subsubsection{In vitro Transkription (in vitro-Synthese von RNA)}

Bei der in vitro Transkription wird eine DNA-Matrize an einer bestimmten Erkennungs- und Bindungsstelle (Promotorsequenz) von RNA-Polymerasen (T3, T7 oder SP6) erkannt und in ihre komplementäre RNA-Sequenz umgeschrieben. Die Matrize wird durch PCR oder Klonierung mit anschließender Linearisierung erzeugt, wobei das 3'-Ende nicht überhängen sollte, da diese ebenfalls als Startpunkte für die RNAPolymerase dienen können (SCHENBORN \& MIERENDORF, 1985). Es handelt sich in vitro um eine run-off Transkription, da die RNA-Polymerase am 3'-Ende abdissoziert.

Die Ansätze (Tabelle 2.3) wurden bei $37^{\circ} \mathrm{C}$ für $1-2$ Stunden inkubiert. Als Templates für die Transkriptionsansätze dienten die synthetisierten Oligonukleotide. Um nach der Transkription ungebundene $\alpha^{32}$-P-ATP's (Amersham Biosciences GmbH, Freiburg) zu entfernen, wurde die RNA mit Phenol-Chloroform gereinigt und zur Ankonzentrierung mit $5 \mathrm{M}$ Ammoniumacetat (Endkonzentration 0,25 M) gefällt.

Tabelle 2.3: Transkriptionsansatz mit $\alpha^{32}$-P-ATP

\begin{tabular}{|c|c|}
\hline Komponenten & Eingesetzte Volumina $[\boldsymbol{\mu l}]$ \\
\hline \hline DNA-Template (Endkonz.: 5 pmol) & $\mathrm{x}$ \\
\hline 5X RNA Polymerase-Puffer & 4 \\
\hline 10X NTP-Mix (5 mM CTP, GTP, UTP, 130 $\mu \mathrm{M}$ ATP) & 2 \\
\hline$\alpha^{32}$-P-ATP & 2 \\
\hline 100 mM DTT & 1 \\
\hline T7 RNA-Polymerase & 1 \\
\hline steriles $\mathrm{H}_{2} \mathrm{O}_{\text {bidest }}($ RNase frei) & $\mathrm{ad} \mathrm{20}$ \\
\hline
\end{tabular}




\subsection{BIOCHEMISCHE METHODEN}

\subsubsection{Heterologe Genexpression in E. coli}

Die Analyse von Genen kann auf verschiedenen Ebenen erfolgen. Für Untersuchungen auf Ebene der finalen Genprodukte (= Proteine) ist es notwendig, größere Mengen mit Hilfe von sogenannten Expressionssystemen zu synthetisieren.

Die bei der Transformation in die E. coli Zellen eingebrachten Expressionsvektoren enthalten die Fremd-DNA und ein Antibiotikaresistenzgen. Die durch die Antibiotikaresistenz gegebene Selektivität verhindert Kontaminationen mit Bakterien, die nicht das gewünschte Plasmid tragen. Bei Verwendung des pET-Systems (plasmid for Expression by T7 RNA Polymerase; STUDIER ET AL., 1983) wird die Expression der rekombinanten Proteine durch den Isopropyl- $\beta$-D-thiogalaktopyranosid (IPTG)induzierbaren T7-Promotor kontrolliert.

Zur Herstellung einer Vorkultur wurde LB-Medium mit selektiven Antibiotika und einer einzelnen Bakterienkultur angeimpft und bei $37^{\circ} \mathrm{C}$ über Nacht inkubiert. Mit den Vorkulturen wurden die Expressionskulturen 1:20 angeimpft. Das Anwachsen und Vermehren der Zellen geschah bei $20^{\circ} \mathrm{C}$ (aNop48) beziehungsweise $37^{\circ} \mathrm{C}$ (aL7 \& aFib) bis zu einer $\mathrm{OD}_{600 \mathrm{~nm}}$ von $\sim 0,6$. Die Expression der Proteine wurde anschließend mit IPTG (Endkonzentration: 0,5-1 mM) induziert. Nach weiterem Wachstum bis zu einer $\mathrm{OD}_{600 \mathrm{~nm}}$ von $\sim 1,2$ wurden die Zellen bei $5000 \mathrm{~g}$ für 15 Minuten abzentrifugiert. Die Pellets wurden in einer proteinabhängigen Menge Aufschlußpuffer resuspendiert und direkt aufgeschlossen oder bei $-20^{\circ} \mathrm{C}$ gelagert.

Neben der herkömmlichen LB-Schüttelkultur wurden die Zellen auch in einem 101 Fermenter (Applikon, Knuellwald) mit LB-Medium oder ECPM1-Medium kultiviert. Da die Zellen in ECPM1-Medium bis zu einer $\mathrm{OD}_{600} \mathrm{~nm}$ von $\sim 10$ vor und $\sim 20$ nach der Induktion heranwachsen und somit einen erhöhten Sauerstoffbedarf besitzen, war es notwendig die Zellen in diesem Medium im Fermenter zu kultivieren.

Die Expression der Proteine wurde mittels SDS-PAGE (s. 2.3.4) kontrolliert. 
Kultivierungsbedingungen:

- pET3d-aL7 wurde in E. coli BL21(DE3)pLysE transformiert und bei $37^{\circ} \mathrm{C}$ in LB-Medium sowohl in Schüttelkolben als auch im Fermenter kultiviert. Als selektive Antibiotika wurden dem Medium Ampicillin und Chloramphenicol zugesetzt. Um zu vermeiden, daß das Protein als Einschlußkörperchen (inclusion bodies) exprimiert wird, wurden $2 \%$ Glukose zugegeben.

- Das in E. coli BL21(DE3) transformierte pET28a-aNop56-Plasmid wurde bei $20^{\circ} \mathrm{C}$ in kanamycinhaltiger LB-Schüttelkultur kultiviert.

- aFib wurde in E. coli BL21(DE3)pLysS-Zellen bei $37^{\circ} \mathrm{C}$ im Fermenter in EPCM1 überexprimiert. Ampicillin und Chloramphenicol wurden als Antibiotika zugegeben.

\subsubsection{Reinigung der exprimierten Proteine aus E. coli-Zellen}

Die überexprimierten, rekombinanten Proteine aL7, aNop56 und aFib wurden auf ähnliche Weise aus den Bakterienzellen isoliert. Im Anschluß an jeden Reinigungsschritt wurden die Proben mit einer SDS-PAGE (s. 2.3.4) überprüft.

\subsubsection{Zellaufschluß und Hitzedenaturierung}

Um Proteine aus Zellen isolieren zu können, müssen die Zellen zuerst aufgebrochen werden. Dazu können verschiedene Methoden angewandt werden, wie z.B. die chemische Lyse oder mechanisches Aufbrechen. Bei der Verwendung von Lysozym werden die Polysaccharide, die der Bakterienzellwand Stabilität verleihen und ein Platzen der Zelle durch einen zu hohen osmotischen Druck verhindern, gespalten. Zur Vermeidung eines Proteinabbaus durch Proteasen wurden beim Zellaufschluß noch Protease-Inhibitoren, z.B. Complete EDTA-free Tabletten (Roche, Mannheim) zugesetzt, die Serin- und Cystein-Proteasen vollständig hemmen.

Die Zellen wurden mit einer Kombination aus Lysozym und Ultraschall aufgeschlossen. Eine Zugabe von Lysozym zu den E. coli BL21(DE3)pLysE + S-Zellen war 
jedoch nicht notwendig, da bei diesen Zellen ein Plasmid vorhanden ist, das für Lysozym codiert. Je nach Protein wurde ein 4 1 Zellpellet (bei ECPM1-Medium nur 1 1) in 40-200 ml Aufschlußpuffer resuspendiert. Der Aufschlußpuffer enthielt eine Spatelspitze Lysozym und eine gelöste Tablette Complete EDTA-free Protease-InhibitorCocktail. Die Zellsuspensionen wurden bei Raumtemperatur (RT) für einige Minuten inkubiert und anschließend, im Eisbad stehend, mit Ultraschall (Sonify, Bransdon, USA) $3 \times 45$ Sekunden aufgeschlossen. Um die Zelltrümmer von den Proteinen, die sich nach dem Zellaufschluß in Lösung befinden, zu trennen, wurden die Zellsuspensionen für 15 Minuten bei $20000 \mathrm{~g}$ zentrifugiert.

Zur weiteren einfachen Aufreinigung der rekombinanten, hitzestabilen Proteine wurde die Proteinlösung erhitzt. Die meisten der Proteine der mesophilen Wirtsorganismen wurden dabei denaturiert und konnten durch Zentrifugation aus der Lösung entfernt werden. Die Proteinlösung wurde im Wasserbad bei $65^{\circ} \mathrm{C}$ für $10-20$ Minuten inkubiert und bei 20000 g für 15 Minuten zentrifugiert, um die denaturierten Proteine aus der Lösung zu entfernen.

Benötigte Lösungen:

- aL7-Aufschlußpuffer: 50 mM Bis-Tris, pH 6,5, 50 mM NaCl, 2 mM DTT

- aNop56-Aufschlußpuffer: 50 mM Tris/HCl, pH 7,5, 200 mM NaCl, 2 mM DTT

- aFib-Aufschlußpuffer: 50 mM Tris/HCl, pH 8,5, 50 mM NaCl, 2 mM DTT

\subsubsection{Chromatographische Trennmethoden}

Das Grundprinzip aller Chromatographiemethoden ist das Aufbringen einer flüssigen Probe auf eine stationäre Phase und das anschließende Auftrennen mittels einer flüssigen mobilen Phase. Einige der Trennmethoden werden im folgenden näher erläutert.

Mit der Fast Protein Liquid Chromatography (FPLC) ist es möglich das zu reinigende Protein schnell und einfach von den anderen störenden Proteinen abzutrennen. Ein weiterer Vorteil der FPLC ist die hohe Reproduzierbarkeit der Läufe. Die Reinigungsläufe wurden mit Äkta Systemen (ÄktaPrime und ÄktaPurifier) und Säulen 
der Firma Amersham Biosciences GmbH (Freiburg) durchgeführt. Die Säulen wurden vor Gebrauch nach Angaben des Herstellers mit Auftragspuffer equilibriert. Alle Proben wurden vor dem Auftragen auf die Säulen sterilfiltriert (Minisart® 0,22 $\mu$ m Porengröße, Sartorius, Göttingen), um eventuell vorhandene Schwebteilchen aus den Lösungen zu entfernen.

a. Ionenaustauscherchromatographie

Proteine binden bei der Ionenaustauscherchromatographie durch elektrostatische Wechselwirkungen an positiv geladene (Anionenaustauscher) oder negativ geladene (Kationenaustauscher) Gruppen einer Matrix. Ob und wie stark ein Protein an die Ionenaustauschermatrix bindet, hängt vom isoelektrischen Punkt des Proteins, der Ionenstärke und dem pH-Wert des Puffers und der Ladungsdichte des Säulenmaterials ab.

Nach der Hitzedenaturierung wurden die Proteine aNop56 und aFib mittels Anionenaustauscherchromatographie (MonoQ HR 10/10) von weiteren störenden Proteinen abgetrennt. aFib wurde nicht an das Material gebunden und wurde im Durchfluß wieder von der Säule gewaschen. Die anderen Proteine wurden mit einem ansteigenden Salzgradienten eluiert.

Mit einem langsam steigenden $\mathrm{NaCl}-\mathrm{Gradienten}$ wurde das an die MonoQSäule gebundene aNop56 zwischen 400 und 600 mM wieder eluiert.

Benötigte Lösungen:

- Niedrigsalz-Puffer aNop56: 50 mM Tris/HCl, pH 7,5, 2 mM DTT

- Hochsalz-Puffer aNop56: 50 mM Tris/HCl, pH 7,5,1 M NaCl, 2 mM DTT

- Niedrigsalz-Puffer aFib: 50 mM Tris/HCl, pH 8,5, 2 mM DTT

- Hochsalz-Puffer aFib: $50 \mathrm{mM}$ Tris/HCl, pH 8,5, $1 \mathrm{M} \mathrm{NaCl}, 2 \mathrm{mM}$ DTT 
b. Hydrophobe Chromatographie

Auf der Oberfläche besitzen viele Proteine hydrophobe Bereiche. Diese binden in wäßriger Lösung an hydrophobe Oberflächen. Durch hohe Konzentrationen von bestimmten Salzen werden die hydrophoben Wechselwirkungen verstärkt, während diese durch chaotrope Salze verringert werden. Die Probe wird bei hoher Ionenstärke auf die hydrophobe Matrix (Phenyl Sepharose®) geladen. Die Säule wird gewaschen, und mit einem abnehmenden Salzgradienten kann das Protein wieder von der Säule eluiert werden.

Der hitzedenaturierte aL7-Proteinrohextrakt wurde mit Ammoniumsulfat (Endkonzentration in der Proteinlösung: $1 \mathrm{M}$ ) versetzt und auf die equilibrierte Phenyl Sepharose® HiLoad 16/10 geladen. Obwohl das aL7Protein direkt von der Säule gewaschen wurde, konnte diese Methode angewendet werden, da alle E. coli-eigenen Proteine an die Säule gebunden und erst durch einen abnehmenden Salzgradienten entfernt wurden.

Benötigte Lösungen:

- Hochsalz-Puffer: 50 mM Bis-Tris, pH 6,5, $1 \mathrm{M}\left(\mathrm{NH}_{4}\right)_{2} \mathrm{SO}_{4}, 2 \mathrm{mM}$ DTT

- Niedrigsalz-Puffer: 50 mM Bis-Tris, pH 6,5, 2 mM DTT

c. Gelfiltration

Bei der Gelfiltration werden Proteine nach Größenunterschieden getrennt. Deshalb wird sie auch als Größenausschlußchromatographie bezeichnet. Bei den verwendeten Superdex®-Säulen handelt es sich um Dextransäulen mit extrem dicht gepackten, sehr kleinen, porösen und gleichmäßigen Teilchen. Je nach Größe dringen die Moleküle unterschiedlich weit in die Gelmatrix ein. Während kleine Moleküle in die Gelporen diffundieren und ihr Fluß verzögert wird, laufen größere Moleküle durch die Zwischenräume des Gelbettes und werden schneller von der Säule eluiert.

Alle drei Proteine wurden im letzten Reinigungsschritt auf eine mit Laufpuffer equilibrierte Säule $(2 \mathrm{ml} / \mathrm{min})$ aufgetragen, um die restlichen 
Kontaminanten zu entfernen. Die Elutionsprofile wurden mit einer Eichgerade, die unter gleichen Bedingungen erstellt wurde, verglichen und die Größe der Proteine bestimmt.

Durch die ungenaue Konzentrationsbestimmung der Proteine durch das Bradford-Reagenz, können die einzelnen Komponenten nicht direkt in einem stöchiometrischen Verhältnis zueinander als Kristallisationsansätze pipettiert werden. Daher wurde die Gelfiltration auch zur Aufreinigung des rekonstituierten sRNP-Komplexes genutzt.

Benötigte Lösung:

- Laufpuffer: $20 \mathrm{mM}$ Tris/HCl, pH 7,5, $100 \mathrm{mM} \mathrm{NaCl,} 2 \mathrm{mM}$ DTT

\subsubsection{Ankonzentrierung einer Proteinlösung}

Zur Kristallisation werden Proteinkonzentrationen von mehreren $\mathrm{mg} / \mathrm{ml}$ benötigt, die normalerweise jedoch nicht nach dem letzten Aufreinigungsschritt vorhanden sind. Um die Konzentration zu erhöhen, werden Konzentratoren (Sartorius, Göttingen) eingesetzt. Hierbei wird die zu konzentrierende Proteinlösung auf einen Filter mit definierter Ausschlußgrenze (cut off) pipettiert und bei 3000-4000 g zentrifugiert. Das Konzentrat kann nach Abspülen der Filtermembran in ein Eppendorfgefäß zur weiteren Lagerung überführt werden.

Die Protein-enthaltenden Gelfiltrationsfraktionen wurden mit Konzentratoren (Sartorius, Göttingen) bis zu einer Konzentration von 8-10 mg/ml ankonzentriert. 


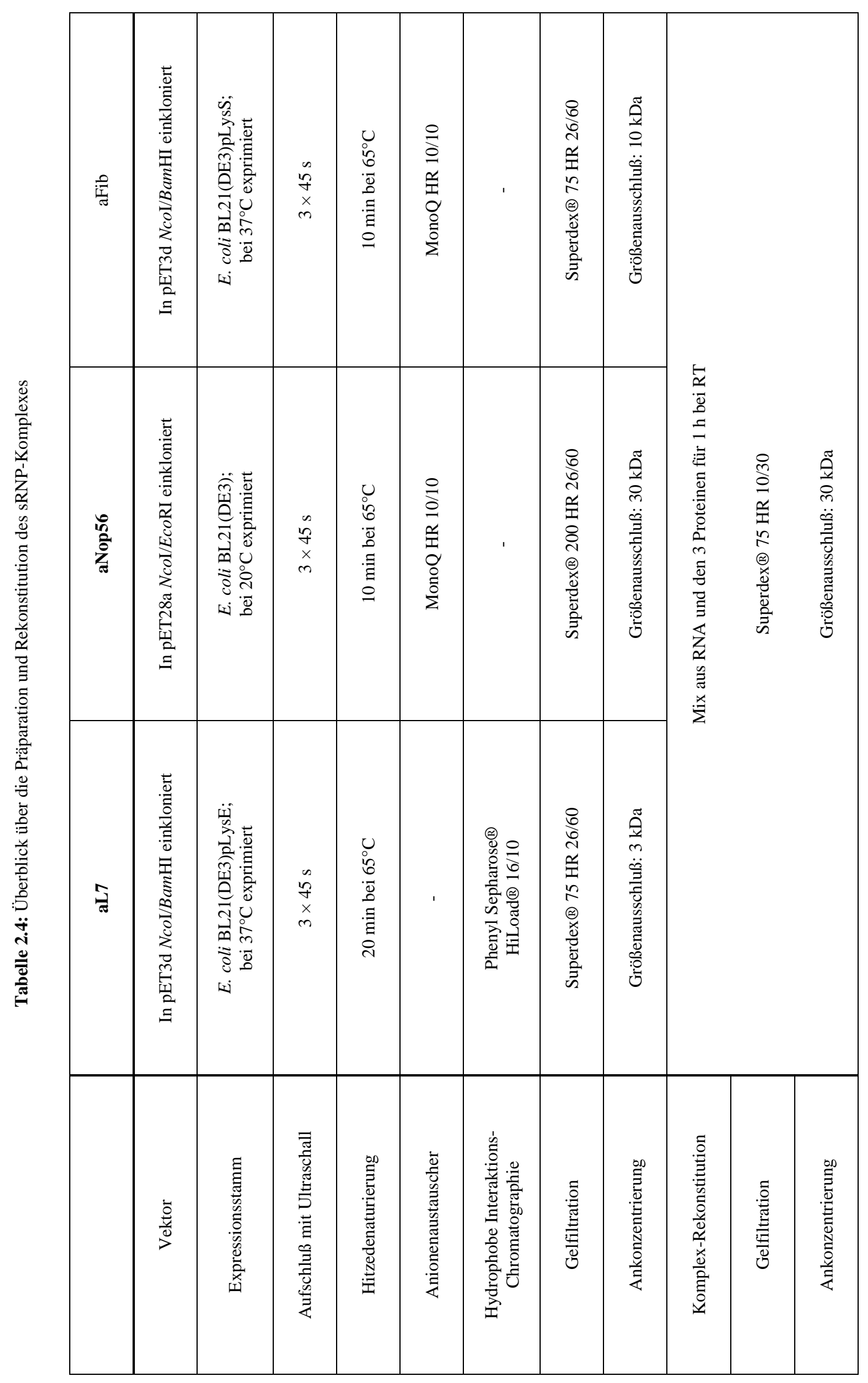




\subsubsection{Proteinbestimmung nach BRADFORD (1979)}

Der Bradford-Test basiert auf einer Verschiebung des Absorptionsmaximums des Farbstoffes Coomassie Brilliant Blau G250 von 465 nm auf 595 nm bei der Bildung eines Farbstoff-Protein-Komplexes. Ein Maß für die Proteinkonzentration in der zu untersuchenden Lösung ist die Absorptionszunahme.

$980 \mu \mathrm{l}$ einer 1:5 mit $\mathrm{H}_{2} \mathrm{O}$ verdünnte Bradfordreagenzlösung ( $1 \mathrm{mg} / \mathrm{ml}$ Coomassie Brilliant Blau G250 in 85\%iger $\mathrm{H}_{3} \mathrm{PO}_{4}$; BioRad, München) wurden mit $20 \mu 1$ Proteinlösung vermischt und 5 Minuten bei Raumtemperatur inkubiert. Die Absorption wurde bei $595 \mathrm{~nm}$ gegen einen Leerwert bestimmt und die Konzentration berechnet.

\subsubsection{Diskontinuierliche SDS-Polyacrylamid-Gelelektrophorese nach LAEMMLI (1970)}

Bei der Elektrophorese wandern geladene Teilchen im elektrischen Feld. Dabei ist die Wanderungsgeschwindigkeit der geladenen Teilchen bei gleicher Feldstärke abhängig von Molekulargewicht, Gestalt und Ladung der Teilchen.

Um die Auftrennung von Proteinen nach ihren Molekulargewichten zu erreichen, muß die Eigenladung der Proteinmoleküle ausgeschaltet werden. Dies geschieht bei der SDS-Polyacrylamid-Gelelektrophorese (SDS-PAGE) mit Hilfe des anionischen Detergenzes SDS (Natriumdodecylsulfat), das sich an die hydrophoben Regionen der Proteine anlagert, die Wasserstoffbrückenbindungen löst und somit die Zerstörung der Tertiär- und Quartärstruktur bewirkt. Eine weitere Denaturierung, d.h. Auflösen der Sekundärstruktur, der Proteine wird durch die Zugabe des starken Reduktionsmittels $\beta$-Mercaptoethanol, das Disulfidbrücken löst, erreicht.

Die Bindung der hydrophoben Reste der Aminosäurenseitenketten mit dem SDS führt dazu, daß die Proteine in anionischer Form vorliegen und somit im elektrischen Feld zur Anode wandern. Die native Ladung der Proteine wird überdeckt und die Auftrennung erfolgt ausschließlich über das Molekulargewicht.

Zur erfolgreichen Auftrennung von Proteinen eignen sich Polyacrylamidgele. Diese bestimmen durch ihre Gesamtkonzentration an Acrylamid und dem Verhältnis 
Acrylamid zu N,N`-Methylen-Bisacrylamid den Grad der Vernetzung und die Porengröße. Die Trennung beruht daher nur auf der Wanderungsgeschwindigkeit der SDSProtein-Komplexe im Gel, die mit zunehmender Größe (Stokes-Radius) wegen des Molekularsiebeffektes abnimmt.

Abhängig von den Molekulargewichten der einzelnen Proteine wurden Trenngele mit Acrylamidkonzentrationen zwischen 10 und 17,5\% und Sammelgele mit einer Konzentration von 5\% verwendet.

Bevor die Proteinproben auf das Gel aufgetragen werden konnten, wurden sie zur Denaturierung 1:1 mit Probenpuffer versetzt und 5 Minuten bei $95^{\circ} \mathrm{C}$ inkubiert. Neben den Proben wurde ein Molekulargewichtsstandard auf das Gel aufgetragen, um die Größen der aufgetrennten Proteine zu verifizieren. Im Sammelgel wurden die Proben bei einer geringen Stromstärke ( $\sim 35 \mathrm{~mA})$ zunächst fokussiert, damit eine exakte Trennung der einzelnen Proteine im Trenngel ( 50 mA) gewährleistet war.

Benötigte Lösungen:

- $30 \%$ Acrylamid-Stammlösung (PAA 30 ; Verhältnis Acrylamid:Bisacrylamid von $37,5: 1)$

- Trenngelpuffer: $1,88 \mathrm{M}$ Tris/HCl, $\mathrm{pH} 8,8$

- Sammelgelpuffer: 0,625 M Tris/HCl, pH 6,8

- $\quad 0,5 \%(w / v)$ SDS-Lösung

- $100 \% \mathrm{~N}, \mathrm{~N}, \mathrm{~N}^{`}, \mathrm{~N}^{`}-$ Tetramethylendiamin (TEMED)

- $10 \%(w / v)$ Ammoniumpersulfat (APS)

- Laufpuffer: 25 mM Tris/HCl, pH 8,8, 192 mM Glycin, 0,1\% (w/v) SDS

- $2 \times$ SDS-Probenpuffer: $20 \%$ 0,625 M Tris/HCl, pH 6,8, $2 \%$ (w/v) SDS, 50\% (v/v) Glycerin, 5\% (v/v) $\beta$-Mercaptoethanol, $1 \%$ (v/v) Bromphenolblau (1\%-ig in Ethanol)

- Molekulargewichtsstandard: Mark $12^{\mathrm{TM}}$ Unstained Standart, Invitrogen (Karlsruhe); Broad Range Protein Marker, New England Biolabs 
Tabelle 2.5: Pipettierschema für denaturierende Polyacrylamidgele

\begin{tabular}{|c|c|c|c|c|}
\hline Komponenten & $\begin{array}{l}10 \% \text { iges } \\
\text { Trenngel }\end{array}$ & $\begin{array}{l}\text { 12,5\%iges } \\
\text { Trenngel }\end{array}$ & $\begin{array}{l}\text { 17,5\%iges } \\
\text { Trenngel }\end{array}$ & $\begin{array}{c}5 \% \text { iges } \\
\text { Sammelgel }\end{array}$ \\
\hline $\mathrm{PAA}_{30}[\mathrm{ml}]$ & 2,0 & 2,5 & 3,5 & 0,33 \\
\hline Trenngelpuffer [ml] & 1,2 & 1,2 & 1,2 & - \\
\hline Sammelgelpuffer [ml] & - & - & - & 0,4 \\
\hline SDS-Lösung [ml] & 1,2 & 1,2 & 1,2 & 0,4 \\
\hline $\mathrm{H}_{2} \mathrm{O}[\mathrm{ml}]$ & 1,6 & 1,1 & 0,1 & 0,87 \\
\hline TEMED $[\mu 1]$ & 5 & 5 & 5 & 6 \\
\hline APS $[\mu 1]$ & 30 & 30 & 30 & 25 \\
\hline
\end{tabular}

\subsubsection{Protein-Färbemethoden}

Im Anschluß an die Elektrophorese wurden die Gele entweder mit der Coomassie-Proteinfärbung oder der Silberfärbung fixiert.

\subsubsection{Coomassie-Proteinfärbung}

Die Coomassie-Färbung eignet sich ausschließlich zur Visualisierung von Proteinen und wurde daher zur Kontrolle der Aufreinigung der einzelnen Proteine eingesetzt. Sie ist einfach in ihrer Durchführung und gut reproduzierbar, jedoch zeitaufwendig und nicht besonders sensitiv (untere Grenze: 200-400 ng/Bande).

Zum Anfärben der Proteine wurden die Gele für 15 Minuten in einer erwärmten Coomassie-Färbelösung schüttelnd inkubiert. Nach dem Färben wurde der Überschuß an Farbstoff durch mehrmaliges Waschen mit Coomassie-Entfärbelösung beseitigt.

Benötigte Lösungen:

- Coomassie-Färbelösung: 25\% (v/v) Isopropanol, $10 \%$ (v/v) Eisessig, 0,2\% (w/v) Coomassie Brilliant Blau R250, 0,05\% (w/v) Coomassie Brilliant Blau G250

- Coomassie-Entfärbelösung: 45\% (v/v) Ethanol, $10 \%$ (v/v) Eisessig 


\subsubsection{Silberfärbung nach NESTERENKO et al. (1994)}

Um geringere Mengen (untere Grenze: ca. 50-100 pg/Bande) an Proteinen auf Gelen nachweisen zu können, wurde die Silberfärbung verwendet. Bei dieser Reaktion bildet das $\mathrm{Ag}^{+}$-Ion Komplexe mit den Glutaminsäure-, Asparaginsäure- und CysteinResten der Proteine. Das nun in den Komplexen gebundene $\mathrm{Ag}^{+}$wird durch alkalisches Formaldehyd zu Ag reduziert. Bei der Silberfärbung handelt es sich nicht um eine Protein-spezifische Färbemethode, denn sie färbt z.B. auch Nukleinsäuren an. Durch diesen Mangel eignete sich die Silberfärbung zur Verifizierung der Komplexbildung von aL7, aNop48, aFib und sR13del3.

Benötigte Lösungen und Durchführung:

\begin{tabular}{|c|c|c|c|}
\hline \multirow[t]{3}{*}{ Fixierlösung: } & $60 \mathrm{ml}$ & $50 \%(\mathrm{v} / \mathrm{v})$ Aceton & \multirow{3}{*}{$5 \min$} \\
\hline & $1,5 \mathrm{ml}$ & $50 \%$ (w/v) Trichloressigsäure & \\
\hline & $25 \mu 1$ & $37 \%$ Formaldehyd & \\
\hline Waschen: & $60 \mathrm{ml}$ & $\mathrm{H}_{2} \mathrm{O}_{\text {bidest }}$ & $3 \times 5 s$ \\
\hline Waschen: & $60 \mathrm{ml}$ & $\mathrm{H}_{2} \mathrm{O}_{\text {bidest }}$ & $5 \mathrm{~min}$ \\
\hline Waschen: & $60 \mathrm{ml}$ & $\mathrm{H}_{2} \mathrm{O}_{\text {bidest }}$ & $3 \times 5 s$ \\
\hline Vorbereitungslösung I: & $60 \mathrm{ml}$ & $50 \%(\mathrm{v} / \mathrm{v})$ Aceton & $5 \mathrm{~min}$ \\
\hline \multirow[t]{2}{*}{ Vorbereitungslösung II: } & $100 \mu 1$ & $10 \%$ (w/v) $\mathrm{Na}_{2} \mathrm{~S}_{2} \mathrm{O}_{3} \times 5 \mathrm{H}_{2} \mathrm{O}$-Lösung] & \multirow{2}{*}{$1 \mathrm{~min}$} \\
\hline & $60 \mathrm{ml}$ & $\mathrm{H}_{2} \mathrm{O}_{\text {bidest }}$ & \\
\hline Waschen: & $60 \mathrm{ml}$ & $\mathrm{H}_{2} \mathrm{O}_{\text {bidest }}$ & $3 \times 5 s$ \\
\hline \multirow[t]{3}{*}{ Silbernitratlösung: } & $800 \mu 1$ & $20 \%$ (w/v) $\mathrm{AgNO}_{3}$-Lösung & \multirow{3}{*}{$8 \mathrm{~min}$} \\
\hline & $600 \mu 1$ & $37 \%$ Formaldehyd & \\
\hline & $60 \mathrm{ml}$ & $\mathrm{H}_{2} \mathrm{O}_{\text {bidest }}$ & \\
\hline Waschen: & $60 \mathrm{ml}$ & $\mathrm{H}_{2} \mathrm{O}_{\text {bidest }}$ & \\
\hline \multirow[t]{4}{*}{ Entwickler: } & $1,2 \mathrm{~g}$ & $\mathrm{Na}_{2} \mathrm{CO}_{3}$ & \multirow{4}{*}{$10-20 \mathrm{~s}$} \\
\hline & $25 \mu 1$ & $37 \%$ Formaldehyd & \\
\hline & $25 \mu 1$ & $10 \%$ (w/v) $\mathrm{Na}_{2} \mathrm{~S}_{2} \mathrm{O}_{3} \times 5 \mathrm{H}_{2} \mathrm{O}$-Lösung & \\
\hline & $60 \mathrm{ml}$ & $\mathrm{H}_{2} \mathrm{O}_{\text {bidest }}$ & \\
\hline Stoplösung: & $60 \mathrm{ml}$ & $7 \%$ (v/v) Essigsäure & $30 \mathrm{~s}$ \\
\hline Waschen: & $60 \mathrm{ml}$ & $\mathrm{H}_{2} \mathrm{O}_{\text {bidest }}$ & $10 \mathrm{~s}$ \\
\hline
\end{tabular}




\subsubsection{Band-Shift-Assay}

Nukleinsäuren wandern, je nach Größe, im elektrischen Feld unterschiedlich weit. Wenn die Nukleinsäure an ein Protein gebunden wird, verändert sich zwangsläufig ihre Größe und damit auch die Laufstrecke im Gel. Da der Nukleinsäure-ProteinKomplex größer als die freie Nukleinsäure ist, wandert er langsamer durch das vernetzte Gel. Nach Anfärbung oder Autoradiographie erkennt man eine Nukleinsäure-Bande und eine dazu verschobene Komplex-Bande (band-shift) im Gel.

Die bei der T7-Transkription synthetisierte RNA (s. 2.2.7) wurde mit unterschiedlichen aL7-Konzentrationen (0-400 nM) auf ihre Bindungsfähigkeit untersucht. Daneben wurde mit allen drei Proteinen und den RNA-Transkripten versucht, den sRNP-Komplex zu rekonstituieren.

Benötigte Lösungen:

- 5X RNA-Renaturierungspuffer: $125 \mathrm{mM}$ Phosphatpuffer, pH 7, $500 \mathrm{mM} \mathrm{NaCl}$

- 4X Band-Shift-Puffer: 100 mM Phosphatpuffer, pH 7, $400 \mathrm{mM} \mathrm{NaCl,} 4 \mathrm{mM}$ $\mathrm{MgCl}_{2}$

- RNA-Probenpuffer: $1 \%$ (v/v) Bromphenolblau (1\%-ig in Ethanol), $10 \%$ (v/v) Glycerin

- $\quad$ RNA-Mix (für 6 Reaktionen): $6 \mu 1$ RNA, $2 \mu$ l Renaturierungspuffer, $4 \mu 1 \mathrm{H}_{2} \mathrm{O}$

- $30 \%$ Acrylamid-Stammlösung (Verhältnis Acrylamid:Bisacrylamid von 37,5:1)

- $100 \% \mathrm{~N}, \mathrm{~N}, \mathrm{~N}^{`}, \mathrm{~N}^{\star}$-Tetramethylendiamin (TEMED)

- $10 \%(\mathrm{w} / \mathrm{v})$ Ammoniumpersulfat (APS)

- $1 \mathrm{M}$ Phosphatpuffer, $\mathrm{pH} 7$

- Laufpuffer: 50 mM Phosphatpuffer, pH 7

Der RNA-Mix wurde für 1 Minute bei $95^{\circ} \mathrm{C}$ denaturiert und auf $55^{\circ} \mathrm{C}$ abgekühlt. Nach Zugabe von $2 \mu 1$ RNA-Mix zum Reaktionsansatz wurde dieser für 10 Minuten bei $68^{\circ} \mathrm{C}$ inkubiert. Der Reaktions-Mix wurde mit $2 \mu$ RNA-Probenpuffer versetzt und auf ein nicht denaturierendes Gel aufgetragen. Native Gelsysteme enthalten im Gegensatz zur SDS-PAGE keine denaturierenden Reagenzien, wie z.B. SDS oder $\beta$-Mercaptoethanol, d.h. die Proteine behalten ihre native Form und Aktivität. 
Tabelle 2.6: Reaktionsansatz aL7-RNA Band-Shift

\begin{tabular}{|c|c|}
\hline Komponenten & Eingesetzte Volumina [ $\boldsymbol{\mu l}]$ \\
\hline aL7 & $\mathrm{x}$ \\
\hline 4X Band-Shift-Puffer & 2,5 \\
\hline RNA-Mix & 2 \\
\hline steriles $\mathrm{H}_{2} \mathrm{O}$ (RNase frei) & $\mathrm{ad} 10$ \\
\hline
\end{tabular}

Tabelle 2.7: Ansätze für Komplex-Rekonstitutionen

\begin{tabular}{|c|c|c|}
\hline Komponenten & $\begin{array}{c}\text { Volumina }[\boldsymbol{\mu l}] \text { Komplex } \\
\text { RNA-aL7-aNop56 }\end{array}$ & $\begin{array}{c}\text { Volumina }[\boldsymbol{\mu l}] \text { Komplex } \\
\text { RNA-aL7-aNop56-aFib }\end{array}$ \\
\hline aL7 [100 nM] & 1 & 1 \\
\hline aNop56 & 1 & 1 \\
\hline aFib & - & 1 \\
\hline 4X Band-Shift-Puffer & 2,5 & 2,5 \\
\hline steriles $\mathrm{H}_{2} \mathrm{O}$ (RNase frei) & 3,5 & 2,5 \\
\hline RNA-Mix & 2 & 2 \\
\hline
\end{tabular}

Tabelle 2.8: Pipettierschema für native Polyacrylamidgele

\begin{tabular}{|c|c|c|}
\hline Komponenten & $\begin{array}{c}\text { Volumina: } \\
\text { 6\%iges Gel }\end{array}$ & $\begin{array}{c}\text { Volumina: } \\
\text { 10\%iges Gel }\end{array}$ \\
\hline Polyacrylamidlösung $[\mathrm{ml}]$ & 2 & 3,3 \\
\hline 1 M Phosphatpuffer, $\mathrm{pH} 7[\mathrm{ml}]$ & 1 & 1 \\
\hline $\mathrm{H}_{2} \mathrm{O}[\mathrm{ml}]$ & 7 & 5,7 \\
\hline TEMED $[\mu \mathrm{l}]$ & 10 & 10 \\
\hline APS $[\mu \mathrm{l}]$ & 60 & 60 \\
\hline
\end{tabular}

\subsubsection{Rekonstitution des sRNP-Komplexes}

Die gereinigten Proteine wurden mit der RNA gemischt und für eine Stunde bei Raumtemperatur inkubiert. Die ungenauen Konzentrationsbestimmungen des BradfordTests ließen ein exaktes Berechnen der molaren Verhältnisse von Proteinen:RNA nicht $\mathrm{zu}$, daher wurde die RNA mit den Proteinen in einem berechneten 1:1-Verhältnis gemischt und im Anschluß an die Inkubationszeit über eine Superdex® S200 HR10/30Gelfiltrationssäule aufgereinigt. Während der Komplex bei der Elution intakt blieb und 
nun in einem molaren Verhältnis vorlag, wurden die Protein-Überschüsse abgetrennt. Es wurden folgende Komplexe rekonstituiert:
a. $\mathrm{aL} 7+\mathrm{sR} 1 / \mathrm{U} 4-22$
b. $\mathrm{aL} 7+\mathrm{sR} 13-28 \mathrm{a}$
c. $\mathrm{aL} 7+\mathrm{aNop} 56+\mathrm{aFib}+\mathrm{sR} 13-28 \mathrm{a}$
d. $\mathrm{aL7}+\mathrm{aNop} 56+\mathrm{aFib}+\mathrm{sR} 13-28 \mathrm{~b}$
e. $\mathrm{aNop} 56+\mathrm{aFib}$

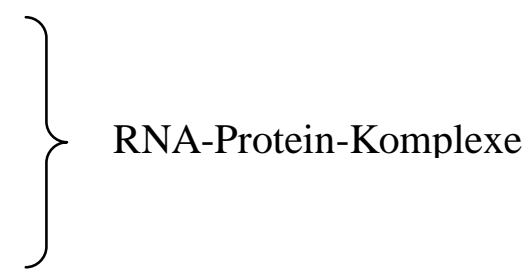

Protein-Protein-Komplex

\subsubsection{Autoradiographie}

Nach der gelelektrophoretischen Auftrennung von radioaktiv-markierten Nukleinsäuren können diese durch Autoradiographie sichtbar gemacht werden. Die Gele wurden hierzu in Cellophanfolie eingeschlagen, auf einen Röntgenfilm (XAR-5; Kodak, Stuttgart) aufgelegt und in einer Filmkassette (Kodak, Stuttgart) für mehrere Stunden bei $-80^{\circ} \mathrm{C}$ exponiert. Auf dem entwickelten Röntgenfilm wurden die radioaktiv-markierten Nukleinsäuren beziehungsweise Nukleinsäure-Protein-Komplexe durch Schwärzung visualisiert.

\subsection{RöNTGENKRISTALLOGRAPHISCHE METHODEN}

Kristalle bestehen aus wiederkehrenden gleichartigen Bausteinen, die in ihren Raumdimensionen hoch geordnet vorliegen und Kristallgitter ausbilden. Dabei besetzen die Bausteine die Gitterpunkte in Form von Atomen, Ionen oder Molekülen. Die Translationsvektoren $\mathrm{a}, \mathrm{b}$ und $\mathrm{c}$ sowie die Winkel $\alpha, \beta$ und $\gamma$, die sogenannten Gitterkonstanten, korrelieren mit den räumlich wiederkehrenden Gitterpunkten und bilden die Einheitszelle (= Elementarzelle). Die asymmetrische Einheit eines Kristalls erhält man durch die weitere Unterteilung der Einheitszelle durch Symmetrieelemente. Diese werden unterschieden in Punktsymmetrieelemente (z.B. Drehachse, Spiegelachse und Translation) und Struktursymmetrieelemente (z.B. Punktsymmetrie plus Translation). 
Es kann zwischen sieben verschiedenen Achsensystemen unterschieden werden, die bestimmt werden durch die Symmetrie im Kristallgitter und möglichst kleiner Vektorbeträge für die Kanten der Einheitszelle. Aus diesen Achsensystemen können durch Translationen auf den drei Koordinatenachsen 14 Bravais-Gitter, die unterschieden werden in primitiv, flächen- und innenzentriert, gebildet werden. Die Kombination der 14 Bravais-Gitter mit den Punktsymmetrieelementen ergibt 32 Kristallklassen (Punktgruppen). In 230 verschiedenen Raumgruppen können Moleküle kristallisieren, wenn die Bravais-Gitter mit den Struktursymmetrieelementen kombiniert werden (KLEBER, 1961). Bei biologischen Molekülen verringert sich die Anzahl der Raumgruppen auf 65, da spiegelnde Symmetrieoperationen aufgrund des enantiomorphen Aufbaus von Proteinen aus L-Aminosäuren und D-Furanosen nicht erlaubt sind.

\subsubsection{Kristallisation biologischer Makromoleküle}

Kleine anorganische und organische Moleküle können häufig durch einfache Methoden (z.B. kontrolliertes Abkühlen einer heißen gesättigten Lösung oder langsame Präzipitation) kristallisiert werden. Das Kristallwachstum von Proteinmolekülen hingegen ist ein Prozeß, der von vielen verschiedenen Faktoren (z.B. Temperatur, Konzentration und Reinheit des Proteins, Art und Konzentration von Puffern und Fällungsmitteln) abhängig ist.

Da in den meisten Fällen die Menge des Proteins, die Zeit und das Geld begrenzt sind, gibt es Initial-Screens (Sparse-Matrix-Screens), deren Zusammensetzung statistisch aus bereits bekannten Kristallisationsbedingungen ermittelt wurde. Auf diese Weise erhält man in ersten Kristallisationsexperimenten Hinweise auf eine mögliche Zusammensetzung der Kristallisationslösung (Mutterlösung). Durch Variation der Komponentenkonzentrationen, den Austausch gleichwertiger Ionen und der Konzentrationsänderung des Proteins können die Kristallisationsbedingungen optimiert werden.

Die verwendete Dampfdiffusion, durchgeführt als hängender oder sitzender Tropfen, ist die häufigste Methode zur Herstellung von Kristallen. Zu Beginn der Experimente werden die Tropfen in einem 1:1-Verhältnis von Proteinlösung zu Kristal- 
lisationslösung gemischt und in einem abgeschlossenen System durch die Plazierung auf einem Stempel oder unter dem Deckel von der Reservoirlösung räumlich getrennt. Ein Konzentrationsgradient wird aufgrund der unterschiedlichen Konzentrationen des Fällungsmittels in Tropfen und Reservoir aufgebaut. Das heißt, daß der Partialdruck des Wassers erhöht ist, da die Reservoirlösung im Tropfen durch die Proteinlösung verdünnt vorliegt. Daraufhin diffundiert das Wasser aus dem vergleichsweise kleinen Tropfenvolumen, und sowohl die Konzentration der Proteinlösung als auch des Fällungsmittels werden erhöht.

\subsubsection{Co-Kristallisation und Derivatisierung durch Diffusion (Soaking)}

Neben der Lösung des Phasenproblems durch Schwermetall-Derivate (s. 2.4.3 Multipler Isomorpher Ersatz) werden die Co-Kristallisation und die Derivatisierung durch Diffusion, dem sogenannten Soaking, auch zur funktionellen Aufklärung von Protein-Interaktionen mit anderen Molekülen eingesetzt. Bei den Molekülen kann es sich dabei um Proteine, Nukleinsäuren oder Liganden wie Inhibitoren, Substrat-Analoga oder Co-Faktoren handeln.

Bei der Co-Kristallisation von Proteinen und Liganden wird das Protein zunächst mit einem molaren Überschuß an Ligand versetzt und anschließend mit der Kristallisationslösung, die Proteinkristalle ohne Liganden hervorbringt, vermischt. Wenn Proteine mit anderen Proteinen und/oder Nukleinsäure kristallisiert werden sollen, ist die Co-Kristallisation die einzige Möglichkeit Kristalle zu produzieren.

Die Derivatisierung von bereits vorhandenen Proteinkristallen durch Diffusion mit Liganden ist möglich, da die Proteine ihre katalytischen Funktionen und Bindungseigenschaften auch im kristallinen Zustand behalten.

\subsubsection{Co-Kristallisation von RNA-Protein- und Protein-Protein-Komplexen}

Zur in vitro Rekonstitution der Komplexe wurden die RNA und die Proteine wie unter 2.3.7 beschrieben miteinander gemixt, bei Raumtemperatur inkubiert und über 
eine Superdex® S200 HR10/30-Gelfiltrationssäule aufgereinigt. Folgende Komplexe standen anschließend zur Kristallisation zur Verfügung:
a. $\mathrm{aL} 7+\mathrm{sR} 1 / \mathrm{U} 4-22$
b. $\mathrm{aL} 7+\mathrm{sR} 13-28 \mathrm{a}$
c. $\mathrm{aL} 7+\mathrm{aNop} 56+\mathrm{aFib}+\mathrm{sR} 13-28 \mathrm{a}$
d. $\mathrm{aL} 7+\mathrm{aNop} 56+\mathrm{aFib}+\mathrm{sR} 13-28 \mathrm{~b}$
e. $\mathrm{aNop} 56+\mathrm{aFib}$

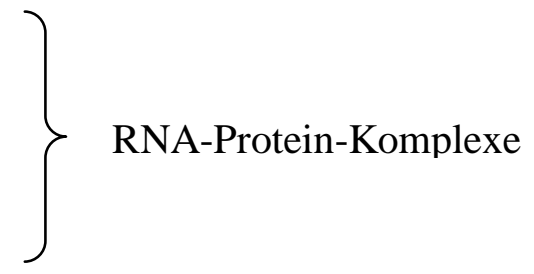

Protein-Protein-Komplex

Zur Kristallisierung der Komplexe wurden sowohl Linbro ${ }^{\mathrm{TM}}$-Platten (hängender Tropfen; Hampton Research, USA) als auch Cryschem ${ }^{\text {TM}}$-Platten (sitzender Tropfen; Hampton Research, USA) verwendet. Im Reservoirbehälter befanden sich 500-1000 $\mu 1$ Kristallisationslösung, von der $1 \mu 1$ mit $1 \mu 1$ RNA-Protein-Komplex-Lösung vermischt wurde. Die Linbro ${ }^{\mathrm{TM}}$-Platten wurden an den Rändern der Reservoirbehälter mit viskoser Silikonpaste eingefettet und mit silanisierten Deckgläschen, auf deren Unterseite der Kristallisationstropfen hing, luftdicht verschlossen. Die Cryschem ${ }^{\mathrm{TM}}-$ Platten, die einen Stempel pro Reservoirbehälter besitzen, auf dem die Tropfen plaziert wurden, wurden mit lösungsmittelbeständigem Klebeband abgedichtet. Kommerzielle Screens der Firma Hampton Research (Crystal Screen I + II, PEG/Ion-Screen, Natrix Screen) wurden für erste Kristallisationsversuche verwendet. Die Ansätze wurden bei $20^{\circ} \mathrm{C}$ aufbewahrt und mit Hilfe eines Leica MZ125-Stereomikroskops in regelmäßigen Abständen kontrolliert. Kristalle wurden mit einer Nikon-Coolpix 4500 Digitalkamera dokumentiert.

\subsubsection{Co-Kristallisation und Soaking von AmyB mit verschiedenen Liganden}

Da für AmyB sowohl die Kristallisationsbedingungen bekannt sind als auch die Struktur weitestgehend gelöst war, die physiologische Funktion des Proteins aber noch völlig ungeklärt ist, sollte mit Hilfe von Co-Kristallisation und Soaking die Bindung verschiedener Liganden an das aktive Zentrum untersucht werden. Das zur CoKristallisation benötigte aufgereinigte Protein AmyB aus Thermotoga maritima MSB 8 wurde freundlicherweise von Meike Ballschmiter, Universität Göttingen, Institut für Mikrobiologie und Genetik, zur Verfügung gestellt. Als Co-Faktoren wurden ver- 
schiedene Zucker (Acarbose, Maltose und Glucose) ausgesucht, da eine hohe Sequenzhomologie von AmyB zu Mitgliedern der Glycosyl Hydrolase Familie 57 festgestellt wurde. Aufgrund der Verfärbung nativer Kristalle von farblos zu rostrot wurden auch zwei- und dreiwertige Metallionen $\left(\mathrm{Fe}^{3+}, \mathrm{Mn}^{2+}\right.$ und $\left.\mathrm{Zn}^{2+}\right)$ als Co-Faktoren untersucht. Des weiteren wurde ATP, das AmyB reguliert, als Ligand geprüft. Alle Kristallisationsund Soakingversuche wurden mit Liganden-Konzentrationen von 0,1-10 mM durchgeführt. Aufbewahrung, Kontrolle und Dokumentation erfolgten wie in 2.4.2.1 beschrieben.

\subsubsection{Kryo-Konservierung und Montage der Kristalle zur Datensammlung}

Innerhalb makromolekularer Kristalle entstehen durch die Absorption von Röntgenstrahlen freie Hydroxylradikale, die zu Schäden im Kristallgitter führen und dadurch eine Verschlechterung der Diffraktionseigenschaften nach sich ziehen. Eine Diffusion der Radikale wird durch tiefe Temperaturen (100 K) während der Datensammlung stark eingeschränkt und eine längere Exposition der Kristalle im Röntgenstrahl ist möglich.

Daneben besitzen Kristalle einen Wassergehalt, der zwischen 30 und 90\% variieren kann (CASPAR ET AL., 1969; COHEN ET AL., 1972) und der große Zwischenräume und Kanäle füllt. Ein Tiefkühlen (es kommt zu keiner Änderung des Aggregatzustandes) der Kristalle ohne Frostschutzmittel (Kryo-Protektant) würde somit in den meisten Fällen zu der Bildung von Eis im Kristallwasser und der umgebenden Flüssigkeit und daraus folgend zu einer mechanischen Zerstörung des Kristalls führen. Daher ist es notwendig die Kristalle in einem geeigneten Kryo-Puffer, der z.B. aus Paraton N oder der Mutterlösung mit Glycerin, PEG 400, MPD oder Kryo-Salzen als Frostschutzmittel besteht, zu äquilibrieren. Mit einer Nylonschlaufe (Größe: 0,05-1 mm), die auf einem Stab mit Magnetkappe befestigt ist, wird der Kristall aus dem Kryo-Puffer gefischt und auf den Goniometerkopf der Drehanode (s. 2.4.4) montiert. Die Suche nach dem optimalen Kryo-Puffer erweist sich oft als langwierig und Kristalle verbrauchend. Bei Erfolg werden die Diffraktionseigenschaften des Kristalls aber verbessert. 
Ist ein erfolgreiches Tiefkühlen des Kristalls jedoch nicht möglich, kann der Kristall mit einem Tropfen Mutterlösung in eine Glaskapillare überführt werden. Diese wird an beiden Enden verschlossen und mit Knete auf dem Goniometerkopf fixiert.

Größere Datenmengen eines einzelnen Kristalls durch Reduzierung der Strahlungsschäden, geringes Hintergrundrauschen durch Reduzierung der Streustrahlung und einfaches Lagern und Handhaben der Kristalle führten dazu, daß die Kryo-Kristallisierung in den meisten Fällen zu Anwendung kommt.

Für die AmyB Experimente wurden die Kristalle nur mit der KryoKristallographie vermessen, während bei den sRNP-Kristallen auch die veraltete Kapillarmethode Anwendung fand. Kristalle, die mit der Kryo-Methode gemessen wurden, wurden während der Experimente durch ein Kryo-System im tiefgekühlten Zustand konserviert, indem sie mit $100 \mathrm{~K}$ kaltem Stickstoffgas umströmt wurden. Mit speziellen Geräten (CryoTong ${ }^{\mathrm{TM}}$, CryoWand ${ }^{\mathrm{TM}}$, Hampton Research, USA), die in flüssigem Stickstoff vorgekühlt wurden, wurden die Kristalle vom Goniometerkopf abmontiert und in einem Stickstoff gefüllten Lagerungsbehälter bis zur weiteren Verwendung aufbewahrt. Auf diese Weise wurden die Kristalle an der Drehanode nach ihren Diffraktionseigenschaften vorselektiert, um die begrenzte Meßzeit am Synchrotron optimal nutzen zu können.

\subsubsection{Strahlungsquellen}

Um geeignete Beugungsbilder zur Strukturbestimmung eines Kristalls zu erhalten, wird Röntgenstrahlung benötigt, die auf unterschiedliche Weise erzeugt werden kann. Als geeignete Strahlungsquellen standen Drehanode und Synchrotron zur Verfügung.

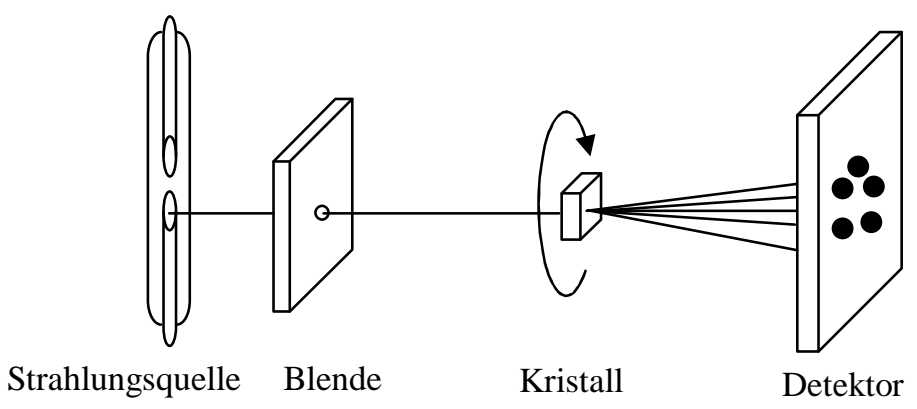

Abbildung 2.1: Schematischer Aufbau eines Röntgenbeugungsexperimentes 


\subsubsection{Drehanode}

Die von einer Kathode gebildeten Elektronen werden durch eine Spannung beschleunigt und prallen auf eine sich drehende Anode (aus Molybdän, Kupfer oder Wolfram), an der sie abgebremst werden. Die Elektronen geben daraufhin ihre Energie ab und verwandeln sie in Strahlung und Wärme, weshalb die Anode gekühlt werden muß. Sehr kleine beziehungsweise schlecht streuende Kristalle und Experimente, zu deren Auswertung mehrere Datensätze mit verschiedenen Wellenlängen benötigt werden (s. 2.4.5 Multiple Anomale Dispersion), erfordern jedoch die intensivere, wellenlängenveränderbare Synchrotronstrahlung.

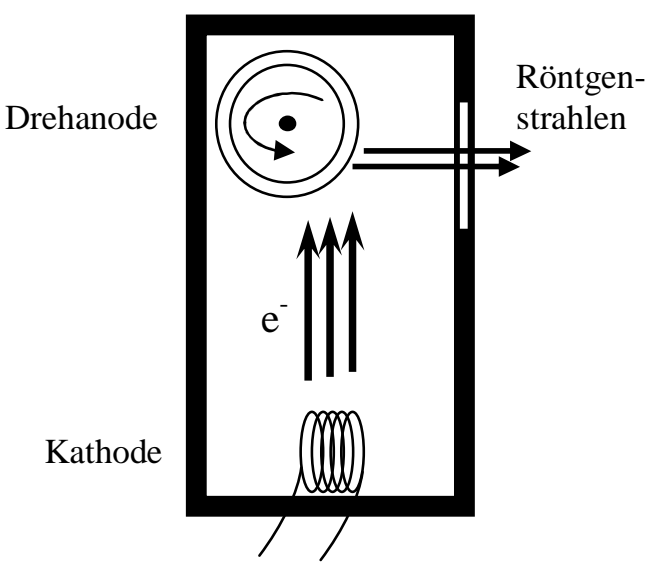

Abbildung 2.2: Schematischer Aufbau einer Drehanode

\subsubsection{Synchrotron}

Beim Synchrotron handelt es sich um einen Teilchenbeschleuniger, der ringförmig aufgebaut ist, und in dem die Elektronen Energien bis $100 \mathrm{MeV}$ erreichen. Die Elektronen werden durch Magnetfelder auf ihrer Sollbahn geführt. Dabei wirkende Kräfte rufen eine Beschleunigung der Elektronen hervor, die elektromagnetische Strahlung aussenden. Die Synchrotronstrahlung, die bis in den Spektralbereich der Röntgenstrahlung reicht, tritt in den Krümmungsbereichen der Bahn stark gebündelt aus und kann für die Untersuchungen an Kristallen genutzt werden. 
Datensätze der AmyB Kristalle wurden sowohl im Labor an Rigaku Drehanoden-Generatoren (Micromax 007 \& RU-H3R, Rigaku MSC, USA) als auch am Deutschen Elektronensynchrotron in Hamburg (DESY, Beamlines: BW7A \& BW7B) und an der Europäischen Synchrotronstrahlungsquelle in Grenoble (ESRF, Beamline: ID14-1) gemessen. Die Reflexdaten wurden mit Image-Plate Systemen (mar345 dtb, MarResearch GmbH, Deutschland) und CCD Detektoren (ADSC Q4R, Area Detector Systems Corporation, USA) aufgenommen. Um die Vollständigkeit der gesammelten Datensätze zu gewährleisten, wurde der abzudeckende Winkelbereich aus der Anfangsorientierung des Kristalls zum Röntgenstrahl und der Kristallsymmetrie bestimmt.

\subsubsection{Röntgenbeugung am Kristallgitter}

Die im Kristall periodisch angeordneten Moleküle treten mit den elektromagnetischen Röntgenwellen in Wechselwirkung. Dabei kommt es zu konstruktiver Interferenz der gebeugten Strahlen, wenn der Gangunterschied zweier Wellen ein ganzzahliges Vielfaches der Wellenlänge $\lambda$ ist (Braggsches Gesetz).

$$
2 d^{*} \sin \theta=n \lambda \quad(\mathrm{n}=1,2,3, \ldots) \quad \text { Braggsches Gesetz }
$$

Im realen Raumgitter wird jeder Ebenenschar, die jeweils einem Reflex auf dem Beugungsbild entspricht, ein Strukturfaktor F mit der Raumlage h, k und 1 (Millersche Indizes) zugeordnet. Während die Wellenlänge der Röntgenstrahlung und die Intensität des Reflexes $I_{h k l}$ (proportional zur Amplitude $\left|F_{h k l}\right|$ ) bekannt sind, muß die Phaseninformation der am Kristallgitter gebeugten Röntgenstrahlen indirekt ermittelt werden. Um das Phasenproblem makromolekularer Kristalle zu lösen, stehen drei verschiedene Ansätze zur Verfügung:

a. Molekularer Ersatz (MR: engl. Molecular Replacement)

Bei dieser Methode wird eine bekannte Struktur als Modell vorausgesetzt, die aufgrund ihrer Sequenz homolog zu dem gesuchten Protein ist. Das bekannte Strukturmodell muß dabei mittels Rotations- und Translations- 
funktionen korrekt in die Einheitszelle der zu lösenden Struktur eingepaßt werden und kann dann zur Phasenberechnung dienen (HOPPE, 1957; RoSSMANN \& BLOW, 1962; HuBER, 1965).

b. Multipler Isomorpher Ersatz (SIR oder MIR: engl. Single oder Multiple Isomorphous Replacement)

Der isomorphe Ersatz wird zur Aufklärung neuer Strukturen angewendet. Es handelt sich um eine Derivatisierung der Kristalle durch Diffusion mit Schwermetallatomen (s. 2.4.2). Ist die Einlagerung der Schwermetallatome gelungen, können bei der Röntgenbeugung Intensitätsänderungen beobachtet werden, welche zur Phasenbestimmung verwendet werden.

c. Multiple Anomale Dispersion (MAD)

Als Alternative zum Isomorphen Ersatz kann die Multiple Anomale Dispersion angesehen werden. Hierbei wird bereits bei der Expression des Proteins in E. coli statt des schwefelhaltigen Methionins das anomal streuende Selenomethionin eingebaut. Die entstandenen Kristalle werden bei verschiedenen Wellenlängen, den sogenannten Absorptionskanten, gemessen. Das Prinzip der Anomalen Streuung war schon lange bekannt, konnte aber erst durch die Kryo-Kristallographie und die hohe Synchrotron-Strahlung richtig eingesetzt werden. Durch die hohe Strahlungsintensität und die Kühlung können mehrere Datensätze mit unterschiedlichen Wellenlängen an einem einzelnen Kristall gemessen werden. $\mathrm{Zu}$ beobachtende Intensitätsänderungen können wie beim Isomorphen Ersatz zur Phasenbestimmung angewandt werden.

\subsubsection{Prozessierung der Meßdaten}

Die in den Diffraktionsexperimenten erhaltenden Datensätze wurden in mehreren Einzelschritten bearbeitet und ausgewertet. Dazu wurden zunächst die Reflexe des ersten Beugungsbildes mit den Programmen XDisplay und DENZO (OTWINOWSKI \& MINOR, 1997) autoindiziert. Durch die Autoindizierung wurden die Raumgruppe und 
die Zellkonstanten bestimmt. Nach Optimierung der Parameter (z.B. Zellkonstanten, Detektorentfernung, Strahlkoordinaten) wurden alle aufgenommenen Beugungsbilder indiziert und integriert. Dabei wurde jedem Reflex eine integrierte Reflexintensität, eine Standardabweichung der Integration und ein Miller'scher Index zugeteilt. Die mit DENZO ausgewerteten Beugungsbilder wurden danach mit dem Programm SCALEPACK (OTWINOWSKI \& MINOR, 1997) skaliert und in einem File zusammengefügt. Reflexe, die auf mehreren Beugungsbildern indiziert wurden, wurden skaliert und die Werte anschließend gemittelt. Als Maß für die Qualität des Datensatzes dient der $\mathrm{R}_{\text {sym- }}{ }^{-}$ Faktor. Er ist jedoch nur begrenzt geeignet, da er stark von der Redundanz der Messung abhängt. Beim $\mathbf{R}_{\mathrm{sym}}$-Faktor werden die Intensitäten der symmetrieverwandten Reflexe mit ihrer mittleren Intensität abgeschätzt.

$$
R_{s y m}=\frac{\sum_{h} \sum_{i}\left|I_{h i}-I_{h}\right|}{\sum_{h i} I_{h i}}
$$

Dabei sind h die Indizes unabhängiger Reflexe mit der mittleren Intensität $I_{h}$, und $\mathrm{I}_{\mathrm{hi}}$ sind die Intensitäten symmetrieverwandter Reflexe.

\subsubsection{Vergleich der AmyB-Struktur mit bekannten Strukturen}

Neben den bekannten Sequenzdatenbanken gibt es auch Strukturdatenbanken (www.ebi.ac.uk/dali/), in denen neue Proteinstrukturen mit bereits veröffentlichten Strukturen aus der Proteindatenbank (www.rscb.org/pdb/) verglichen werden können. Ein solcher Vergleich wurde mit den Strukturkoordinaten des AmyB Enzyms durchgeführt. Aus dem erhaltenen Ergebnis wurden die Proteinstrukturen ausgewählt, deren Z-Faktor (Maß der strukturellen Ähnlichkeit) über einem Wert von 5 (Z-Faktoren über 2 werden als gute Treffer gewertet) lag und die gleichzeitig den Glykosyl-Hydrolase Familien 13 oder 57 angehörten. Um die so identifizierten Strukturen mit der AmyBStruktur (Dr. A. Dickmanns, Veröffentlichung in Vorbereitung) vergleichen zu können, wurden die Strukturkoordinaten mit Hilfe des Programms CCP4 in die gleiche 
Orientierung überführt. Die gleichgerichteten Koordinaten wurden mit dem Programm Pymol (www.pymol.org) in ihrer Sekundärstruktur visualisiert. Durch das Hervorheben einzelner katalytisch relevanter Aminosäuren konnte ihre Lage im Protein respektive im aktiven Zentrum bestimmt und eine Aussage über eine mögliche Bindungsfähigkeit getroffen werden. 


\section{ERGEBNISSE}

\subsection{EXPRESSION UND REINIGUNG DER SRNP-PROTEINE AL7, aNOP56 UND $a F I B$}

Um mit der Methode der Röntgenkristallographie Strukturen aufzuklären, werden Proteinmengen im Milligrammmaßstab benötigt (DRENTH, 1994). Da solche Mengen jedoch normalerweise nicht in den Ursprungszellen exprimiert werden, ist es notwendig die Proteine heterolog in dafür entwickelten Expressionssystemen anzureichern und zu reinigen.

Zur in vitro Rekonstitution des sRNP-Komplexes wurden die drei Proteine aL7, aNop56 und aFibrillarin benötigt. Sie wurden in Abhängigkeit ihrer Stabilität gegenüber Degradationen nacheinander aufgereinigt. Es zeigte sich, daß aFib bei $4^{\circ} \mathrm{C}$ bis zu einem Jahr ohne erkennbare Degradation gelagert werden konnte, während aL7 maximal 11/2-2 Monate und aNop56 nur 3-4 Wochen aufbewahrt werden konnten.

\subsection{1 aL7}

Das Protein aL7 aus Sulfolobus solfataricus konnte in E. coli BL21(DE3)pLysEZellen rekombinant überexprimiert werden (Abb. 3.1). Nach Aufschluß der Zellen mit Ultraschall lag das Protein in löslicher Form im Überstand vor. Der Überstand wurde auf $150 \mathrm{ml}$ mit Aufschlußpuffer aufgefüllt, um eine möglichst große Oberfläche für die Hitzedenaturierung zu schaffen. Durch das Aufteilen in 15-20 ml Portionen konnte die Oberfläche weiter vergrößert werden. Nur so war es möglich viele der mesophilen E. coli Proteine bei $65^{\circ} \mathrm{C}$ zu denaturieren (Abb. 3.1).

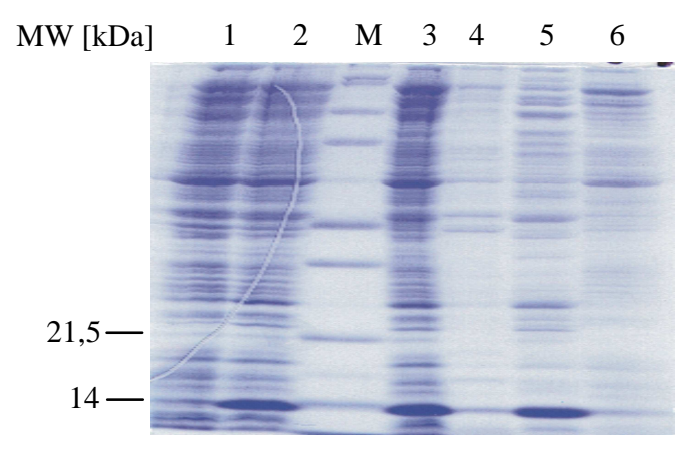

\footnotetext{
Abbildung 3.1:

Überexpression (Spur $1+2$ ), Überstand und Pellet des Zellaufschlusses (Spur $3+4)$ und Überstand und Pellet der Hitzedenaturierung $($ Spur $5+6)$ von aL7 (bei $14 \mathrm{kDa})$
} 
Fast alle restlichen E. coli Proteine, die bisher nicht denaturiert wurden, konnten durch hydrophobe Wechselwirkungen an eine Phenyl Sepharose ${ }^{\circledR}-S a ̈ u l e ~ g e b u n d e n$ werden, gleichzeitig wurde das aL7 nicht an das Material angelagert. Beim Waschen der Säule wurde das zu reinigende Protein von der Säule gespült, während die störenden Proteine erst bei einer Konzentration von $600 \mathrm{mM}$ Ammoniumsulfat eluiert wurden (Abb. 3.2 A + B). Um letzte Verunreinigungen $\mathrm{zu}$ entfernen, wurden die aL7enthaltenden Fraktionen ankonzentriert und über eine Gelfiltrationssäule sauber von den letzten E. coli Proteinen abgetrennt (Abb. 3.2 C). Aus dem Verlauf der Elution ist ersichtlich, daß das aL7 als Monomer von der Säule eluiert wurde (Abb 3.2 D). Aus dem Pellet einer 4 l LB-Kultur konnten durchschnittlich 12-14 mg aL7 gewonnen werden.

A

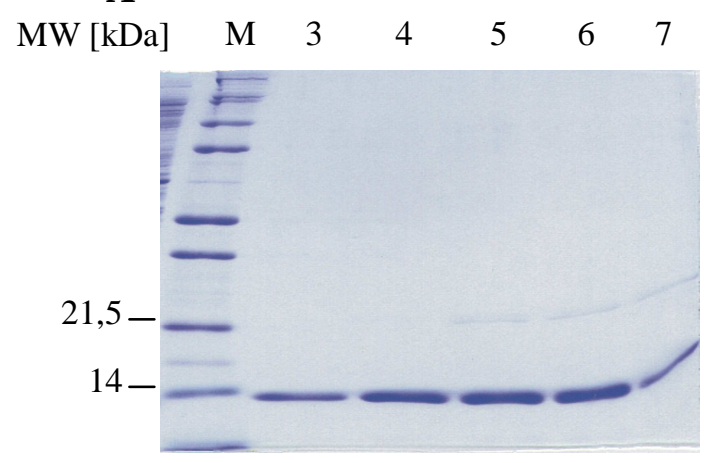

C

MW[kDa] M 3637383940414243

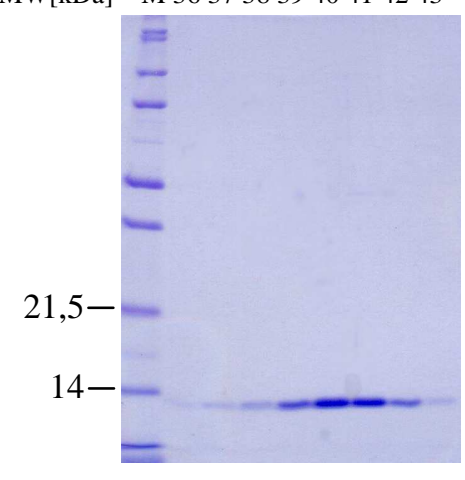

B

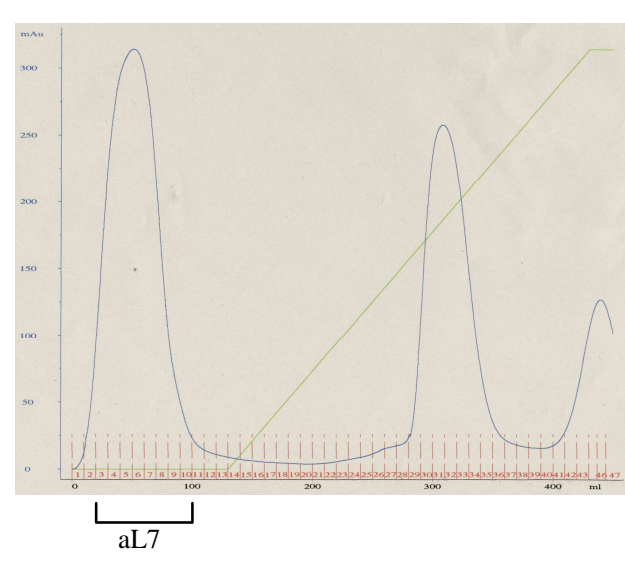

D

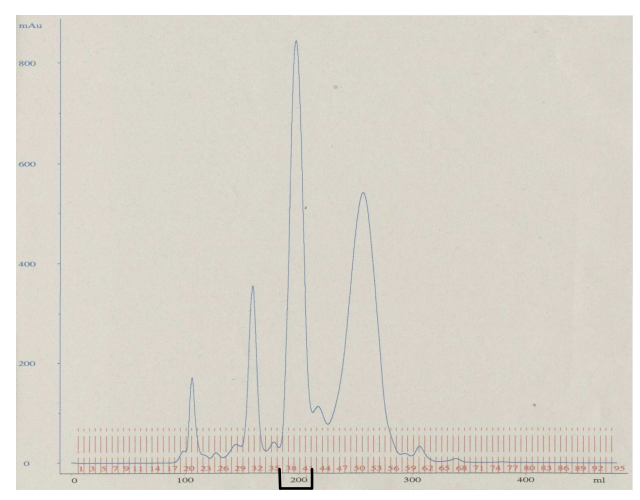

aL7

Abbildung 3.2: Aufreinigung von aL7 über eine Phenyl Sepharose®-Säule. Die auf das 17,5\%ige SDS-Gel geladenen Spuren (A) entsprechen dem markierten Bereich im Phenyl Sepharose®-Elutionsprofil (B). Bei der anschließenden Gelfiltration (Superdex® 75) wurden letzte Verunreinigungen entfernt (D) und mit einer 17,5\%-igen SDS-PAGE überprüft (C) 


\title{
3.1.2 aNop56
}

Im Gegensatz zu aL7 und aFib konnte aNop56 nur bei $20^{\circ} \mathrm{C}$ löslich in E. coli BL21(DE3) exprimiert werden. Daneben war das rekombinante Protein bei der Reinigung anfällig gegenüber Proteasen und längeren Lagerzeiten bei Raumtemperatur. Diese Tatsache erklärt, warum bei dem Schritt der Hitzedenaturierung neben den E. coli Proteinen auch ein Teil ( 20\%) des thermostabilen Proteins denaturiert wurde (Abb. 3.3).

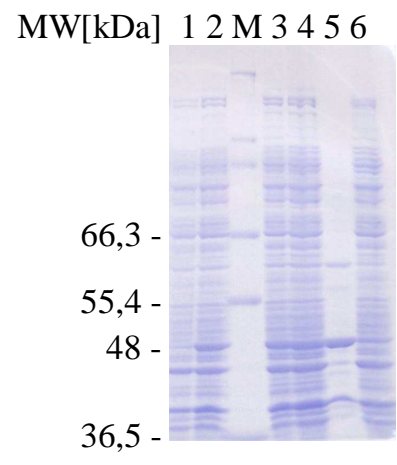

\begin{abstract}
Abbildung 3.3: Kontrolle der Expression, Aufschluß und Hitzedenaturierung von aNop48 durch eine 10\%-ige SDS-PAGE. Spur 1: vor Induktion; Spur 2: nach Induktion; Spur 3: Aufschluß Überstand; Spur 4: Aufschluß Pellet; Spur 5: Hitzedenaturierung Überstand; Spur 6: Hitzedenaturierung Pellet
\end{abstract}

Das aNop56 wurde in einem nächsten Reinigungsschritt an das starke Anionenaustauschermaterial MonoQ gebunden und konnte bei einer $\mathrm{NaCl}$-Konzentration von $550 \mathrm{mM}$ wieder von der Säule eluiert werden (Abb. 3.4 A + B). Die meisten nach der Hitzedenaturierung noch in der Probe enthaltenen E. coli-Proteine wurden zum größten Teil direkt von der Säule gewaschen oder bei anderen niedrigeren NaClKonzentrationen von der Säule eluiert. Als letzter Reinigungsschritt schloß sich ebenfalls eine Gelfiltration an, bei der das 48 kDa große aNop56 von den anderen Proteinen getrennt wurde (Abb. 3.4 C + D). 
$\mathbf{A}$

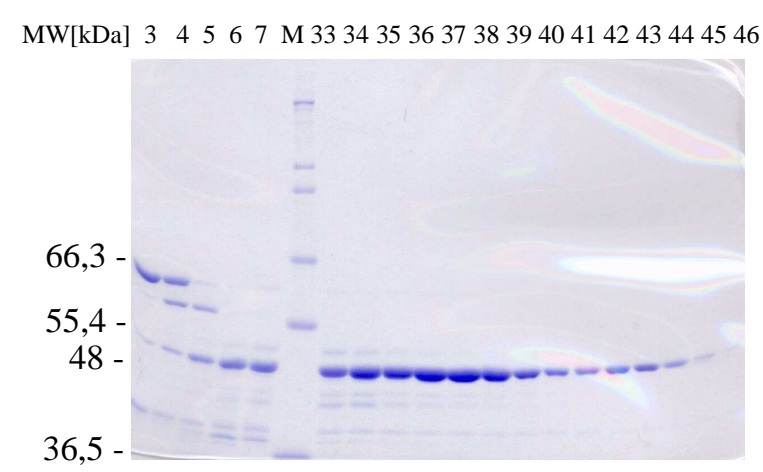

C

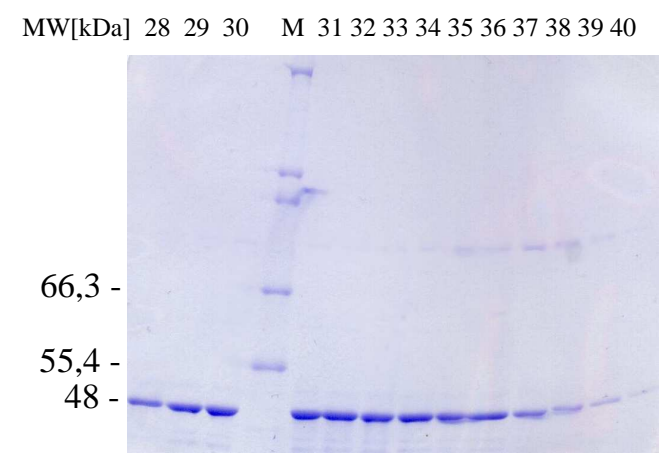

B

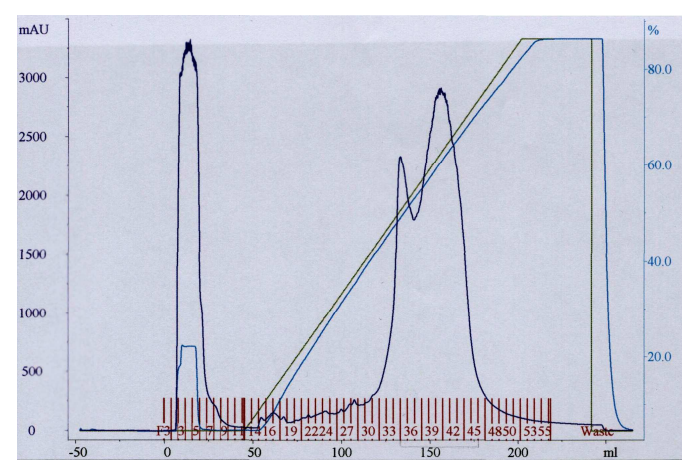

D

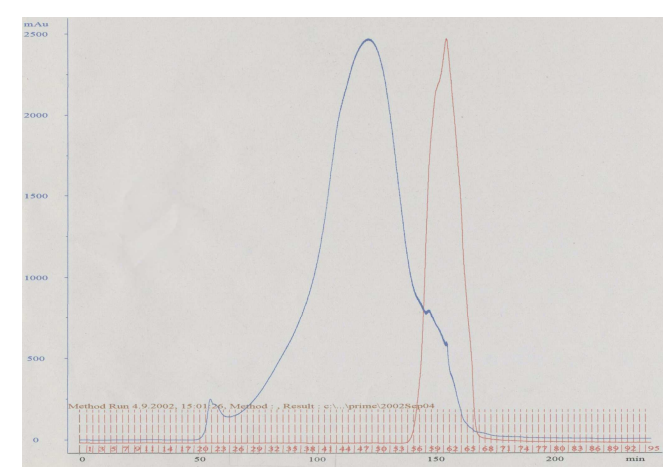

Abbildung 3.4: A + B: Anionenaustauscherchromatographie des aNop56 über MonoQMaterial. Die Kontrolle des Reinigungsschritts erfolgte per gelelektrophoretischer Auftrennung. C + D: Die Fraktionen 28-34 wurden nach der Gelfiltration eingeengt

\subsection{3 aFib}

Das in E. coli BL21(DE3)pLysS rekombinant exprimierte aFib (27 kDa) war das einzige Protein, das in ECPM1 Medium kultiviert werden konnte. Aufgrund der Tatsache, daß die Zellen in diesem Medium bis zu einer $\mathrm{OD}_{600 \mathrm{~nm}}$ von 20 wachsen konnten, wurde etwa 18 mal mehr Protein produziert, als mit herkömmlichem LB-Medium. D.h. aus 1/2 1 ECPM1-Medium konnten 40-45 mg aFib-Protein isoliert werden.

Das aFib wurde mit den gleichen Schritten wie aNop56 (s. 3.1.2) isoliert. Der einzige Unterschied bei Aufreinigung bestand darin, daß das aFib aufgrund seines 
kalkulierten isoelektischen Punktes nicht an das MonoQ-Material gebunden wurde, sondern direkt mit einigen E. coli Proteinen von der Säule gewaschen wurde (Abb. 3.5 A + B). Als Monomer konnte das aFib im letzten Reinigungsschritt von der Gelfiltrationssäule eluiert werden (Abb. 3.5 C + D).

A

AÜ AP HÜ HP M 345671415161718 MW [kDa]

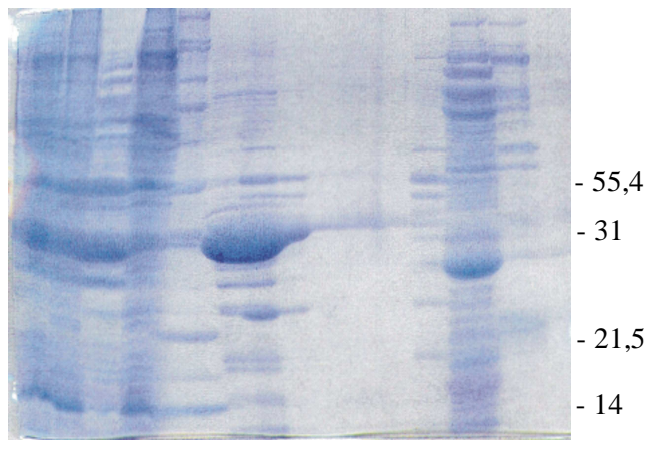

C

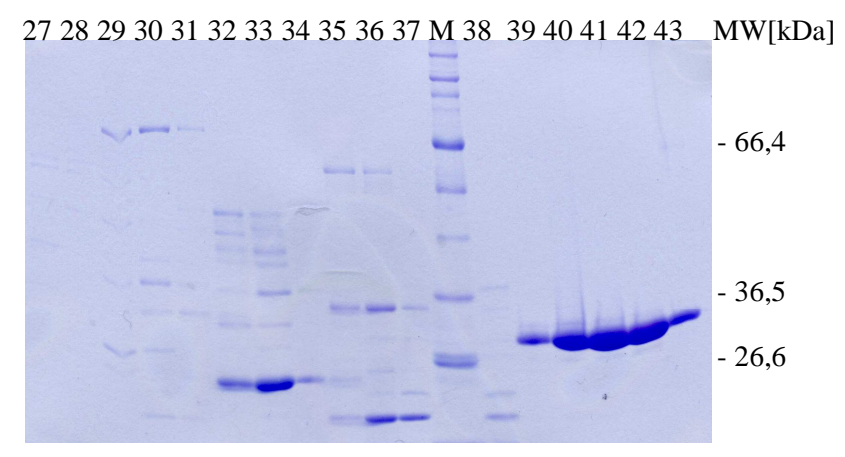

B

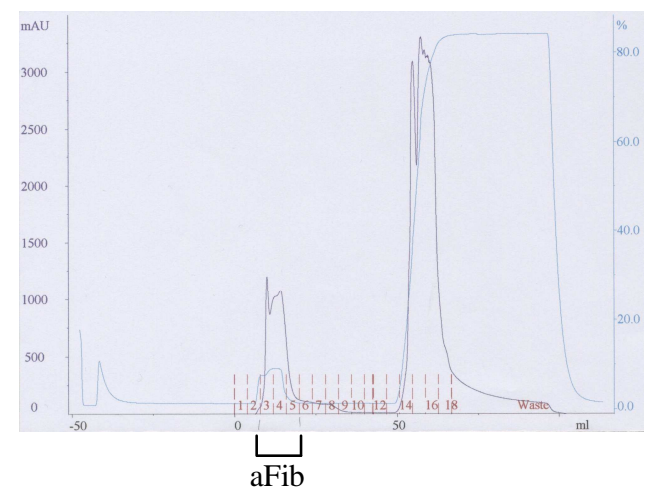

D

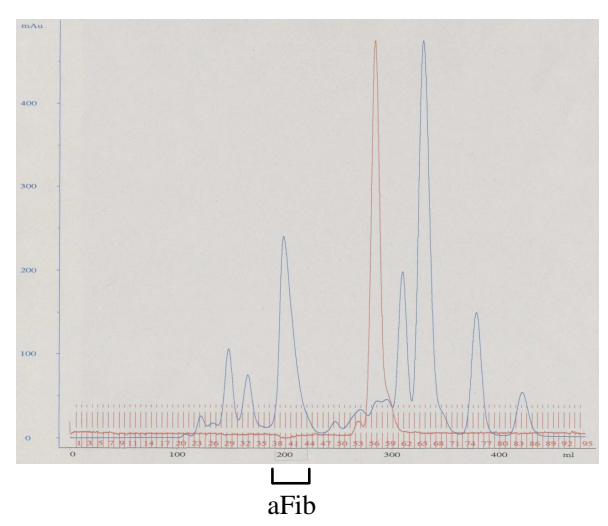

Abbildung 3.5: Die Isolierung von aFib wurde mit 12,5\%-igen SDS-Gelen kontrolliert. A: Aufschluß (AÜ (Überstand) + AP (Pellet)), Hitzedenaturierung (HÜ (Überstand) + HP (Pellet)) und MonoQ-Lauf (Spurnumerierung entsprechen den Fraktionen in B). C + D: Gelfiltration von aFib; die Fraktionen sind über der jeweiligen Bahn des Gels angegeben 


\subsection{BAND-SHIFT EXPERIMENTE}

Die bei der in vitro Transkription hergestellten RNAs wurden in den Band-Shift Experimenten auf ihre Fähigkeit der Komplexbildung mit den drei Proteinen getestet. Zunächst wurde dazu die Proteinkonzentration bestimmt, die für die folgenden Versuche benötigt wurde. Ab Konzentrationen von 100 nM aL7 war ein Band-Shift, also eine Komplex-Bildung von aL7 und RNA (1 pmol) zu erkennen (Abb. 3.6 A). Für die weiteren Versuche wurden Proteinkonzentrationen von 200 nM eingesetzt.

Zur Auffindung einer möglichst kurzen RNA für die Komplexbildung, wurden die in vitro hergestellten verkürzten RNAs im Band-Shift Experiment mit verschieden Protein-Kombinationen auf ihre Komplexbildung getestet. Für sR1del3 (Abb. 3.6 B) konnte ebenso wie für weitere vier verkürzte RNAs (sR1del1 + sR1del2, sR13del1 + sR13del2) keine Bindung mit den Proteinen gezeigt werden. Ausschließlich für die verkürzte Variante sR13del3 konnte eine Komplexbildung mit aL7, aNop56 und aFib festgestellt werden (Abb. 3.6 B).

A

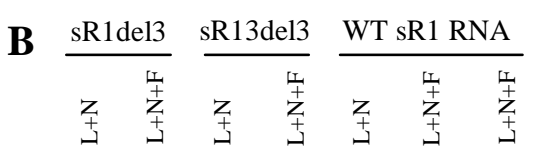

[aL7]

400nM 200nM 100nM 50nM 25nM 0nM

- Komplex 3

- Komplex 2

sR13del3

Abbildung 3.6: Band-Shift Experimente. Eine Bildung von Komplex 1 (sR13del3 RNA $(1 \mathrm{pmol})+\mathrm{aL7})$ wird ab einer aL7-Konzentration von $100 \mathrm{nM}$ erreicht (A). Eine Komplexbildung wie bei WT sR1 RNA mit den drei Proteinen aL7, aNop56 und aFib kann nur bei sR13del3 RNA beobachtet werden (B) 


\subsection{REKONSTITUTION DES SRNP-KOMPLEXES}

Nach der Rekonstitution des sRNP-Komplexes aus sR13-28a, aL7, aNop56 und aFib, wurde dieser Ansatz nochmals über eine Gelfiltrationssäule gereinigt. Dadurch konnten die nicht im Komplex gebundenen Proteine und die überschüssige RNA aus dem Ansatz entfernt werden (Abb. 3.7). Fraktionen in denen alle drei Proteine und die RNA gut zu erkennen waren (Abb. 3.7 A; Fraktionen 19-24), wurden vereinigt, auf $8 \mathrm{mg} / \mathrm{ml}$ ankonzentriert und in Kristallisationsversuchen eingesetzt. Eine Quantifizierung der Banden ist im Silbergel nicht möglich, da verschiedene Proteine mit unterschiedlichen Intensitäten färben (POEHLING \& NEUHOFF, 1981).

A

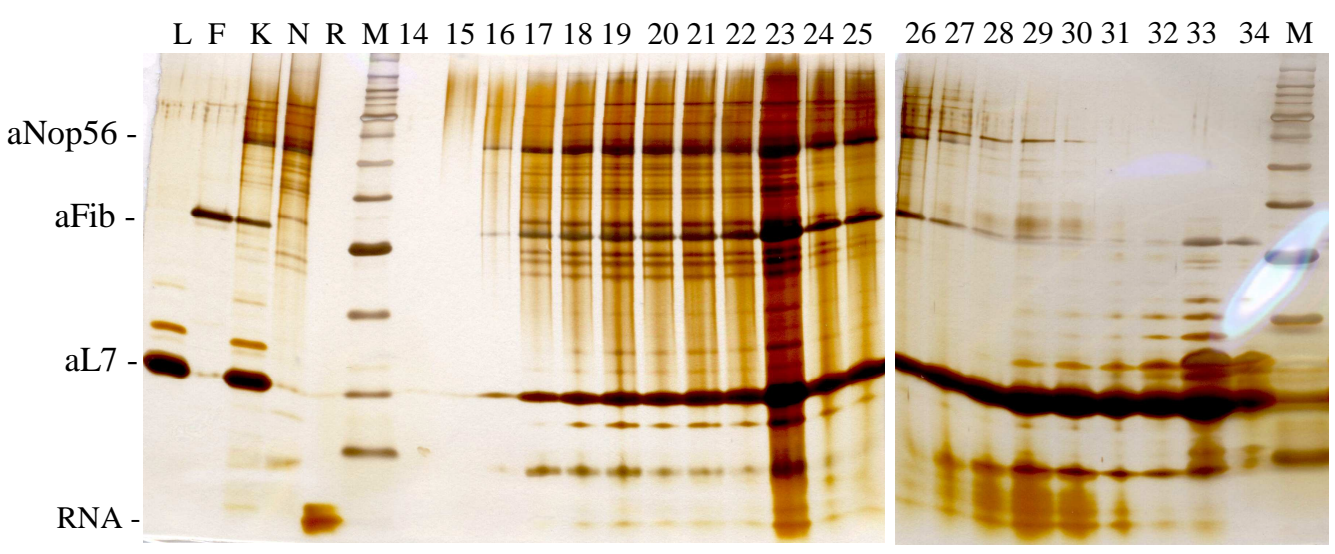

B

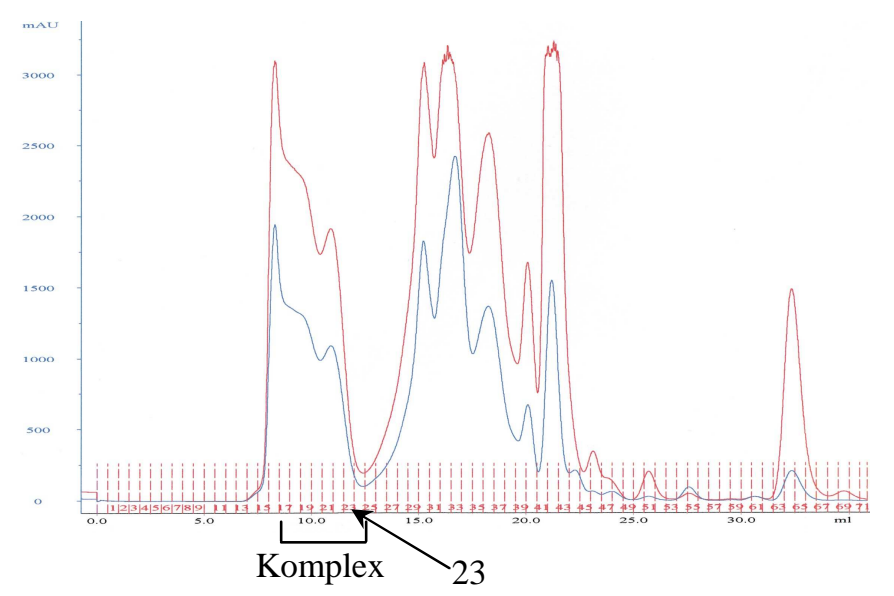

Abbildung 3.7: Aufreinigung des in vitro rekonstituierten Komplexes über eine S200Gelfiltrationssäule. Neben den Kontrollspuren für die Proteine, der RNA und dem Komplex (L, N, F, R und K), korrespondieren die anderen Spuren auf dem 17,5\%-igem Silbergel (A) mit den Fraktionen des Elutionsprofils (B) 
Um zu untermauern, daß es sich bei den Ergebnissen der Gelfiltration tatsächlich um den erwarteten Komplex aus RNA, aL7, aNop56 und aFib handelte, wurde die Fraktion 23 des Gelfiltrationslaufs auf einen ResourceQ-Anionenaustauscher aufgetragen. Aufgrund der unterschiedlichen Ladungsverhältnisse wird aFib alleine nicht an die Säule gebunden, während aNop56 und aL7 gebunden und bei $\mathrm{NaCl}$ Konzentrationen von $550 \mathrm{mM}$ und $600 \mathrm{mM}$ von der Säule eluiert werden.

Die Komplexfraktion 23 wurde vollständig an die Säule gebunden und bei einer $\mathrm{NaCl}$-Konzentration von 500 mM in einem Peak von der Säule eluiert (Abb. 3.8).

A

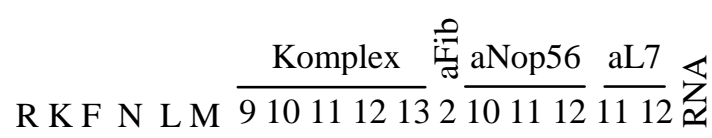

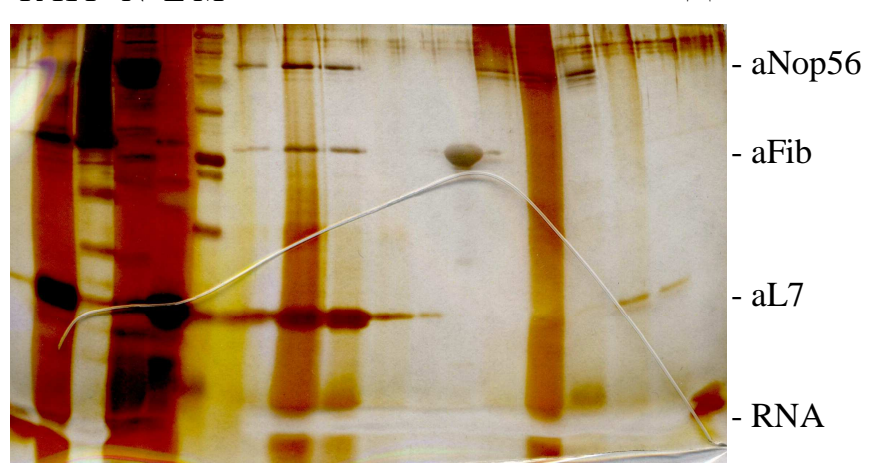

B

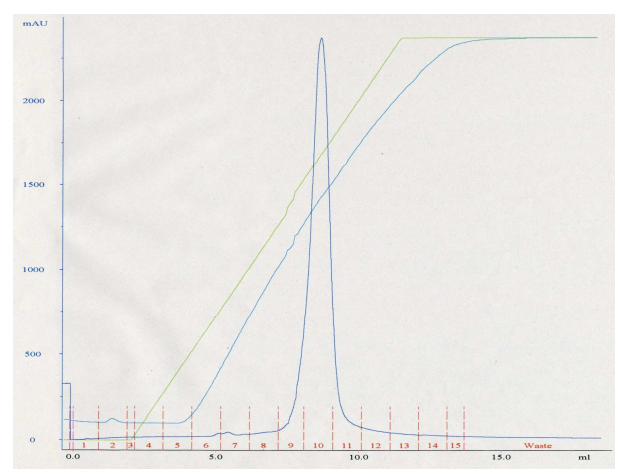

Abbildung 3.8: Anionenaustauscherchromatographie der Fraktion 23 des Gelfiltrationslaufs. Auf einem 17,5\%-igen Gel wurden zur Kontrolle alle Proteine, die RNA und die Gelfiltrations-Fraktion 23 aufgetragen. Daneben korrespondieren die Fraktionen mit den jeweiligen darüber angegebenen Einzel-Läufen der Proteine (A). Im Teil B ist das Elutionsprofil des Komplexes dargestellt

\subsection{KRISTALLISATION DER KOMPLEXE}

Die Kristallisation von Proteinen ist ein von vielen Faktoren abhängiger Prozeß. So nehmen sowohl physikalische (z.B. Temperatur) als auch chemische Bedingungen (z.B. Konzentration von Protein und Fällungsmitteln) direkten Einfluß auf das Kristallwachstum. Die Kristallisationsversuche der verschiedenen Komplexansätze wurden mit den Hampton Research Screens: Crystal Screen I + II, dem PEG/Ion-Screen und dem 
Natrix-Screen gestartet. Die eingesetzte Komplexkonzentration sollte $8 \mathrm{mg} / \mathrm{ml}$ nicht überschreiten, da sonst die Proteine in den meisten Bedingungen direkt ausfielen. Durch diese Versuche konnten erste Erkenntnisse über die Kristallisationsbedingungen erhalten werden. Bei Bedingungen mit PEG 12000 und PEG 20000 und einem im neutralen Bereich liegenden pH-Wert konnten erste kleine Kristalle des möglichen Komplexes aus aL7 + aNop56 + aFib + sR13-28a (Abb. 3.9 A und B) beobachtet werden. Da für alle anderen rekonstituierten Komplexe auf diese Weise keine Kristallisationsbedingungen gefunden werden konnten, wurde versucht, die Bedingungen für die beobachteten Kristalle zu optimieren.

\subsubsection{Optimierung der Kristallisationsbedingungen}

Um eine Stabilisierung der Methyltransferase (aFib) im Komplex zu erreichen, wurde nach der Komplex-Rekonstitution der Ansatz mit S-Adenosylmethionin (Endkonzentration: $2 \mathrm{mM}$ ) versetzt. Eine weitere Stabilisierung des RNA-Komplexes kann durch die Zugabe von $\mathrm{MgCl}_{2}$ erreicht werden. Die Größe und Qualität der Kristalle konnte aber erst durch die Zugabe von ein- und zweiwertigen Alkoholen zur Kristallisationsbedingung verbessert werden.

Die Grundbedingung, die mit verschiedenen Additiven vermischt wurde, bestand aus: 10\% PEG 12000, $10 \mathrm{mM}$ MES, pH 6,5, $20 \mathrm{mM} \mathrm{MgCl}_{2}$. Mit den Additiven 2-Butanol (Abb. 3.9 C; Endkonzentration: 0,7\%) und 1,6-Hexandiol (Abb. 3.9 D; Endkonzentration: $3 \%$ ) wurden die qualitativ besten Kristalle erhalten. Sie waren wie ein Meißel geformt und hatten eine Größe von ca. $550 \mu \mathrm{m} \times 100 \mu \mathrm{m}$. 
A
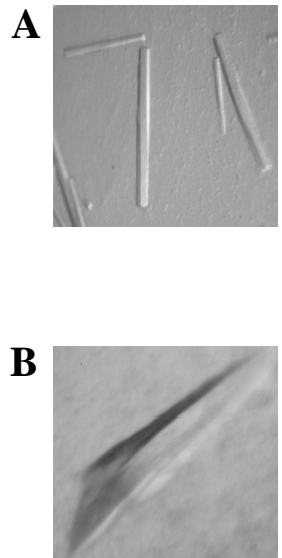

C

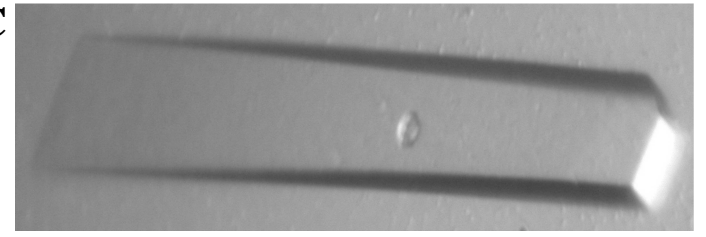

D

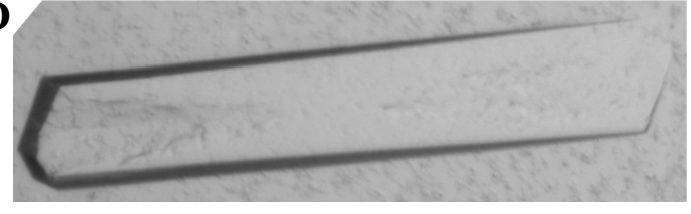

Abbildung 3.9: Kristalle der sRNP-Komplex (aL7 + aNop56 + aFib + sR13-28a) Ansätze. Erste Kristalle in 12 \% PEG 12000 und 0,1 M HEPES, pH 7,4 (A) bzw. PEG 20000 und 0,1 M. MES, pH 6,5 (B). Verbesserte Kristalle in $10 \%$ PEG 12000, $10 \mathrm{mM}$ MES, pH 6,5, $20 \mathrm{mM} \mathrm{MgCl}_{2}$ und 0,7\% 2-Butanol (C) bzw. 3\% 1,6-Hexandiol (D).

Die Reproduzierbarkeit von Kristallen, im besonderen von Komplex-Kristallen, ist generell schwierig. Die Ursache hierfür liegt meistens in der Präparation von Proteinen und Nukleinsäuren; selbst kleinste Abweichungen bei der Reinigung können dazu führen, daß keine Kristalle mehr gebildet werden.

\subsubsection{Röntgenbeugungsexperimente}

Ebenso schwierig wie das Auffinden einer Kristallisationsbedingung gestaltet sich oft auch die Suche nach einer geeigneten Bedingung, den Kristall vor der schädigenden Röntgenstrahlung zu schützen.

Erste Versuche, Kristalle mit verschiedenen herkömmlichen Kryo-Protektantien einzufrieren, scheiterten, da die Kristalle beim Überführen in das Kryo-Protektant sehr leicht zerbrachen. Eine hohe Fragilität bei Kristallen deutet auf einen hohen Wassergehalt hin, daher mußte den Kristallen zunächst kontrolliert ein Teil ihres Wassers entzogen werden. Um diesen Effekt zu erreichen, wurde der Kristallisationspuffer gegen einen MPD-enthaltenden Kristallisationspuffer ausgetauscht. Die MPD-Konzentration wurde dabei schrittweise über mehrere Stunden von 0 auf $20 \%$ erhöht. Die so 
konservierten Kristalle zeigten im Röntgenstrahl trotz allem nur eine sehr schlechte Diffraktion $(\sim 14 \AA)$.

Ein weiterer Versuch, die Röntgenstrahlen besser an dem Kristallgitter zu beugen, war die Kapillarmethode. Der in seiner Mutterlösung in der Kapillare eingeschlossene Kristall konnte aber ebenfalls nicht zur Aufklärung der Struktur beitragen.

\subsubsection{Analyse der Komplex-Kristalle}

Um nachzuweisen, daß es sich bei den Kristallen um Komplexe mit alle drei Proteinen und der RNA (sR13-28a) handelte, wurden die Kristalle mit Reservoirlösung gewaschen und in SDS-Probenpuffer gelöst. Die gelösten Kristalle wurden durch denaturierende SDS-PAGE aufgetrennt und im Anschluß mit Silber gefärbt, um sowohl die Proteine als auch die RNA zu visualisieren. Zur Kontrolle ob alle Proteine und die RNA noch intakt in der Mutterlösung vorhanden sind, wurde diese ebenfalls mit auf das Gel aufgetragen.

Die Analyse des Gels (Abb. 3.10) zeigt eindeutig, daß die RNA und die Proteine aL7 und aFib in der Kristallisationslösung noch in ihrer ursprünglichen Größe vorhanden sind. Dagegen liegt aNop56 nur noch degradiert vor. Die aufgelösten Kristalle zeigten einen Komplex aus aFib und eines 36 kDa großen Fragments. Das es sich bei diesem Fragment um das um 12 kDa verkürzte aNop56 handelte, ließ sich sowohl durch einen Glu-C Verdau (Serin-Endoproteinase aus Staphylococcus aureus V8) als auch bei 4-6 Wochen aufbewahrtem aNop56 im SDS-Gel nachweisen. 


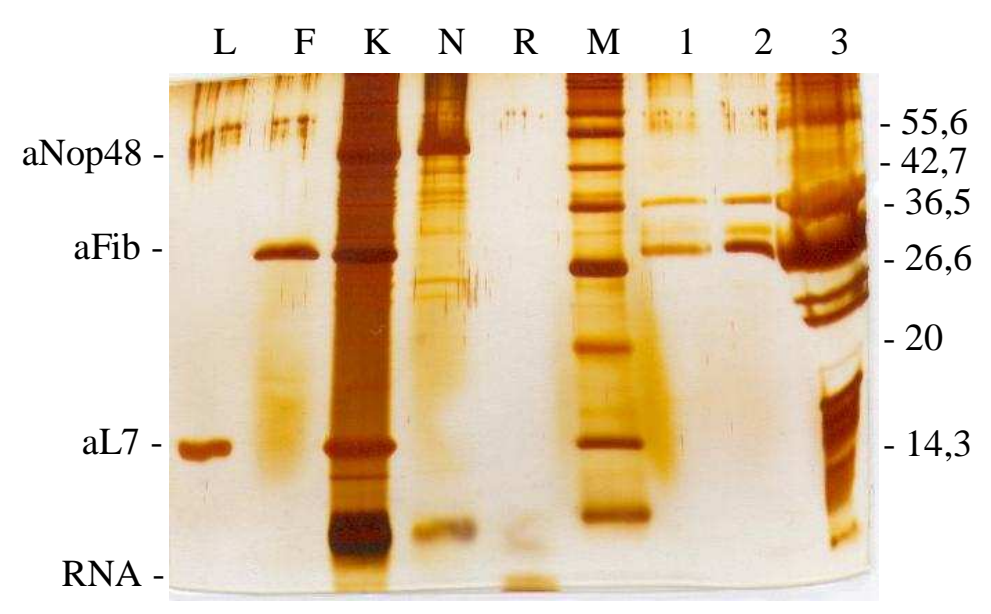

Abbildung 3.10: Kristallanalyse mit Hilfe der SDS-PAGE (17,5\%-iges Gel) und der Silberfärbung. Zum Vergleich wurden alle Proteine (Spuren L, F und N), die RNA (sR13-28a; Spur R) und der Komplex (Spur K) nach der Gelfiltration mit aufgetragen. Die aufgelösten Kristalle wurden in den Spuren 1 und 2 und die Kristallisationslösung in Spur 3 aufgetragen

\subsection{CO-KRISTALLISATION UND SOAKING VON AMYB-KRISTALLEN}

Aufgrund ihrer starken inhibitorischen Wirkung auf AmyB sollten das Pseudotetrasaccharid Acarbose, das als Inhibitor vieler Glykosylhydrolasen bekannt ist, und ATP, einem Produkt der Glykolyse(FüTTERER, 2001), als Komplex mit AmyB kristallisiert werden. Unter den bereits bekannten Kristallisationsbedingungen (3,78 M Natriumformiat, 5\% Isopropanol, 2 mM DTT) wurde versucht das AmyB mit Acarbose und ATP sowohl direkt zu kristallisieren (Co-Kristallisation) als auch zunächst native AmyB-Kristalle herzustellen und dann mit verschieden Konzentrationen von Acarbose oder ATP zu versetzen (Soaking). Der überwiegende Teil dieser Versuche wurde mit inaktivem AmyB durchgeführt, für einen geringen Teil der Versuche stand jedoch isoliertes AmyB zur Verfügung, das nachweislich aktiv war. Bei der Strukturaufklärung der nativen Kristalle zeigte sich allerdings, daß kein Unterschied bei Zellkonstanten oder der Faltung nachgewiesen werden konnte (Dr. A. Dickmanns, unveröffentlichte Ergebnisse).

Auffällig bei mit ATP oder Acarbose co-kristallisierten und gesoakten Kristallen war die schlechte Beugung des Röntgenstrahls. Nur etwa jeder zwanzigste Kristall 
lieferte Streudaten, die konservativ bis $3 \AA$ auswertbar gewesen wären, während native Kristalle mit verwertbaren Daten von $2.6 \AA$ keine Seltenheit waren. Das gleiche Phänomen ließ sich auch, sofern Kristalle entstanden waren, bei den anderen CoKristallisations- und Soaking-Versuchen $\left(\mathrm{Fe}^{3+}, \mathrm{Mn}^{2+}, \mathrm{Zn}^{2+}\right.$, Glukose und Maltose) beobachten, wobei die Kristallisation von AmyB durch $\mathrm{Mn}^{2+}$ und $\mathrm{Zn}^{2+}$ vollkommen verhindert wurde.

Als Gemeinsamkeit aller gemessener Datensätze konnte bei der Auswertung festgestellt werden, daß keiner der getesteten Co-Faktoren in die AmyB-Kristalle eingelagert wurde. Mit der Differenzelektronendichte $F_{0}-F_{c}$ können anhand negativer und positiver Elektronendichten Fehler beim Strukturbau im AmyB-Modell aufgefunden werden. Wird ein Ligand an ein Protein gebunden, ist sowohl in der Differenzelektronendichte $F_{0}-F_{c}$ als auch in der Differenzelektronendichte $2 F_{0}-F_{c}$ eine positive Dichte zu erkennen. Da in keinem der ausgewerteten Datensätze eine zusätzliche positive Dichte zu erkennen war, kann die Aussage getroffen werden, daß keine Co-Faktoren an AmyB gebunden kristallisiert wurden. 


\begin{tabular}{|c|c|c|c|c|c|c|c|c|c|c|c|c|c|c|c|}
\hline 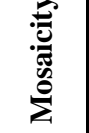 & $\begin{array}{l}n \\
0 \\
i\end{array}$ & $\begin{array}{l}0 \\
\text { a } \\
\vdots \\
0\end{array}$ & $\begin{array}{l}\text { oे } \\
\text { ñ }\end{array}$ & $\begin{array}{l}\text { to } \\
\text { ?n. } \\
0\end{array}$ & 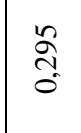 & $\stackrel{f}{0}$ & $\begin{array}{l}n \\
\tilde{n} \\
\vdots \\
0\end{array}$ & 市 & $\stackrel{\tilde{n}}{\stackrel{5}{0}}$ & $\stackrel{n}{m}$ & $\begin{array}{l}\widetilde{0} \\
\stackrel{0}{0} \\
0\end{array}$ & $\begin{array}{l}\text { aे } \\
\text { cे } \\
0\end{array}$ & $\stackrel{2}{m}$ & \begin{tabular}{l}
\multirow{2}{*}{} \\
$\stackrel{3}{0}$
\end{tabular} & 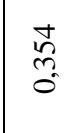 \\
\hline 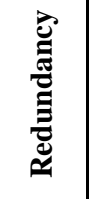 & $\begin{array}{l}\hat{\approx} \\
\hat{心} \\
\hat{\sigma} \\
\text { ले }\end{array}$ & $\begin{array}{l}0 \\
8 \\
i n \\
\infty \\
\cdots \\
i n\end{array}$ & 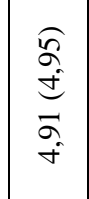 & $\begin{array}{l}\hat{\vec{m}} \\
\hat{\sigma}^{2} \\
\infty \\
\circ \\
\dot{\sigma}\end{array}$ & $\begin{array}{l}\widehat{\sigma} \\
\infty \\
\dot{+} \\
\infty \\
\infty \\
\dot{+}\end{array}$ & $\begin{array}{l}\widehat{J} \\
\stackrel{5}{0} \\
\Delta \\
\sigma \\
0\end{array}$ & 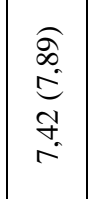 & $\begin{array}{l}\widehat{0} \\
0 \\
0 \\
0 \\
0 \\
0 \\
0\end{array}$ & $\begin{array}{l}\hat{\infty} \\
\hat{e} \\
\hat{b}\end{array}$ & $\begin{array}{l}\widehat{o} \\
+ \\
b \\
m \\
m_{0}\end{array}$ & $\begin{array}{l}\stackrel{\vartheta}{+} \\
\underset{+}{+} \\
= \\
=\end{array}$ & 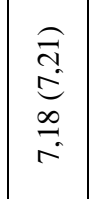 & $\begin{array}{l}\hat{\sigma} \\
\text { di } \\
\hat{i}\end{array}$ & $\begin{array}{l}6 \\
0 \\
d \\
0 \\
\text { in }\end{array}$ & $\begin{array}{l}= \\
\vec{n} \\
m \\
m\end{array}$ \\
\hline$\stackrel{0}{=}$ & $\begin{array}{ll}2 & \widehat{b} \\
\infty & d\end{array}$ & $\begin{array}{ll}\hat{n} & \tilde{\delta} \\
0 & = \\
0 & =\end{array}$ & $\begin{array}{ll}m & \widehat{\sigma} \\
0 & \\
0 & i\end{array}$ & $\begin{array}{l}\infty \\
\infty \\
\vec{N} \\
\overrightarrow{0}\end{array}$ & 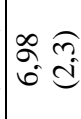 & $\begin{array}{ll}\infty & 0 \\
0 & 0 \\
\hat{\sim} & 0\end{array}$ & $\begin{array}{ll}\hat{n} & = \\
\tilde{C} & =\end{array}$ & 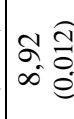 & $\begin{cases}n & 0 \\
n & n \\
\infty & 0\end{cases}$ & 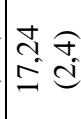 & 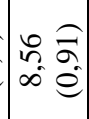 & 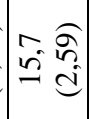 & 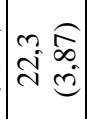 & 교 & 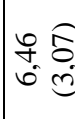 \\
\hline 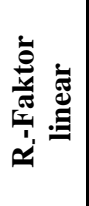 & \begin{tabular}{l}
$\hat{\infty}$ \\
\multirow{y}{y}{} \\
$\stackrel{0}{0}$ \\
0 \\
$\stackrel{0}{0}$ \\
$\stackrel{0}{0}$
\end{tabular} & $\begin{array}{l}1 \\
\text { Oे } \\
0\end{array}$ & $\begin{array}{l}\hat{\infty} \\
\stackrel{n}{\hat{n}} \\
\hat{e} \\
\stackrel{5}{E} \\
0\end{array}$ & $\begin{array}{l}\hat{f} \\
\text { m. } \\
\stackrel{0}{0} \\
\hat{5} \\
\hat{0} \\
0\end{array}$ & $\begin{array}{l}\widehat{\widehat{d}} \\
\stackrel{0}{0} \\
\hat{0} \\
\stackrel{0}{0}\end{array}$ & $\begin{array}{l}+ \\
\stackrel{0}{0} \\
0 \\
0\end{array}$ & $\begin{array}{l}\infty \\
\stackrel{0}{0} \\
0\end{array}$ & $\begin{array}{l}\widehat{a} \\
\hat{n} \\
\hat{e} \\
\sigma \\
\delta \\
0 \\
0\end{array}$ & $\begin{array}{l}\hat{m} \\
\overrightarrow{+} \\
e \\
0 \\
0 \\
0 \\
0\end{array}$ & $\begin{array}{l}\widehat{\Theta} \\
\infty \\
0 \\
0 \\
0 \\
0 \\
0\end{array}$ & 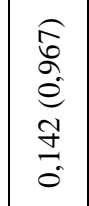 & $\begin{array}{l}\frac{\pi}{2} \\
0 \\
0 \\
0 \\
\Xi \\
0 \\
0\end{array}$ & 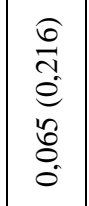 & 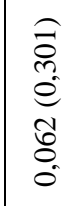 & 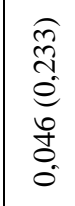 \\
\hline 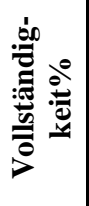 & 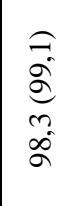 & 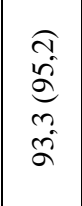 & 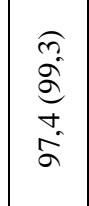 & $\begin{array}{l}\hat{a} \\
\hat{\sigma} \\
a \\
\text { ḋ }\end{array}$ & 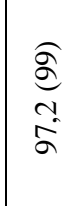 & $\begin{array}{l}\stackrel{\sigma}{\varrho} \\
\stackrel{\sigma}{\sigma} \\
\infty\end{array}$ & $\begin{array}{l}\widehat{a} \\
\hat{2} \\
\hat{2}\end{array}$ & $\begin{array}{l}\underset{\Xi}{\varrho} \\
\text { à }\end{array}$ & $\begin{array}{l}\hat{\infty} \\
\stackrel{2}{2} \\
\text { as }\end{array}$ & 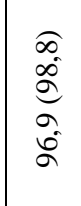 & 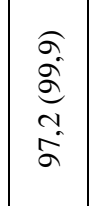 & $\begin{array}{l}\underset{\delta}{\delta} \\
\stackrel{\infty}{\sigma} \\
\delta\end{array}$ & 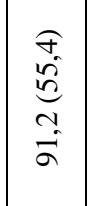 & $\begin{array}{l}\widehat{f} \\
\hat{\sigma} \\
\hat{\sigma} \\
\text { a }\end{array}$ & $\begin{array}{l}\hat{\sigma} \\
\hat{d} \\
\text { d. } \\
\text { id } \\
\infty\end{array}$ \\
\hline 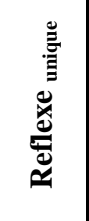 & 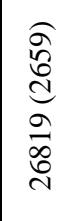 & 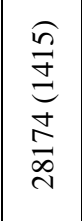 & $\begin{array}{l}\widehat{\widehat{\delta}} \\
\stackrel{\overbrace{}}{\Xi} \\
\stackrel{\infty}{\infty} \\
\stackrel{\infty}{=}\end{array}$ & 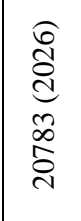 & $\begin{array}{l}\infty \\
\infty \\
\infty \\
\infty \\
\infty \\
\stackrel{\infty}{=}\end{array}$ & 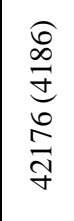 & 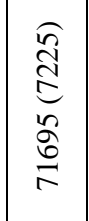 & 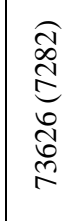 & 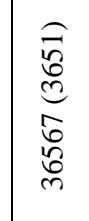 & 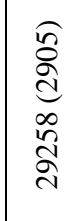 & 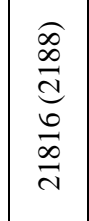 & $\begin{array}{l}\widehat{\curvearrowright} \\
\stackrel{d}{d} \\
\widetilde{d} \\
\stackrel{d}{d}\end{array}$ & 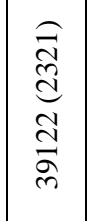 & 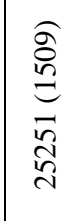 & 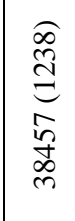 \\
\hline 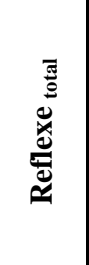 & 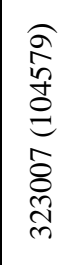 & 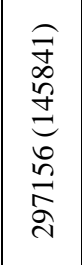 & 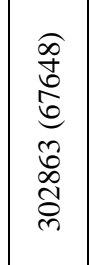 & 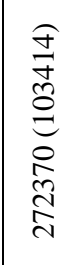 & 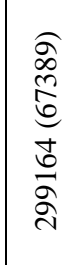 & 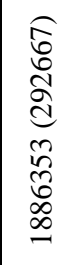 & 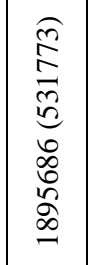 & 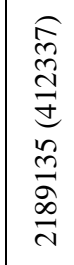 & 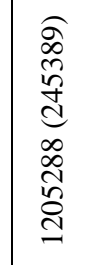 & \begin{tabular}{l}
$\widetilde{N}$ \\
$\infty$ \\
\multirow{1}{*}{} \\
$\infty$ \\
$\stackrel{\infty}{\leftrightarrows}$ \\
$\infty$ \\
$\infty$ \\
$\infty$ \\
$\stackrel{+}{n}$ \\
$\stackrel{+}{n}$
\end{tabular} & 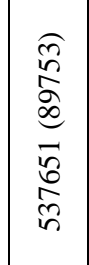 & 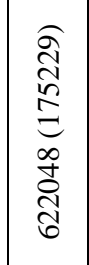 & 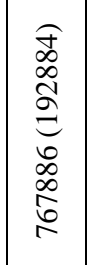 & 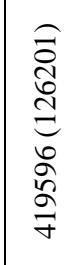 & 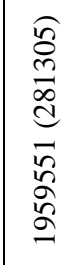 \\
\hline 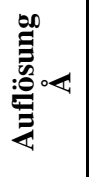 & 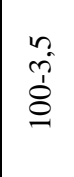 & $\begin{array}{l}\hat{i} \\
\text { s. } \\
\text { in }\end{array}$ & $\begin{array}{l}n \\
\text { nे } \\
\text { nे }\end{array}$ & $\begin{array}{l}0 \\
\tilde{j} \\
\dot{j}\end{array}$ & $\begin{array}{l}n \\
\tilde{1} \\
\text { nे }\end{array}$ & 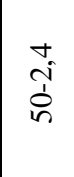 & $\begin{array}{l}0 \\
i \\
i \\
i\end{array}$ & $\begin{array}{l}0 \\
i \\
i \\
\text { in }\end{array}$ & 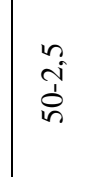 & $\begin{array}{l}\hat{i} \\
\hat{n} \\
\hat{n}\end{array}$ & $\begin{array}{l}0 \\
\hat{j} \\
\text { हn }\end{array}$ & $\begin{array}{l}\hat{i} \\
\hat{i} \\
\text { in }\end{array}$ & $\begin{array}{l}\stackrel{+}{i} \\
\stackrel{s}{n} \\
\stackrel{n}{n}\end{array}$ & $\begin{array}{l}\bar{\infty} \\
\hat{i} \\
\hat{n} \\
\text { nd }\end{array}$ & $\begin{array}{l}m \\
\text { r. } \\
\text { ș }\end{array}$ \\
\hline 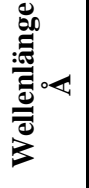 & $\stackrel{\infty}{\underset{*}{*}}$ & \begin{tabular}{l}
$q$ \\
\multirow{0}{*}{} \\
$\infty$ \\
0 \\
0
\end{tabular} & $\begin{array}{l}9 \\
0 \\
\infty \\
0 \\
0\end{array}$ & $\begin{array}{l}\text { Oे } \\
0 \\
\infty \\
0\end{array}$ & $\begin{array}{l}\text { q } \\
\stackrel{\infty}{\circ}\end{array}$ & $\begin{array}{l}\stackrel{q}{0} \\
\text { o. } \\
0\end{array}$ & 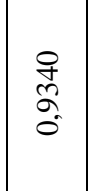 & 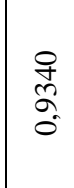 & \begin{tabular}{l}
9 \\
\multirow{\sigma}{*}{} \\
$o$ \\
0
\end{tabular} & & $\stackrel{\infty}{\underset{\forall}{\hbar}}$ & $\stackrel{\infty}{\underset{+}{n}}$ & $\frac{n}{\partial}$ & $\frac{n}{a}$ & $\begin{array}{l}\infty \\
\infty \\
\vdots \\
0 \\
0\end{array}$ \\
\hline$\frac{\vec{*}}{\stackrel{0}{0}}$ & 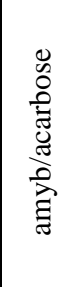 & 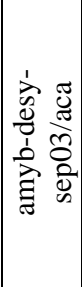 & 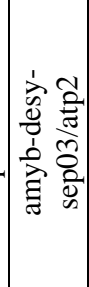 & 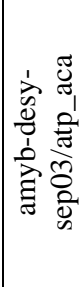 & 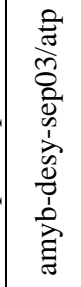 & 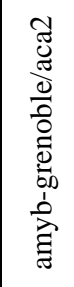 & 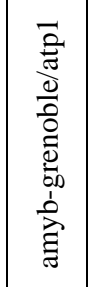 & 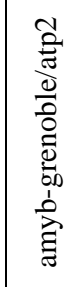 & 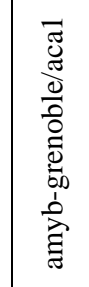 & 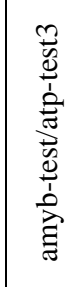 & 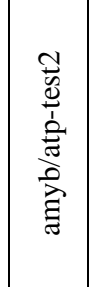 & 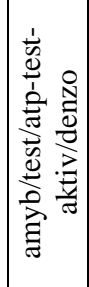 & 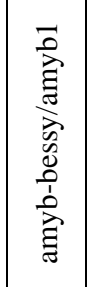 & 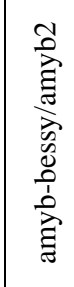 & 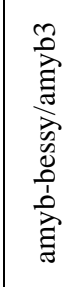 \\
\hline
\end{tabular}




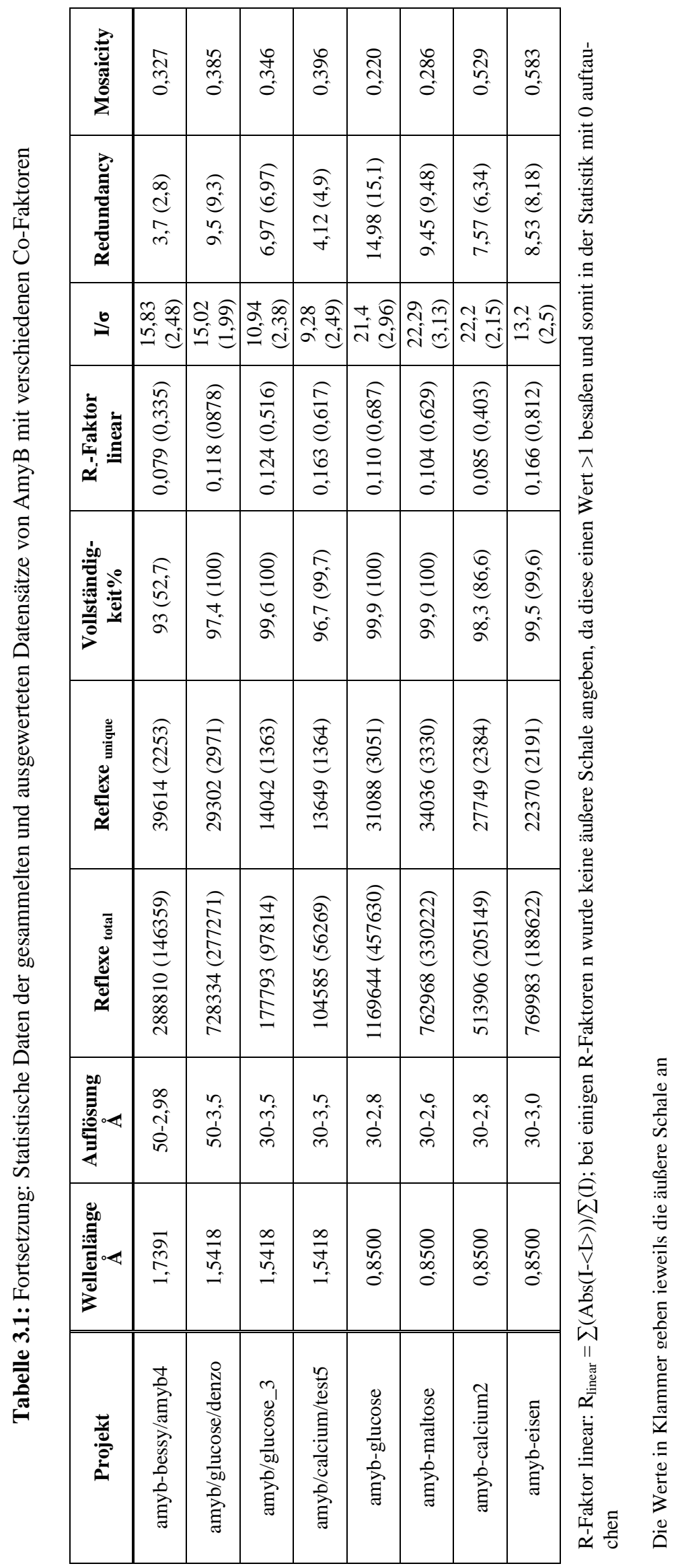




\subsection{ERMITTLUNG VERWANDTER STRUKTUREN MIT HILFE DER DALI-SUCHE}

Die bei der Strukturlösung von AmyB erhaltenen Atomkoordinaten wurden mit Hilfe des DALI-Servers (HoLM \& SANDER, 1993; www.ebi.ac.uk/dali/) mit allen bekannten Proteinstrukturen verglichen.

Tabelle 3.2: Die ersten 11 Treffer mit einem Z-Faktor $>5$ der DALI-Suche

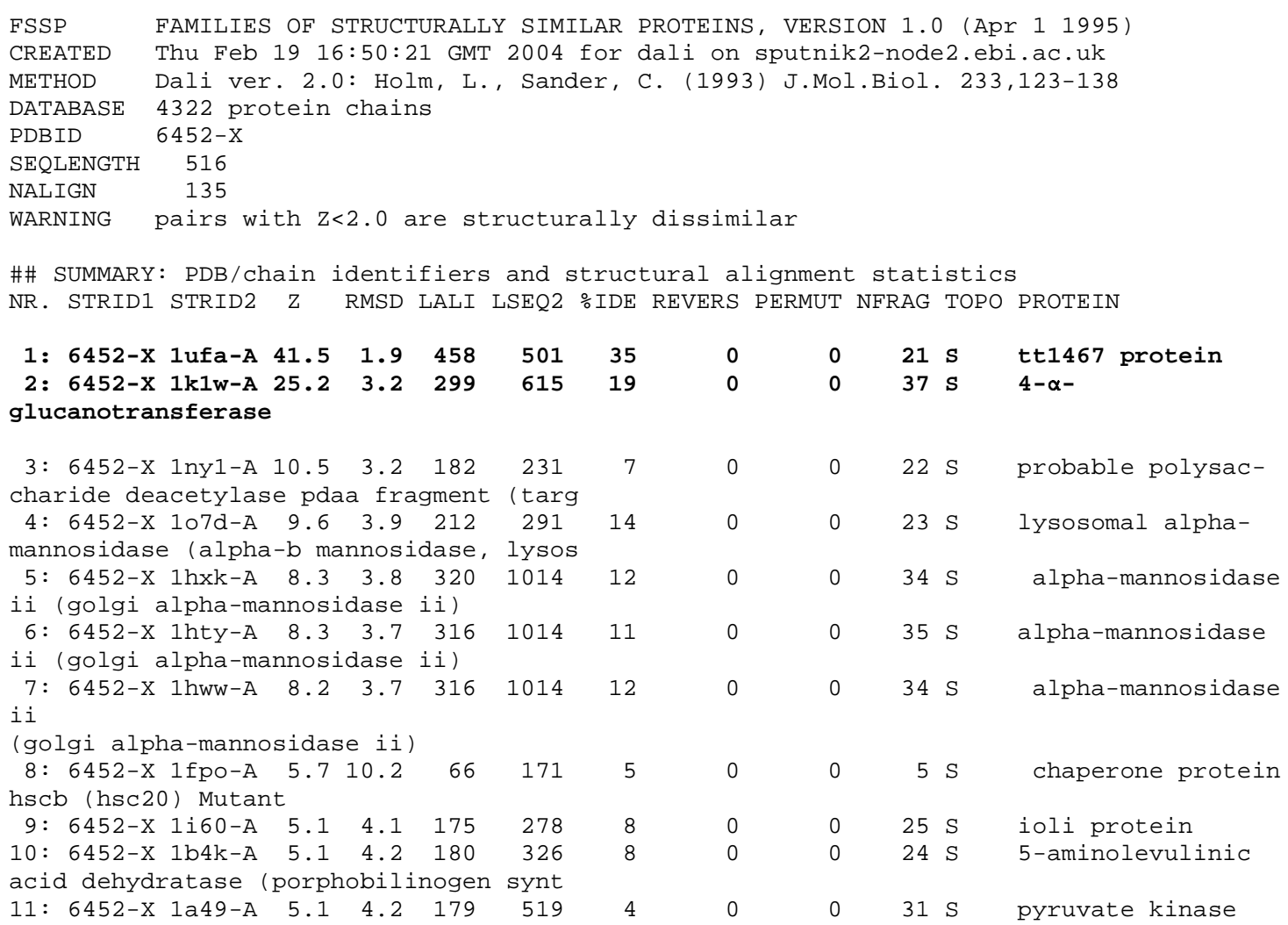
biological_unit

The following notation is used for data columns:

STRID1/STRID2 PDB identifiers of search structure and aligned structure with

RMSD

LALI

LSEQ2

$\because I D E$

REVERS

PERMUT

NFRAG

TOPO

PROTEIN COMPND chain identifier

Z-score, i.e., strength of structural similarity in standard deviations above expexted. The matched structures are sorted by $\mathrm{Z}$-score. Only matches above a threshold of $\mathrm{Z}=2$ are reported. positional root mean square deviation of superimposed CA atoms in Angstroms

total number of equivalenced residues

length of the entire chain of the equivalenced structure percentage of sequence identity over equivalenced positions number of fragments matching in reversed chain direction number of topological permutations (loop reconnections between query and matched structure)

total number of equivalenced fragments

'S' sequential connectivity of equivalenced fragments

' $N$ ' non-sequential alignment

record from the $\mathrm{PDB}$ file of the aligned structure

SeqNo, PDBNo, AA, STRUCTURE, BP1, BP2, ACC

sequential and $\mathrm{PDB}$ residue numbers, amino acid (lower case =

Cys), secondary structure, solvent exposure as in DSSP 
Das erhaltene Ergebnis (Tab. 3.2) weist dabei z.B. Informationen über den Verwandtschaftsgrad (Z-Faktor) der gefundenen Strukturen zu AmyB und die Bereiche, in denen Elemente der jeweiligen Strukturen mit AmyB übereinstimmen, auf. Die größten Übereinstimmungen zeigten sich bei 1UFA, einem uncharakterisierten neuen Enzym aus Thermus thermophilus Hb8 (IDAKA ET AL., 2003) mit einem Z-Faktor von 37,2 (Tab. 3.2). Ein Vergleich zeigt bis auf kleinere Abweichungen zwei fast identische Strukturen (Abb. 3.11).

A
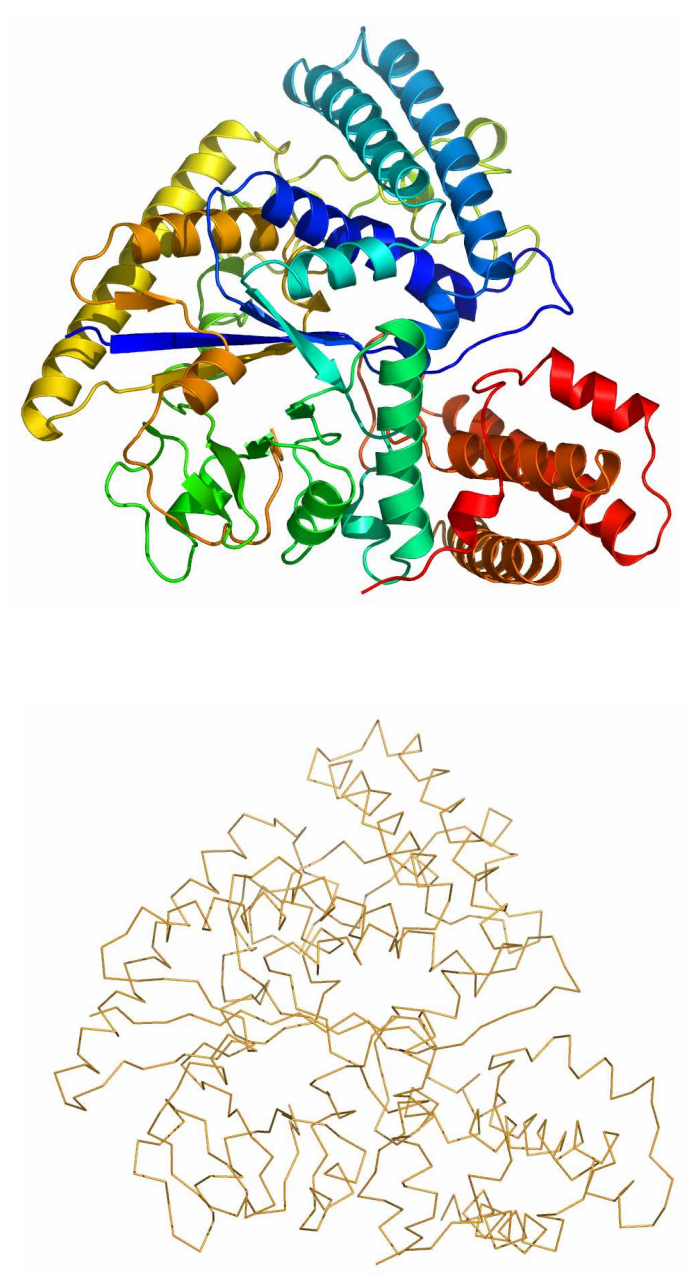

AmyB
B
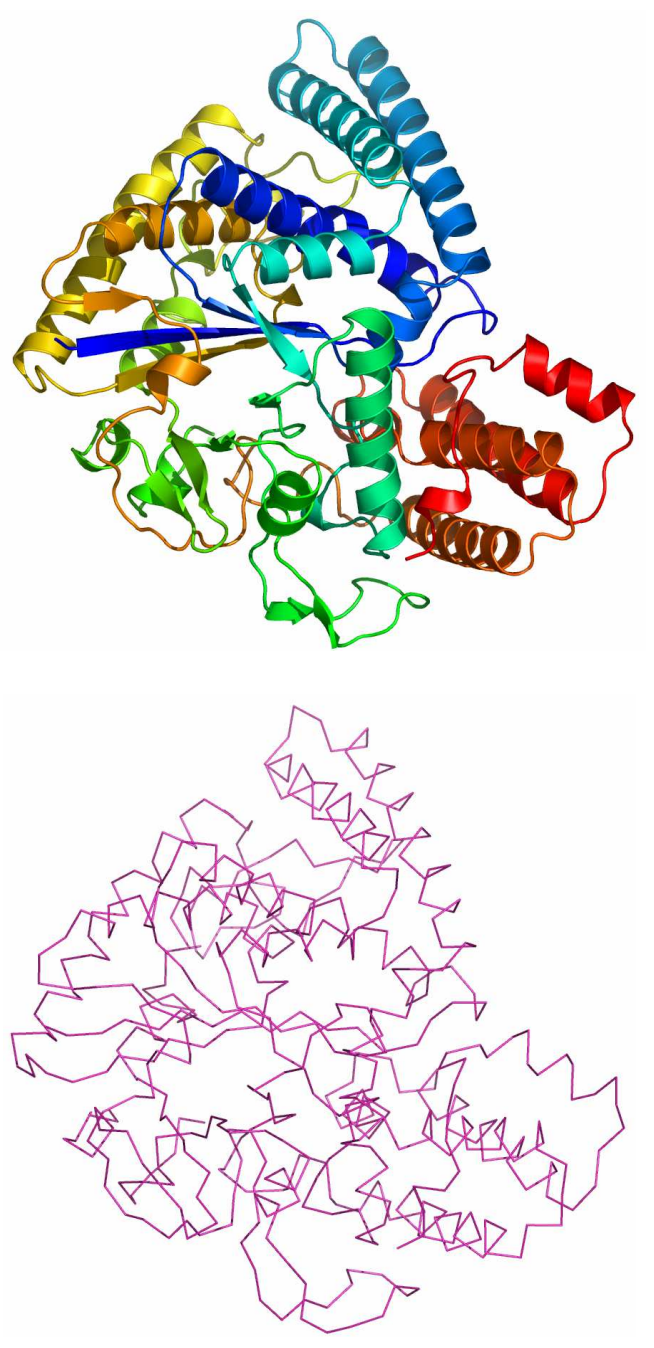

1UFA

Abbildung 3.11: Struktur und $\mathrm{C}_{\alpha}$-Skelett der untersuchten $\alpha$-Amylase AmyB (A) aus Thermotoga maritima MSB8 im Vergleich mit der Struktur und $\mathrm{C}_{\alpha}$-Skelett von 1UFA (B) aus Thermus thermophilus $\mathrm{Hb} 8$ 
Da bisher nur die Struktur aber keine Funktion von 1UFA bekannt ist, war der Treffer mit dem zweithöchsten Z-Faktor jedoch interessanter. Es handelte sich dabei um die 4- $\alpha$-Glukanotransferase aus Thermococcus litoralis, einem näher beschriebenen Enzym, das der GHF 57 zugeordnet wird (IMAMURA ET AL., 2003). Aufgrund seiner biochemischen Eigenschaften wurde auch das untersuchte AmyB aus Thermotoga maritima MSB8 in diese Familie eingeordnet (FÜTTERER, 2001).

\subsubsection{Vergleich von AmyB mit der 4- $\alpha$-Glukanotransferase}

Die beiden in die GHF 57 eingeordneten Proteine AmyB und 4- $\alpha$-Glukanotransferase (1K1Y/1K1W: PDB-Kürzel mit beziehungsweise ohne Acarbose) weisen in großen Bereichen hohe strukturelle Gemeinsamkeiten auf. Besonders auffällig sind die Übereinstimmungen im katalytischen Zentrum. Dieses besteht in beiden Fällen aus einem verzerrten und um ein $\beta$-Faltblatt und eine $\alpha$-Helix verkürztes $(\beta, \alpha)_{8}$-Faß. Das verkürzte $(\beta, \alpha)_{7}-\mathrm{Fa} \beta$ ist ein in der GHF $57 \mathrm{zu}$ findendes Strukturelement (www.cnrs-mrs.fr/ cazy/CAZY/index.html), das für diese Familie charakteristisch ist. Neben der katalytischen Domäne (Domäne A) besitzt die 4- $\alpha$-Glukanotransferase noch eine $\beta$-Faltblatt-reiche Domäne (Domäne $\mathrm{B}$ ), an die $\mathrm{Ca}^{2+}$ gebunden wird. 


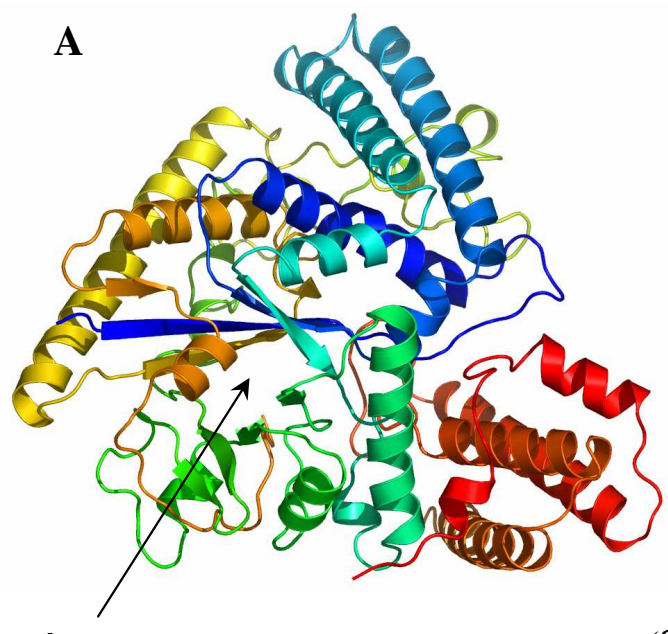

$(\beta, \alpha)_{7}-\mathrm{Faß}$
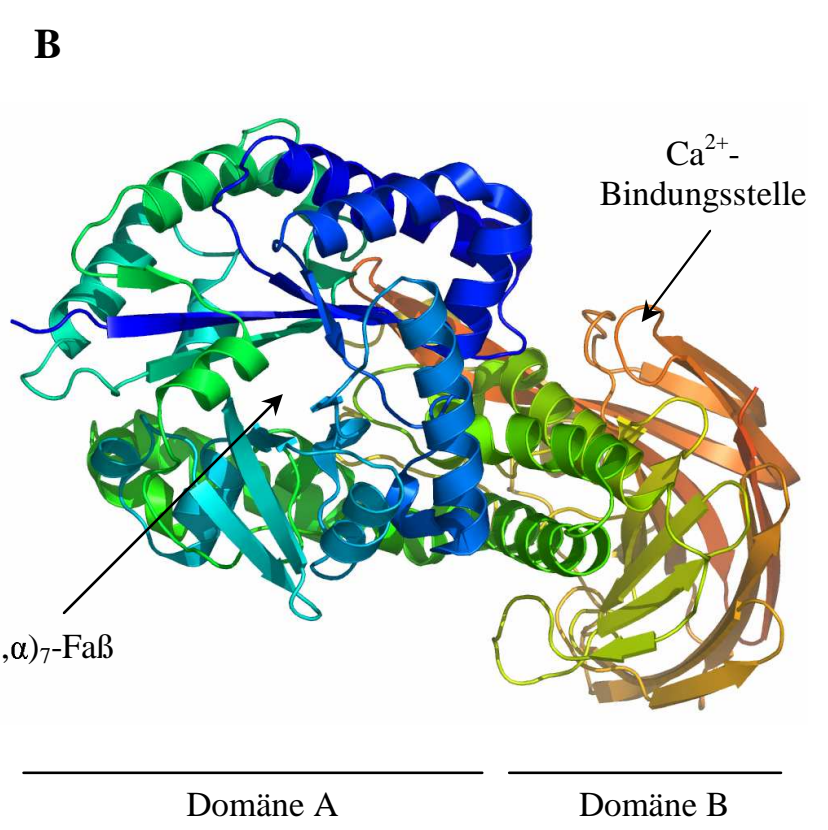

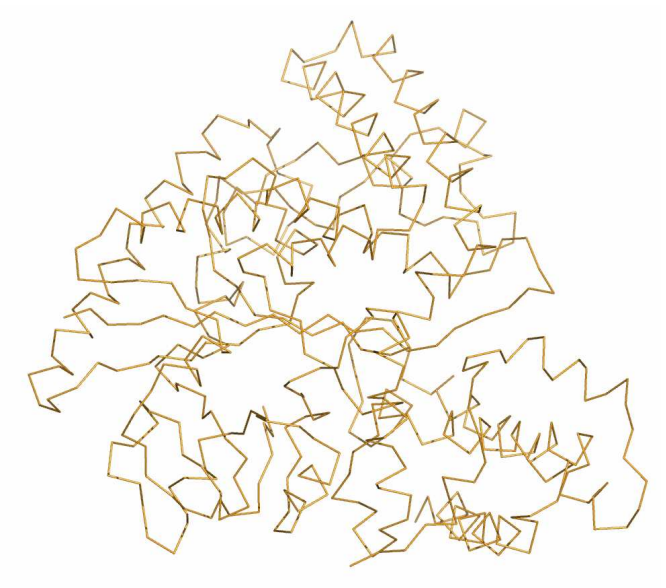

AmyB

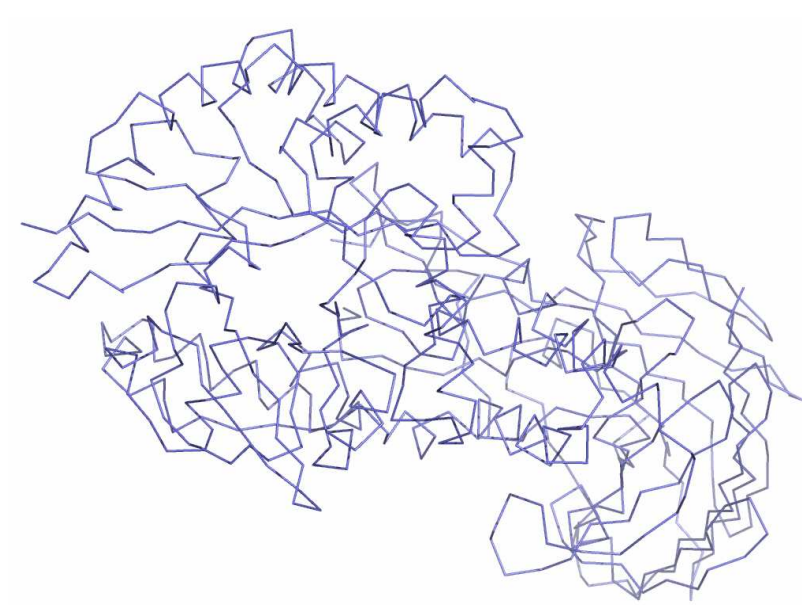

1K1W (ohne Acarbose)

Abbildung 3.12: Vergleich der Strukturen AmyB (A) und 1K1W (4- $\alpha$-Glukanotransferase) aus Thermococcus litoralis. Die Struktur 1K1W (B) weist neben der katalytischen Domäne A auch noch eine weitere Domäne B auf, die eine Kalziumbindungsstelle enthält. Beide Strukturen enthalten ein verzerrtes $(\beta, \alpha)_{7}-\mathrm{Fa} \beta$ 
Ein Vergleich der Oberflächen-Potentiale zeigt, daß beide Proteine an der katalytischen Bindungsstelle stark negativ geladen sind. Die negativen Ladungen deuten auf optimale Voraussetzungen für eine Bindungsstelle hin.

A

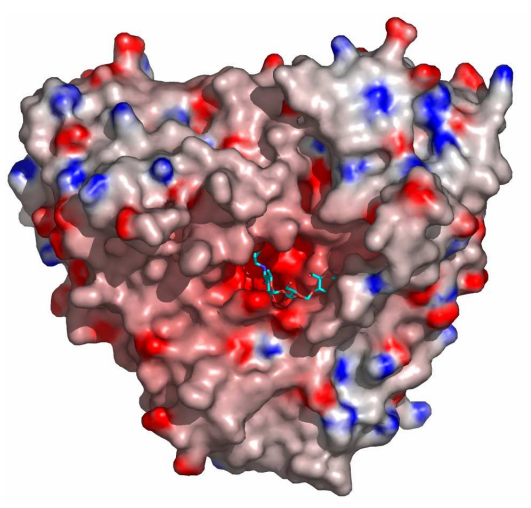

AmyB
B

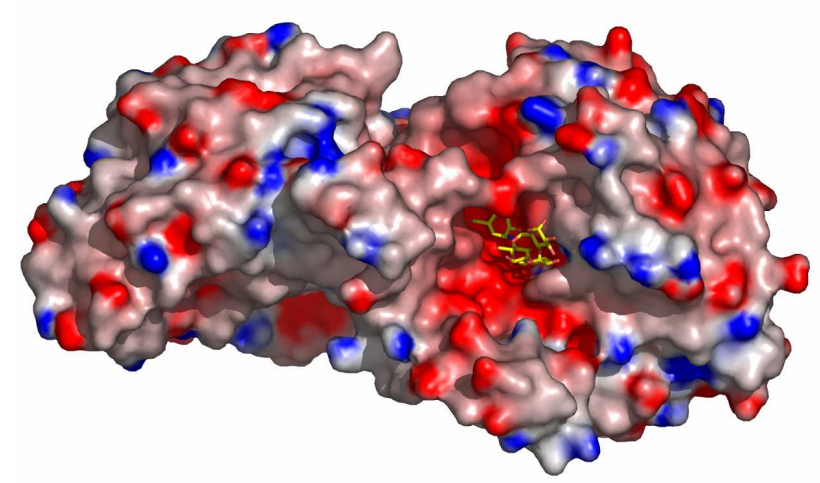

1K1Y

Abbildung 3.13: Oberflächen-Potentiale von AmyB mit theoretisch gebundener Acarbose (A: Acarbose in türkis) und 1K1Y mit gebundener Acarbose (B: Acarbose in gelb) in der Bindungstasche

Daß die Acarbose sich perfekt an die Bindungstasche von 1K1Y anpaßt und die beiden katalytisch notwendigen Aminosäurereste Asp214 und Glu123 durch das Stickstoffatom der Acarbose blockiert werden, konnte von IMAMURA ET AL. (2003) kristallographisch gezeigt werden.

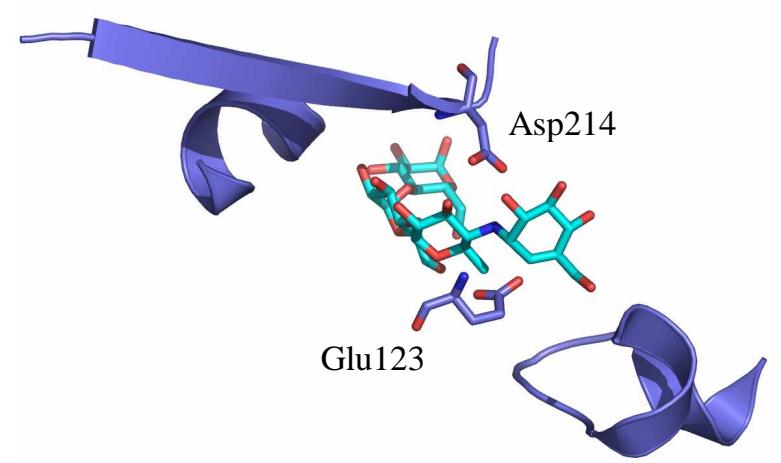

Abbildung 3.14:

Blockierung der Bindungsstelle

Glu123/Asp214 durch Acarbose in 1K1Y 
Eine Bindung von Acarbose an die Bindungsstelle von AmyB konnte kristallographisch nicht beobachtet werden. Bei näherer Betrachtung der AmyB-Bindungstasche und einem Vergleich mit 1K1Y erkennt man die beiden, bei $\alpha$-Amylasen konservierten Aminosäurereste Aspartat (AmyB: Asp349) und Glutamat (AmyB: Glu185). Daneben ist erkennbar, daß drei weitere Aminosäurereste (Glu243, Ser247 und Thr469) in die Bindungstasche hereinragen, die Platz für die Bindung eines Acarbosemoleküls blockieren.

A

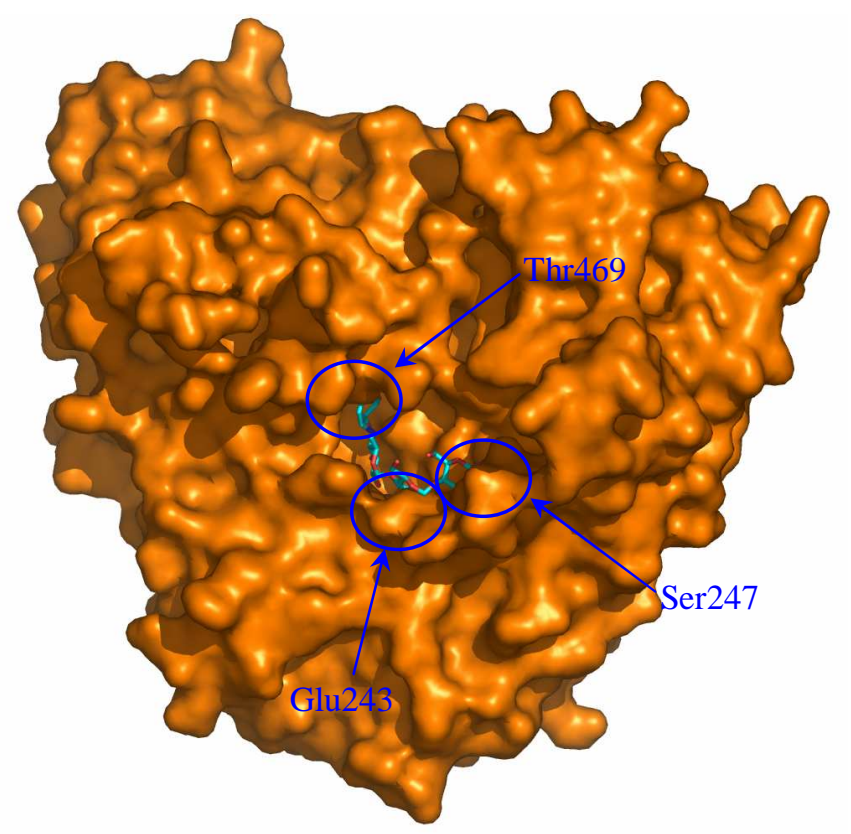

B

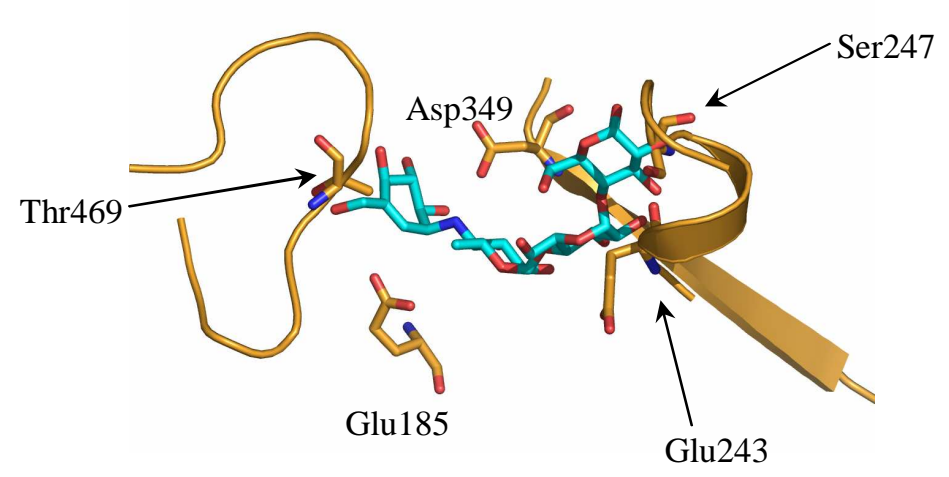

Abbildung 3.15: Bindungstasche von AmyB mit theoretisch eingefügter Acarbose. Die Aminosäurereste Glu243, Ser247 und Thr469 ragen in den Bereich der Acarbose hinein. Im Oberflächenmodell ist deutlich zu erkennen, daß die Bindungstasche für Acarbose keinen Platz zur Anlagerung an AmyB bietet (A). Detaildarstellung der beteiligten Aminosäureresten (B) 

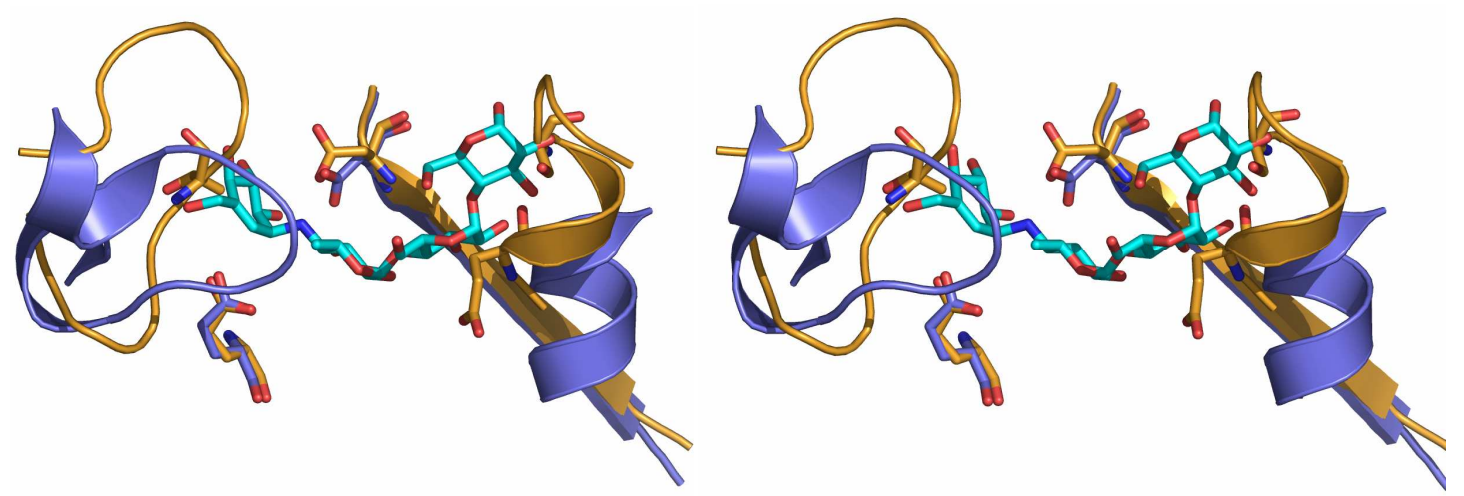

Abbildung 3.16: Stereoansicht der Bindungstaschen von AmyB (orange) und 1K1Y (blau) im Vergleich. Es ist deutlich zu erkennen, daß die Acarbose in $1 \mathrm{~K} 1 \mathrm{Y}$ den entsprechenden Platz zum Binden finden kann, während bei Amy B Aminosäurereste in die Bindungsstelle hineinragen und damit eine Bindung verhindern

\subsubsection{Vergleich von AmyB mit 1UFA aus Thermus thermophilus Hb8}

Wie bereits in Abbildung 3.11 zu erkennen ist, sind sich die beiden Strukturen von AmyB und 1UFA sehr ähnlich. Bei einer näheren Betrachtung der möglichen Bindungsstelle wird deutlich, daß 1UFA ebenso wie das AmyB die Bindungsstelle auf ähnliche Weise blockiert (Abb. 3.17). Da eine Sequenzhomologie von $\sim 30 \%$ zu beobachten ist (vgl. Anhang A.3), handelt es sich bei AmyB und 1UFA um strukturhomologe Proteine mit wahrscheinlich ähnlicher oder sogar gleicher Aufgabe.

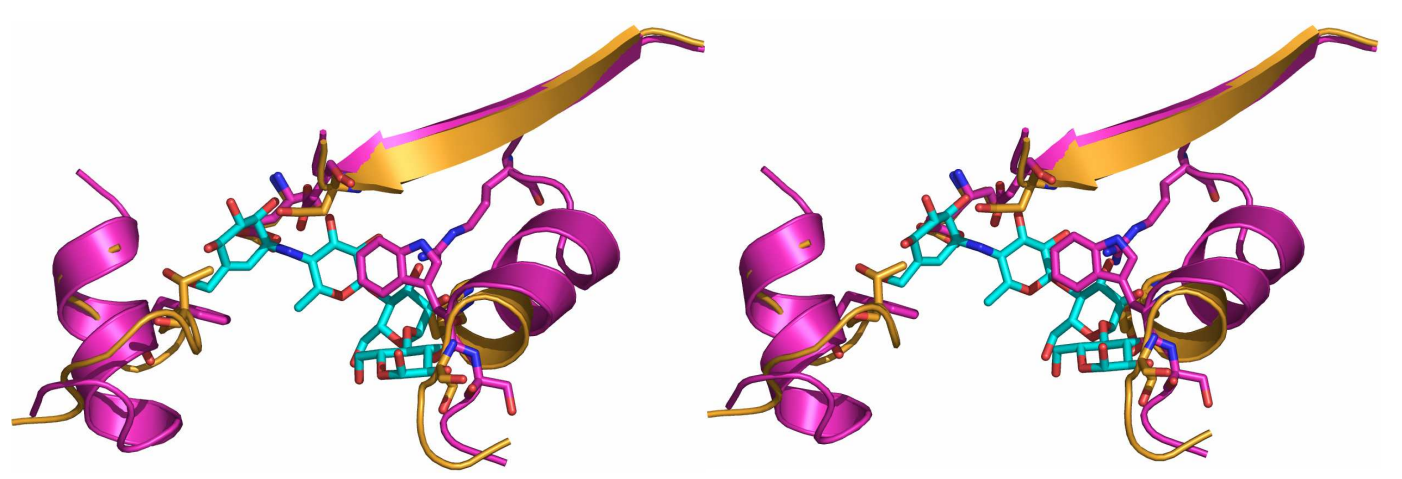

Abbildung 3.17: Stereodarstellung der Bindungsstellen von AmyB (orange) und 1UFA (magenta) mit einer theoretisch eingefügten Acarbose. In beiden Fällen wird die Bindung von Acarbose durch hereinragende Aminosäurereste verhindert 


\section{DISKUSSION}

\subsection{REKONSTITUTION UND KRISTALLISATIONSVERSUCHE EINES SRNP- KOMPLEXES}

Nach ihrer Prozessierung werden die meisten RNAs posttranskriptional modifiziert. Neben der Umwandlung von Uridin in Pseudouridin ist die Methylierung der 2'-Hydroxylgruppe von Zuckerresten die am häufigsten auftretende Modifikation durch snoRNAs beziehungsweise sRNAs in Archaea. Bei den C/D-Box snoRNAs lagert sich die reife RNA an einen komplementären Abschnitt, der vor dem Beginn der Doder D'-Box liegt (BACHALLERIE ET AL., 1995), an die snoRNA an und wird am fünften Nukleotid vor dem Start der D-Box methyliert (TYCOWSKI ET AL., 1996, KISS-LÁSZLÓ ET AL., 1998). Der Prozeß der Methylierung von rRNAs findet aber nicht allein an den snoRNAs statt, sondern benötigt nukleoläre Proteine, die zusammen mit der snoRNA einen snoRNP-Komplex bilden. Vergleicht man die Sequenzen von C/D-Box snoRNAs, die zwei hoch konservierte C- und D-Motive enthalten, und die U4 snRNA, stellt man fest, daß die snoRNA die gleiche Struktur wie die U4 snRNA ausbildet. Die dabei gebildete purinreiche 5+2 Schleife (vgl. Abb. 1.2), die von zwei Stämmen flankiert wird (WeINSTEIN \& STEITZ, 1999; WATKINS ET AL., 2000), bindet z.B. an das humane 15,5 kDa Protein (NotTrotT ET AL., 1999). Ohne die Bindung dieses Proteins an die snoRNA könnten die anderen, für die Methylierung benötigten Proteine nicht angelagert werden. An archaebakteriellen Homologen der Proteine und den sRNAs aus verschiedenen Sulfolobus Stämmen konnten die gleichen Beobachtungen gemacht werden (OMER ET AL., 2002). Um herauszufinden, wie kurz eine RNA sein darf, die nur die konservierten Motive C und D, die kurzen flankierenden Stämme und einen kurze zweite Schleife enthält, wurden in vitro transkribierte RNAs verschiedener Längen in Band-Shift Experimenten untersucht. Dabei konnte eine 28 Nukleotide lange RNA identifiziert werden, die sowohl einen Komplex mit aL7 (homolog zu 15,5 kDa) ausbildet als auch die anderen Proteine anschließend anlagert (Abb. 3.6). Ferner konnte beobachtet werden, daß die Proteine aNop56 und aFibrillarin ohne aL7 keinen Komplex mit der RNA ausbilden können. 
Nach Entfernung der nicht an den Gesamtkomplex gebundenen Komponenten aus dem in vitro rekonstituierten Komplex aus sR13-28a, aL7, aNop56 und aFib durch eine Gelfiltration wurde durch eine Anionenaustauscherchromatographie die Existenz des sRNP-Komplexes, der alle RNA- und Protein-Komponenten enthält, verifiziert (Abb. 3.8). Der entstandene sRNP-Komplex ist demnach für einige Zeit stabil, muß aber wieder dissoziiert werden, da die entstandenen Kristalle ausschließlich aus den Proteinen aFib und aNop56, das obendrein degradiert vorliegt, bestehen (Abb. 3.10). Eine Möglichkeit diese Beobachtung zu erklären, wären noch vorhandene Proteasen in der aNop56- oder der Komplexlösung. Diese Proteasen spalten das aNop56 in Fragmente auf, von denen eines eine Größe von $36 \mathrm{kDa}$ besitzt und an aFib gebunden wird (Abb 3.10). Daß der Spaltprozeß über einen Zeitraum von 4-6 Wochen abläuft, kann am aufgereinigten aNop56-Protein beobachtet werden, das in dieser Zeitspanne in ein $36 \mathrm{kDa}$ großes und mehrere kleinere Fragmente aufgespalten wird. Aus diesem Umstand würde sich auch erklären lassen, warum die Kristalle des aFib-aNop56Komplexes erst nach $\sim 5$ Wochen in einer für sie optimalen Bedingung gebildet wurden.

Daneben kann auch die Dissoziation des Komplexes mit der Degradierung des aNop56-Proteins einhergehen, indem das aNop56 im Bereich des abgespaltenen $12 \mathrm{kDa}$ großen Fragments an den RNA-aL7-Komplex und im Bereich des 36 kDa großen Fragments an das aFib gebunden ist. Ob das aNop56 am N- oder C-terminalen Ende oder sogar an beiden Enden verkürzt wurde, müßte über eine Proteinsequenzierung geklärt werden, denn das homologe Nop5p aus Archaeoglobus fulgidus, das um 150 Aminosäuren kürzer ist, bindet sowohl in der C-terminalen als auch der N-terminalen Region, wobei den Aminosäure-Resten Arg169 und Lys235 eine besondere Bedeutung beigemessen wird (AITTALEB ET AL., 2003). Da die meisten Aminosäuren des gut konservierten C-Terminus nicht in Protein-Protein- oder Protein-Adomet-Interaktionen involviert sind, und das Oberflächen-Potential des Nop5p-Fibrillarin Komplexes in diesem Nop5p-Bereich eine hohe positive Ladung aufweist, gehen AITTALEB ET AL. (2003) davon aus, daß das Nop5p an die RNA bindet. Durch Band-Shift Experimente konnte diese Annahme untermauert werden. Trotz dieser Ergebnisse von AITTALEB ET AL. (2003) bleibt ein genauer Assemblierungsmechanismus weiterhin unklar. Sie unterstützen die Vermutung, daß zumindest das C-terminale Ende des aNop56 durch Proteasen verkürzt wird, und der sRNP-Komplex dissoziiert. In Kristallisationsansätzen mit aFib und einem GluC-verdauten, definierten 36 kDa großen aNop56 konnten keine Kristalle 
erhalten werden, was zu der Annahme führt, daß auch das N-terminale Ende von aNop56 im Ansatz mit dem Volllängenprotein verkürzt wird.

\subsection{AUSBLICK: SRNP-KOMPLEX}

Bisher konnten nur Komplexe aus einer verkürzten RNA und dem archaebakteriellen L7Ae-Protein aus Archaeoglobus fulgidus (MOORE ET AL., 2004) beziehungsweise dem humanen 15,5 kDa Protein (VIDOVIC ET AL., 2000) auf der einen Seite und den zwei Proteinen Fibrillarin und Nop5p (AitTAlEB ET AL., 2003) auf der anderen Seite kristallisiert werden. Sowohl AitTALEB ET AL. (2003) als auch MoORE ET AL. (2004) postulieren, daß die verwendete RNA für einen Gesamtkomplex aus allen vier Komponenten sowohl die C/D-Box als auch die C'/D'-Box beinhalten muß, da die Proteine ein Heterodimer bilden, das durch die RNA und das Nop zusammen gehalten wird. Für weitere Kristallisationsversuche muß daher entweder eine neue RNA, die sowohl das C/D-Motiv als auch das C'/D'-Motiv enthält, konstruiert und synthetisiert werden, oder die Wildtyp-RNA sR1 in großem Maßstab vervielfältigt und gereinigt werden.

Der bei dem verwandten Archaeoglobus fulgidus kristallisierte strukturell aufgeklärte Komplex der C/D-Box Proteine Nop5p und Fibrillarin, konnte mit den orthologen Proteinen aNop56 und aFib aus Sulfolobus solfataricus ebenfalls kristallisiert werden, wobei das aNop56 im Kristall in degradierter Form vorlag. Da die erhaltenen Komplexkristalle extrem fragil waren und kaum erkennbar streuten, ist es möglich, daß entstehende Kristalle des Gesamtkomplexes mit RNA und allen drei Proteinen ebenfalls solche Eigenschaften aufweisen. Daher wird es nötig, ein geeignetes System zu etablieren, daß den Komplex schützt und die Streudaten verbessert. Daneben wäre es ebenfalls sinnvoll, daß degradierte aNop56 ansequenzieren zu lassen, um herauszufinden, wo eine Verkürzung stattfindet. 


\subsection{VERGLEICHENDE UNTERSUCHUNGEN VON AMYB MIT VERWANDTEN STRUKTUREN}

\subsubsection{Charakteristische Sequenz- und Strukturelemente von AmyB, einem Mit- glied der Glykosyl-Hydrolase Familie 57}

AmyB, ein Enzym mit $\alpha$-Amylase Aktivität, wurde 2001 von FütTERER aufgrund seiner enzymatischen und chemischen Eigenschaften als Mitglied der GlykosylHydrolase Familie 57 charakterisiert. Das hervorstechendeste Kennzeichen der $\alpha$-Amylase Familien, die katalytische Domäne in Form eines $(\beta, \alpha)_{8}$-Fasses, das zum ersten Mal 1980 in der $\alpha$-Amylase A aus Aspergillus oryzae identifiziert wurde (MATsuURA et AL., 1980), kann auch in der Struktur des GHF Mitglieds AmyB aus Thermotoga maritima MSB8 wiedererkannt werden (Abb 3.11). Beim Übereinanderlegen der Strukturen eines typischen $\alpha$-Amylase Fasses mit dem AmyB-Faß wird sowohl eine Verkürzung um ein $\beta$-Faltblatt und eine $\alpha$-Helix als auch eine Verzerrung des Fasses deutlich. Daß es sich bei dem fehlenden Teil des katalytischen Fasses um das erste $\beta$-Faltblatt und die erste $\alpha$-Helix handelt, wird durch einen Vergleich der Sequenzen sichtbar. Zwar sind sich die Familienmitglieder der $\alpha$-Amylasen in ihrer Gesamtsequenz nur zu maximal 10\% ähnlich (JANEČEK, 1997; PUJADAS \& PALAU, 2001), aber sie besitzen charakteristische Aminosäure-Sequenzmotive (FrIEDBERG, 1983; ROGERS, 1985; NAKAJIMA, 1986) mit einigen hoch konservierten Aminosäuren. So sind zwei dieser konservierten Aminosäuren das Glycin 56 und das Prolin 64. Sie schließen am C-terminalen Ende des zweiten $\beta$-Faltblattes eine 7-9 Aminosäuren lange Sequenz ein und lassen in den meisten Fällen eine Unterscheidung zwischen $\alpha$-Amylasen (7 Aminosäuren) und Cyclodextrin Glukanotransferasen (8 Aminosäuren) zu (JANEČEK ET AL., 1995; MACGREGOR ET AL., 2001). Und eben diese zwei Aminosäuren können im ersten Faltblatt von AmyB identifiziert werden, wobei allerdings das gesamte $\beta$-Faltblatt überspannt wird, und insgesamt 10 Aminosäuren eingeschlossen werden. Der Vergleich der konservierten Sequenz, die bei $\alpha$-Amylasen eingeschlossen wird, und der AmyBSequenz zeigt, daß bei der AmyB-Sequenz überwiegend hydrophobe Reste auftreten, 
während bei den $\alpha$-Amylasen hydrophobe Reste und Reste, die sowohl hydrophob als auch hydrophil reagieren können, im gleichen Verhältnis vorkommen.

Das katalytische Zentrum des zentralen Strukturelements der $\alpha$-Amylasen liegt in allen bekannten $(\beta, \alpha)_{8}$-Faß-Strukturen am C-terminalen Ende (FARBER \& PETSKO, 1990; BRÄNDÉN \& TOOZE, 1991). Bei der Überprüfung verschiedener AmyBStrukturmodelle (Oberfläche, Oberflächen-Potentiale und Ribbon-Modell) erkennt man auf der C-terminalen Seite des $(\beta, \alpha)_{7}$-Fasses eine eindeutige Bindungstasche (Abb. 3.13 $+3.15)$.

Entsprechend den Aminosäuren Aspartat 206 und Glutamat 230 in der TAKAAmylase A (QIAN ET AL., 1994), konnten in AmyB die Aminosäuren Glu185 und Asp349 als katalytische Reste identifiziert werden (Prof. Dr. W. Liebl, persönliche Mitteilung). Von den weiteren fünf konservierten Aminosäuren, die typischerweise bei $\alpha$-Amylasen im aktiven Zentrum vorhanden sind, sind die Histidine 10 und 12 (TAA: His122 und His296) und das Arginin 471 (TAA: Arg204) im aktiven Zentrum von AmyB auffindbar.

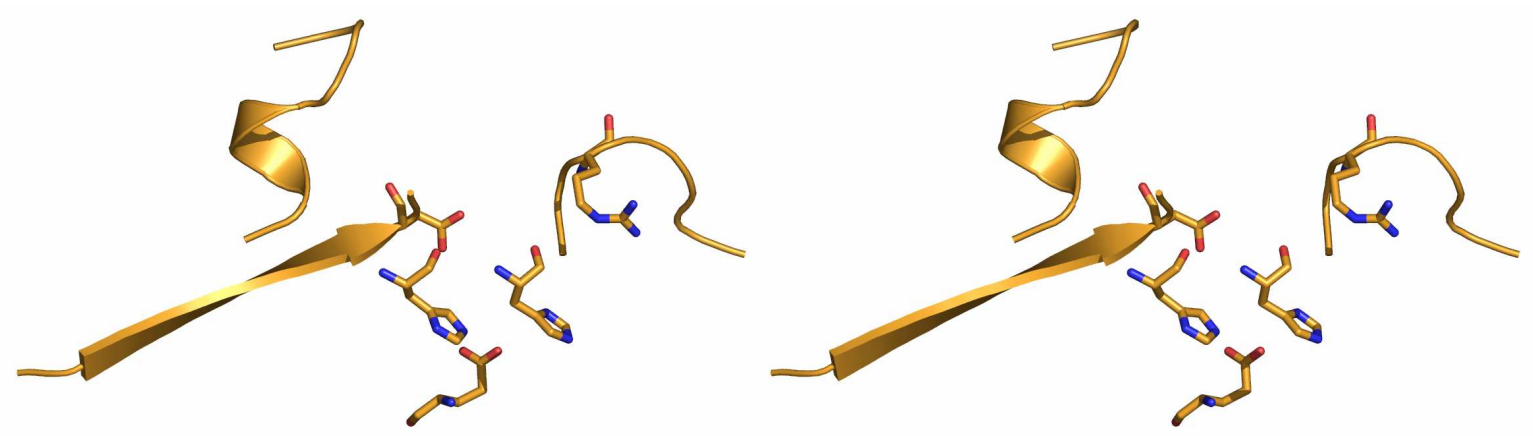

Abbildung 4.1: Stereodarstellung des aktiven Zentrums von AmyB. Das Zentrum enthält sowohl die katalytischen Aminosäuren Glu185 und Asp349 als auch die Aminosäuren His10, His12 und Arg471

D.h. in der Sequenz eines Mitglieds der GHF 57 konnten fünf der sieben in der GHF 13 hoch konservierten Reste im aktiven Zentrum wiedererkannt werden. Aus dieser Tatsache und der $\alpha$-Amylase Aktivität läßt sich folgern, daß es sich bei der Amylase AmyB aus Thermotoga maritima MSB8, ebenso wie die $\alpha$-Amylase aus 
Methanococcus jannaschii (JANEČEK, 1998), um ein Intermediat zwischen der GHF 13 und der GHF 57 handeln könnte.

\subsubsection{Vergleich von AmyB mit anderen $(\beta, \alpha)_{7}-$ Strukturen}

Anhand der Atomkoordinaten von AmyB konnte mit Hilfe des DALI-Servers eine Reihe verwandter Strukturen ermittelt werden. Dabei wurden zwei Strukturen gefunden, die im Bereich des $(\beta, \alpha)_{7}$-Fasses einen Verwandtschaftsgrad (Z-Faktor) von 37,2 (Gesamtsequenz: 41,5 für 1UFA aus Thermus thermophilus Hb8) und 21,4 (Gesamtsequenz: 25,2 für die 4- $\alpha$-Glukanotransferase aus Thermococus litoralis) aufweisen (Gesamtsequenz vgl. Tab. 3.2).

\subsubsection{AmyB und die Thermococcus litoralis 4- $\alpha$-Glukanotransferase}

An der 4- $\alpha$-Glukanotransferase aus Thermococcus litoralis wurde die erste Struktur eines Mitglieds der GHF 57 aufgeklärt (IMAMURA ET AL., 2003). Bis zu diesem Zeitpunkt war über Enzyme der GHF 57 nur wenig bekannt. So wußte man aus CrossLink-Experimenten über die 4- $\alpha$-Glukanotransferase ausschließlich, daß das Glutamat 123 als Nukleophil bei der katalytischen Reaktion fungiert (IMAMURA ET AL., 2001). Mit Aufklärung der Struktur der Acarbose-komplexierten 4- $\alpha$-Glukanotransferase, konnte das aktive Zentrum in der N-terminalen Domäne A lokalisiert werden. Dabei besetzt Acarviosin, die inhibitorische Disaccharid-Einheit der Acarbose, die Bindungsstellen -1 und +1 und blockiert die Reaktion des Nukleophils. Auf diese Art und Weise wird in den meisten $\alpha$-Amylasen das aktive Zentrum durch Acarbose blockiert (PRZYLAS ET AL., 2000). Durch seine Nähe zum $\mathrm{C}_{\alpha}$-Atom des Valienamin-Teils der Acarbose kann das Glu123 nur als katalytisches Nukleophil angreifen, während die einzige weitere saure Aminosäure, Asp214, durch seine Nähe zum Stickstoff nur als Säure/Base-Katalysator in Frage kommt (Abb. 3.14).

Der Vergleich der AmyB-Struktur mit der Acarbose-komplexierten 4- $\alpha$-Glukanotransferase zeigt zwei Strukturen, die in großen Bereichen ihrer katalytischen Fässer übereinstimmen (Abb. 3.12). Geht man auf die Aminosäuren-Ebene der 
katalytischen Zentren, kann man erkennen, daß das aktive Zentrum der 4- $\alpha$-Glukanotransferase weiter aufgeklappt ist als das von AmyB, und somit die Möglichkeit besitzt, größere Saccharide aufzunehmen. Das Nukleophil Glu123 aus der 4- $\alpha$-Glukanotransferase und das Glu185 aus AmyB liegen beide in der gleichen Orientierung vor, wodurch eine Funktion als Nukleophil des AmyB Glu185 durchaus sinnvoll erscheint (Abb. 3.16). Daneben sind die Aspartat-Reste zueinander verdreht (Abb. 3.16). Dies könnte neben einigen anderen Anhaltspunkten ein Hinweis darauf sein, daß die Konformation im aktiven Zentrum verändert wird, um Saccharide zu binden. Weitere Zeichen für eine benötigte Konformationsänderung sind die Aminosäure-Reste Glu243, Ser247 und Thr469, die alle in den Bereich ragen, wo sich Polysaccharide anlagern sollten, es aufgrund von Platzmangel jedoch nicht können (Abb. $3.15 \mathbf{A}+\mathbf{B})$. Bei der 4- $\alpha$-Glukanotransferase konnte ein Aufklappen des aktiven Zentrums bei der Bindung von Acarbose beobachtet werden (IMAMURA ET AL., 2003). Dies untermauert die Annahme, daß das aktive Zentrum der $\alpha$-Amylase AmyB gleichfalls aufklappt, um ein Zuckermolekül zu binden. Auch am Oberflächen-Potential von AmyB lassen sich die optimalen Voraussetzungen für die Bindung von Zuckermolekülen durch eine stark negative Ladung der Bindungstasche ausmachen (Abb. 3.13).

Im Gegensatz zur 4- $\alpha$-Glukanotransferase konnte in AmyB keine Bindung von einem $\mathrm{Ca}^{2+}$-Ion beobachtet werden, was durch das Fehlen der Domäne B erklärt werden kann. An der Domäne $\mathrm{B}$ wird das $\mathrm{Ca}^{2+}$-Ion entweder ganz gebunden oder zur Stabilisierung der katalytischen Domäne zum Teil an das aktive Zentrum und zum anderen Teil an die Domäne B gebunden, ein Phänomen, das ebenfalls in echten $\alpha$-Amylasen auftritt (BOEL ET AL., 1990).

\subsubsection{AmyB und 1UFA}

Den höchsten Verwandtschaftsgrad zu AmyB weist ein bisher uncharakterisiertes Enzym aus Thermus thermophilus Hb8 auf. Der Vergleich beider Strukturen zeigt zwei fast identische Strukturbilder, die nur durch kleinere Abweichungen, wie z.B. einer etwas längeren $\alpha$-Helix oder kurzer $\beta$-Faltblätter in nur einer Struktur, unterschieden werden können (Abb. 3.11). 
Stellt man die Sequenzen der beiden Enzyme gegenüber, ist trotz der strukturellen Homologie nur eine Ähnlichkeit der Sequenzen von $\sim 30 \%$ zu erkennen. Trotz der fehlenden Sequenzhomologie sind sich die beiden Enzyme so ähnlich, daß sie die Bindungstasche für ihr Substrat unzugänglich machen, indem mehrere AminosäureReste in die Bindungstasche hineinragen (Abb. 3.17), d.h. auch 1UFA muß seine geschützte Bindungstasche aufklappen, um ein Zuckermolekül binden zu können. Fehlende Sequenzhomologien der beiden Enzyme führen in diesem Fall zu der Annahme, daß bei der Entwicklung des $(\beta, \alpha)_{7}$-Fasses auch die Theorie der konvergenten Evolution, sprich der Entwicklung desselben Motives aus unterschiedlichen Ursprüngen, nicht völlig ausgeschlossen werden kann.

\subsubsection{Thermostabilität von AmyB und anderen GHF 57 Familienmitgliedern}

Es gibt zwei Begründungen, warum die Thermostabilität bei Proteinen, also auch bei $\alpha$-Amylasen, ansteigt. Zum einen gehen SUZUKI und Mitarbeiter davon aus, daß eine ansteigende Zahl von Prolinen an bestimmten Stellen im Protein von entscheidender Bedeutung sind (SUZUKI ET AL., 1987; SUZUKI, 1989). Diese Behauptung konnte durch Untersuchungen an Oligo-1,6-Glukosidasen aus drei unterschiedlich thermostabilen Bacillus Stämmen untermauert werden (WATANABE ET AL. 1991, 1994 \& 1996). Sie konnten zeigen, daß die Thermostabilität der Oligo-1,6-Glukosidasen zunahm, je mehr Proline im Protein vorhanden waren. Einen besonderen Einfluß auf die Thermostabilität zeigten dabei Proline, die an zweiter Stelle in den $\beta$-Schleifen und am Anfang von $\alpha$-Helices auftraten. Anhand dieser Gegebenheiten kann die Thermostabilität von AmyB jedoch nicht eindeutig begründet werden, denn bei einer genaueren Betrachtung der prozentualen Anteile an Prolinen in AmyB und den Oligo-1,6Glukosidasen, stellt man fest, daß AmyB zwischen der thermolabilen und der leicht thermostabilen Glukosidase angesiedelt wäre. Für die Theorie der Stabilisierung durch Proline spricht dagegen die Tatsache, daß von den zwanzig in AmyB vorkommenden Prolinen sieben an Positionen in den $\beta$-Schleifen und $\alpha$-Helices, die eine Bedeutung für die Thermostabilität haben, lokalisiert sind. Es befindet sich nur ein Prolin an der zweiten Stelle in einer $\beta$-Schleife, jedoch zwei weitere an der dritten Position. Die restlichen sechs der sieben Proline liegen in der ersten Windung der $\alpha$-Helices. 
Zum anderen wird die Thermostabilität von Proteinen dadurch erklärt, daß das Innere des Proteins möglichst viele hydrophobe Aminosäuren enthält, während die Aminosäuren auf der Oberfläche überwiegend hydrophil seien sollten. Im Besonderen beachtet man bei den $\alpha$-Amylasen das $(\beta, \alpha)_{7}-\mathrm{Fa} \beta$ und seine Hydrophobie im Inneren des Fasses, respektive der $\beta$-Faltblätter, und die Hydrophilie auf der Außenseite der $\alpha$-Helices. Bei der genaueren Betrachtung der $\beta$-Faltblätter im Inneren des $(\beta, \alpha)_{7}$-Fasses von AmyB wird deutlich, daß die $\beta$-Faltblätter zu $62 \%$ aus hydrophoben Aminosäuren bestehen, während nur 16\% der Aminosäuren hydrophil sind. Eine solch deutliche Verschiebung zu den hydrophoben Aminosäuren, wie sie in den $\beta$-Faltblättern stattfindet, läßt sich bei den $\alpha$-Helices zur anderen, hydrophilen Seite hin nicht beobachten. Außer der sechsten Helix des $(\beta, \alpha)_{7}$-Fasses (entspricht der siebten Helix in $(\beta, \alpha)_{8}$-Fässern der GHF 13) bestehen alle anderen $\alpha$-Helices aus einer ähnlichen Anzahl von hydrophilen und hydrophoben Aminosäuren. Die Hydrophilie der $\alpha$-Helices wird nur durch Aminosäuren erreicht, die sowohl hydrophil als auch hydrophob reagieren können, überwiegend aber hydrophil agieren. Das die $\alpha$-Helix 6 mehrheitlich aus hydrophoben Resten besteht, läßt sich durch das Vorliegen im Inneren des Proteins erklären und wird auch in anderen $\alpha$-Amylase $(\beta, \alpha)_{8}$-Fässern beobachtet (JANEČEK, 1993).

\subsection{AUSBLICK: AMYB}

Bei der Struktur von AmyB ist deutlich zu erkennen, daß die Bindungstasche mit den katalytischen Aminosäuren Asp349 und Glu185 nicht genügend Platz für die Spaltung langkettiger Saccharide beziehungsweise in umgekehrter Richtung den Aufbau solcher Saccharide bietet. Aufgrund dieser Beobachtungen wird deutlich, daß im aktiven Zentrum von AmyB eine Änderung der Konformation stattfinden muß, um eine Bindung von Sacchariden zu ermöglichen. Ob und wie anschließend Polysaccharide wahrscheinlich gespalten werden, ist ebenfalls noch zu untersuchen.

Unter den bisher gegebenen Hochsalz-Bedingungen, in denen native und auch Selenomethionin Kristalle gewachsen sind, ist es unmöglich Kristalle zu züchten, an die ein Co-Faktor durch Co-Kristallisation binden kann. Dies ist auf den Umstand zurïckzuführen, daß Proteine ihre Konformation in hohen Salz-Konzentrationen ungern verändern. In weiterführenden Versuchen müßte nun geklärt werden, ob Kristalle unter 
anderen Kristallisationsbedingungen, die deutlich weniger Salz enthalten, wachsen. Diese Kristalle sollten die gleiche Raumgruppe aufweisen, und sich neben der nativen Form auch in einer z.B. mit einem Zucker komplexierten Form produzieren lassen. Um eine konformelle Änderung des aktiven Zentrums nicht zu behindern, sollte das in diesen Versuchen eingesetzte Protein aktiv sein. Auch eine Anhebung der Temperatur beim Kristallisieren könnte die entstehenden Kristalle der thermophilen Amylase AmyB positiv beeinflussen. Komplexierte Kristalle können dann weiteren Aufschluß über die Funktion und den Katalyse-Mechanismus liefern, die dann unter biochemischen Gesichtspunkten verifiziert werden müssen. 


\section{LITERATURVERZEICHNIS}

Aittaleb, M., Rashid, R., Chen, Q., Palmer, J. R., Daniels, C. J. \& Li, H. (2003): Structure and function of archaeal box C/D sRNP core proteins. Nat. Struct. Biol. 10(4), 256-263.

Ausubel, F. M., Brent, R., Kingston, R. Z., Moore, D. D., Seidman, J. G., Smith, J. A. \& Struht, K. (eds.) (1992): Current protocols in molecular biology. Greene Publishing Associates and Wiley-Interscience, New York.

Bachellerie, J.-P., Michot, B., Nicoloso, M., Balakin, A, Ni, J \& Fournier, M. J. (1995): Antisense snoRNAs: a family of nucleolar RNAs with long complementarity to rRNA. Trends Biochem. Sci. 20(7), 261-264.

Baecker, P. A., Greenberg, E. \& Preiss, J. (1986): Biosynthesis of bacterial glycogen. Primary structure of Escherichia coli 1,4- $\alpha$-D-glucan: 1,4- $\alpha$-D-glucan $6-\alpha-\mathrm{D}-(1,4-\alpha$-Dglucano)-transferase as deduced from the nucleotide sequence of the glg B gene. J. Biol. Chem. 261(19), 8738-8743.

Balakin, A. G., Lempicki, R. A., Huang, G. M. \& Fournier, M. J. (1994): Saccharomyces cerevisiae U14 small nuclear RNA has little secondary structure and appears to be produced by post-transcriptional processing. J. Biol. Chem. 269(1), 739746.

Balakin, A. G., Smith, L. \& Fournier, M. (1996): The RNA world of the nucleolus: Two major families of small RNAs defined by different box elements with related functions. Cell 86, 823-834.

Banner, D. W., Bloomer, A. C., Petsko, G. A., Phillips, D. C., Pogson, C. I., Wilson, I.A., Corran, P. H., Furth, A. J., Milman, J. D., Offord, R. E., Priddle, J. D. \& Waley, S. G. (1975): Structure of chicken muscle triose phosphate isomerase determined crystallographically at $2.5 \AA$ resolution using amino acid sequence data. Nature 255(5510), 609-614. 
Bertoldo, C. \& Antranikian, G. (2001): Amylolytic enzymes from hyperthermophiles. Methods Enzymol. 330, 269-289.

BIRnBoIM, H. C. \& DOLY, J. (1979): A rapid alkaline extraction procedure for screening recombinant Plasmid DNA. Nucleic Acids Res. 56, 779-826.

Boel, E., Brady, L., Brzozowski, A. M., Derewenda, Z., Dodson, G. G., Jensen, V. J., Peterson, S. B., Swift, H., Thim, L. \& Woldike, H. F. (1990): Calcium binding in $\alpha$-amylases: an X-ray diffraction study at $2.1 \AA$ resolution of two enzymes from Aspergillus. Biochemistry 29(26), 6244-6249.

Bork, P., Holm, L. \& SAnder, C. (1994): The immunoglobulin fold. Structural classification, sequence patterns and common core. J. Mol. Biol. 242(4), 309-320.

Bortolin, M.-L., GANOT, P. \& Kiss, T. (1999): Elements essential for accumulation and function of small nucleolar RNAs directing site-specific pseudouridinylation of ribosomal RNAs. EMBO J. 18(2), 457-469.

Bousquet-Antonelli, C., Henry, Y., Gélugne, J.-P., CAizerguez-Ferrer, M. \& KISS, T. (1997): A small nucleolar RNP protein is required for pseudouridinylation of eucaryotic ribosomal RNAs. EMBO J. 16(15), 4770-4776.

BRADFORD, M. (1976): A rapid and sensitive method for the quantitation of microgram quantities of protein utilizing the principles of protein-dye binding. Analyt. Biochemistry 72, 248-254.

BRÄNDÉN, C. I. \& ToOzE, J. (1991): Introduction to Protein Structure. Garland, New York.

Buisson, G., DuÉE, E., HASER, R. \& PAyAn, F. (1987): Three dimensional structure of porcine pancreatic alpha-amylase at $2.9 \AA$ resolution. Role of calcium in structure and activity. EMBO J. 6(13), 3909-3916. 
Bult, C. J., White, O., Olsen, G. J., Zhou, L., Fleischmann, R. D., Sutton, G. G., Blake, J. A., Fitzgerald, L. M., Clayton, R. A., Gocayne, J. D., Kerlavage, A. R., Dougherty, B. A., Tomb, J. F., AdAms, M. D., Reich, C. I., Overbeek, R., Kirkness, E. F., Weinstock, K. G., Merrick, J. M., Glodek, A., Scott, J. L., Geohagen, N. S. M., Weidman, J.F., Fuhrmann, J. L., Presley, E. A., Nguyen, D., Utterback, T. R., Kelley, J. M., Peterson, J. D., Sadow, P. W., Hanna, M. C., Cotton, M. D., Hurst, M. A., Roberts, K. M., Kaine, B. P., Borodovsky, M., Klenk, H. P., Fraser, C. M., SMith, H. O., Woese, C. R. \& Venter, J. C. (1996): Complete genome sequence of the methanogenic archaeon, Methanococcus jannaschii. Science 273, 1058-1073.

Carvalho, T., Almeida, F., Calapez, A., Lafarga, M, Berciano, M. T. \& CarmoFONESECA, M. (1999): The spinal muscular atrophy disease gene product, SMN: a link between snRNP biogenesis and the Cajal (coiled) body. J. Cell Biol. 147, 715-727.

Caspar, D. L., Cohen, C. \& Longley, W. (1969): Tropomyosin: crystal structure, polymorphism, and molecular interactions. J. Mol. Biol. 41(1), 87-107.

ChU, S., Zengel, J. M. \& LindAHL, L. (1997): A novel protein shared by RNase MRP and RNase P. RNA 3(4), 382-391.

Cohen, C., Caspar, D. L., Parry, D. A.\& LuCAS, R. M. (1972): Tropomyosin crystal dynamics. Cold Spring Harb. Symp. Quant. Bio. 36, 205-216.

Coutinho, P. M. \& Henrissat, B. (1999): Carbohydrate-active enzymes server. URL: www.cnrs-mrs.fr/ cazy/CAZY/index.html

COWAN D. (1996): The outer reaches of life. Tibtech 13, 177.

CRICK, F. (1970): Central dogma of molecular biology. Nature 227(258), 561-563.

Darzacq, X., Jády, B.E., Verheggen, C., Kiss, A. M., Bertrand, E. \& Kiss, T. (2002): Cajal body-specific small nuclear RNAs: a novel class of 2'-O-methylation and pseudouridinylation guide RNAs. EMBO J. 21(11), 2746-56. 
DAVIES, G. J., WiLSON, K. S. \& HENRISSAT, B. (1997): Nomenclature for sugar-binding subsites in glycosyl hydrolases. Biochem J. 321, 557-559.

DeLonG, E. F. (2001): A phylogenetic perspective on hyperthermophilic microorganisms. Methods Enzymol. 330, 3-11.

Dichtl, B \& Tollervey, D. (1997): Pop3p is essential for the activity of the RNase MRP and RNase P ribonucleoproteins in vivo. EMBO J. 16(2), 417-429.

Dong, G., Vieille, C., SAvchenk, A. \& Zeikus, J. G. (1997): Cloning, sequencing, and expression of the gene encoding extracellular alpha-amylase from Pyrococcus furiosus and biochemical characterization of the recombinant enzyme. Appl. Environ. Microbiol. 63(9), 3569-3576.

DrEnTH, J. (1999): Principles of protein X-ray crystallography. Springer Verlag, $2^{\text {nd }}$ Edition.

Farber, G. K. \& Petsko, G. A. (1990): The evolution of $\alpha / \beta$ barrel enzymes. Trends Biochem. Sci. 15(6), 228-234.

Filipowicz, W., Pelczar, P., Pogacic, V. \& Dragon, F. (1999): Structure and biogenesis of small nucleolar RNAs acting as guides for ribosomal RNA modification. Acta Biochim. Pol. 46(2), 377-389.

FRIEDBERG, F. (1983): On the primary structure of amylases. FEBS Lett. 152(2), 139140.

FÜTTERER, O. (2001): Vergleichende Untersuchung von drei Amylasen des hyperthermophilen Bakteriums Thermotoga maritima MSB8. Dissertation, Georg-AugustUniversität Göttingen. 
Fukusumi, S., Kamizono, A., Horinouchi, S. \& Beppu, T. (1988): Cloning and nucleotide sequence of a heat-stable amylase gene from an anaerobic thermophile, Dictyoglomus thermophilum. Eur. J. Biochem. 174(1), 15-21.

Gaboriaud, C., Bissery, V., Benchetrit, T. \& Mornon, J. P. (1987): Hydrophobic cluster analysis: an efficient new way to compare and analyse amino acid sequences. FEBS Lett. 224(1), 149-155.

GANOT, P., BORTOLIN, M.-L. \& KISS, T. (1997a): Site-specific pseudouridine formation in preribosomal RNA is guided by small nucleolar RNAs. Cell 89, 799-809.

GANOt, P., CAIZERgues-Ferrer, M. \& Kiss, T. (1997b): The family of box ACA small nucleolar RNAs is defined by an evolutionarily conserved secondary structure and ubiquitous sequence elements essential for RNA accumulation. Genes Dev. 11, 941956.

GAnOt, P., JÁdy, B. E., Bortolin, M.-L., DARZACQ, X. \& Kiss, T. (1999): Nucleolar factors direct the 2'-O-methylation and pseudouridinylation of U6 spliceosomal RNA. Mol. Cell Biol. 19(10), 6906-6917.

Gautier, T., Bergès, T., Tollervey, D. \& Hurt, E. (1997): Nucleolar KKE/D repeat proteins Nop56p and Nop58p interact with Nop1p and are required for ribosome biogenesis. Mol. Cell. Biol. 17(12), 7088-7098.

Guerrier-Takada, C., Gardiner, K., Marsh, T., Pace, N. \& Altman, S. (1983): The RNA moiety of ribonuclease $\mathrm{P}$ is the catalytic subunit of the enzyme. Cell 35, 849-857.

Henras, A., Henry, Y., Bousquet-Antonelli, C., NoAillac-Depeyre, J., GÉlugne, J.-P. \& GAizergues-Ferrer, M. (1998): Nhp2p and Nop10p are essential for the function of H/ACA snoRNPs. EMBO J. 17(23), 7078-7090.

HENRISSAT, B. (1991): A classification of glycosyl hydrolases based on amino acid sequence similarities. Biochem. J. 280, 309-316. 
HENRISSAT, B. \& BAIROCH, A. (1993): New families in the classification of glycosyl hydrolases based on amino acid sequence similarities. Biochem. J. 293, 781-788.

HENRISSAT, B. \& BAIROCH, A. (1996): Updating the sequence-based classification of glycosyl hydrolases. Biochem. J. 316(2), 695-696.

Henrissat, B. (1998): Glycosidase families. Biochem. Soc. Trans. 26(2), 153-156.

Holm, L., Koivula, A. K., Lehtovaara, P. M., Hemminki, A. \& Knowles, J. K. (1990): Random mutagenesis used to probe the structure and function of Bacillus stearothermophilus $\alpha$-amylase. Protein Eng. 3(3), 181-191.

Holm, L. \& SANDER, C. (1993): Protein structure comparison by alignment of distance matrices. J. Mol. Biol. 233, 123-138.

HopPe, W. (1957): Die Faltmolekülmethode: eine neue Methode zur Bestimmung der Kristallstruktur bei ganz oder teilweise bekannten Molekülstrukturen. Acta Cryst. 10, 750-751.

Huber, R (1965): Die automatisierte Faltmolekülmethode. Acta Cryst. 19, 353-356.

Hough, D. W. \& Danson, M. J. (1999): Extremozymes. Curr. Opin. Chem. Biol. 3(1), $39-46$.

Idaka, M., Terada, T., Murayama, K., Yamaguchi, H., Nureki, O., Ishitani, R., Shirouzu, M. \& Yokoyama, S. (2003): Crystal structure of Tt1467 from Thermus thermophilus $\mathrm{Hb} 8$, unpubliziert.

Imamura, H., Fushinobu, S., JeOn, B. S., WAKagi, T. \& MatsuZawa, H. (2001): Identification of the catalytic residue of Thermococcus litoralis 4- $\alpha$-glucanotransferase through mechanism-based labelling. Biochemistry 40(41), 12400-12406. 
Imamura, H., Fushinobu, S., Yamamoto, M., Kumasaka, T., JeOn, B.-S., WaKagi, T. \& Matsuzawa, H. (2003): Crystal structures of 4- $\alpha$-Glucanotransferase from Thermococcus litoralis and its complex with an inhibitor. J. Biol. Chem. 278(21), 19378-19386.

IshiKaWA, K., Matsui, I., HondA, K. \& NAKATANI, H (1992): Multi-functional roles of a histidine residue in human pancreatic $\alpha$-amylase. Biochem. Biophys. Res. Commun. 183(1), 286-291.

Ishikawa, K., Matsui, I., Kobayashi, S., Nakatani, H. \& Honda, K. (1993): Substrate recognition at the binding site in mammalian pancreatic $\alpha$-amylases. Biochemistry 32(24), 6259-6265.

JÁDY, E. A. \& KISS, T. (2001): A small nucleolar guide RNA functions both in 2'-O-ribose methylation and pseudouridinylation of the U5 spliceosomal RNA. EMBO J. 20(3), 541-551.

JANEČEK, Š (1992): New conserved amino acid region of $\alpha$-amylases in the third loop of their $(\beta / \alpha)_{8}$-barrel domains. Biochem. J. 288(3), 1069-1070.

JANEČEK, Š (1993): Does the increased hydrophobicity of the interior and hydrophilicity of the exterior of an enzyme structure reflect its increased thermostability? Int. J. Biol. Macromol. 15(5), 317-318.

JANEČEK, $\check{S}$ (1994): Parallel $\beta / \alpha$-barrels of $\alpha$-amylase, cyclodextrin glycosyltransferase and oligo-1,6-glucosidase versus the barrel of $\beta$-amylase: evolutionary distance is a reflection of unrelated sequences. FEBS Lett. 353(2), 119-123.

JANEČEK, Š \& TÓTH, D. (1994): Amino acid sequence alignment of microbial, plant and animal $\alpha$-amylases. Some evolutionary implications. Biologia 49, 301-306. 
JANEČEK, Š (1994): Close evolutionary relatedness among functionally distantly related members of the $(\alpha / \beta)_{8}$-barrel glycosyl hydrolases suggested by the similarity of their fifth conserved sequence region. FEBS Lett. 377(1), 6-8.

JANEČEK, Š, MACGREgor, E. A. \& Svensson, B (1995): Characteristic differences in the primary structure allow discrimination of cyclodextrin glucanotransferases from $\alpha$-amylases. Biochem. J. 305, 685-686.

JANEČEK, Š., SVENSSON, B. \& HENRISSAT, B. (1997): Domain evolution in the $\alpha$-amylase family. J. Mol. Evol. 45, 322-331.

JANEČEK, Š. (1997): $\alpha$-Amylase family: molecular biology and evolution. Prog. Biophys. Mol. Biol. 67, 67-97.

JANEČEK, Ц̌. (1998): Sequence of archaeal Methanococcus jannaschii $\alpha$-amylase contains features of the families 13 and 57 of glycosyl hydrolases: a trace of their common ancestor? Folia Microbiol. 43, 123-128.

JANEČEK, Š. (2002): A motif of microbial starch-binding domain found in human genethonin. Bioinformatics 18(11), 1534-1537.

JANEČEK, Š., Svensson, B. \& MACGREGOR, E. A. (2003): Relation between domain evolution, specificity, and taxonomy of the $\alpha$-amylase family members containing a C-terminal starch-binding domain. Eur. J. Biochem. 270(4), 635-645.

Jespersen, H. M., MacGregor, E. A., Sierks, M. R. \& Svensson, B. (1991): Comparison of the domain-level organisation of starch hydrolases and related enzymes. Biochem. J. 280, 51-55.

Jespersen, H. M., MacGregor, E. A., Henrissat, B., Sierks, M. R. \& Svensson, B. (1993): Starch- and glycogen-debranching and branching enzymes: prediction of structural feature of the catalytic $(\beta, \alpha)_{8}$-barrel domain and evolutionary relationship to other Amylolytic enzymes. J. Protein Chem. 12(6), 791-805. 
Kiss-LÁszló, Z., Henry, Y., BAChellerie, J.-P., CAizergues-Ferrer, M. \& Kiss, T. (1996): Site-specific ribose methylation of preribosomal RNA: A novel function for small nucleolar RNAs. Cell 85, 1077-1088.

KISS-LÁsZló, Z., HENRY, Y. \& KISS, T. (1998): Sequence and structural elements of methylation guide snoRNAs essential for site-specific ribose. EMBO J. 17(3), 797-807. KISS, T. (2001): Small nucleolar RNA-guided post-transcriptional modification of cellular RNAs. EMBO J. 20(14), 3617-3622.

KLEBER, W. (1961): Einführung in die Kristallographie. Verlag Technik, Berlin.

KLEIN, C. \& SCHULZ, G. E. (1991): Structure of cyclodextrin glycosyltransferase refined at 2.0 Å resolution. J. Mol. Biol. 217(4), 737-750.

Laderman, K. A., Davis, B. R., Krutzsch, H. C., Lewis, M. S., Griko, Y. V., PRIVAlOV, P. L. \& ANFInSEN C. B. (1993): The purification and characterization of an extremely thermostable alpha-amylase from the hyperthermophilic archaebacterium Pyrococcus furiosus. J. Biol. Chem. 268(32), 24394-24401.

LÄMMLI, U. K. (1970): Cleavage of structural proteins during assembly of the head of bacteriophage T4. Nature 227(259), 680-685.

Lafontaine, D. L. J., Bousquet-Antonelli, Y., Henry, M., Caizergues-Ferrer, M. \& TOLLERVEY, D. (1998): The box H + ACA snoRNAs carry Cbf5p, the putative rRNA pseudouridine Synthase. Genes Dev. 12, 527-537.

LANGe, T. S. \& GerbI, S. A. (2000): Transient nucleolar localization of U6 small nuclear RNA in Xenopus laevis oocytes. Mol. Biol. Cell 11(7), 2419-2428.

LESK, A. M., BRÄNDÉN, C. I. \& CHOTHIA, C. (1989): Structural principles of $\alpha / \beta$ barrel proteins: the packing of the interior of the sheet. Proteins 5(2), 139-148. 
Liu, W., De Castro, M. L., Takrama, J., Bilous, P. T., Vinayagamoorthy, T., MAdSEN, N. B. \& BlEACKLEY, R. C. (1993): Molecular cloning, sequencing, and analysis of the cDNA for rabbit muscle glycogen debranching enzyme. Arch. Biochem. Biophys. 306(1), 232-239.

Lygerou, Z., Mitchell, P., Petfalski, E., Seraphin, B. \& Tollervey, D. (1994): The POP1 gene encodes a protein component common to the RNase MRP and RNase P ribonucleoproteins. Genes Dev. 8(12), 1423-1433.

MacGregor, E. A. (1988): Alpha-amylase structure and activity. J. Protein Chem. 7(4), 399-415.

MacGregor, A. W., Jespersen, H. M. \& Svensson, B.(1996): A circularly permuted $\alpha$-amylase-type $\alpha / \beta$-barrel structure in glucan-synthesizing glucosyltransferases. FEBS Lett. 378(3), 263-266.

MACGREGOR, A. W., JANEČEK, Š. \& SVENSSON, B. (2001): Relationship of sequence and structure to specificity in the alpha-amylase family enzymes. Biochim. Biophys. Acta 1546, 1-20.

MADEN, B. E. H. (1990): The numerous modified nucleotides in eucaryontic ribosomal RNA. Prog. Nucleic Acid Res. Mol. Biol. 39, 241-303.

Matsuura, Y., Kusunoki, M., Harada, W., Tanaka, N., Iga, Y., Yasuoka, N., TODA, H., NARITA, K. \& KAKUDO, M. (1980): Molecular structure of taka-amylase A. Backbone chain folding at 3 Å resolution. J. Biochem. (Tokyo). 87(5), 1555-1558.

Matsuura, Y., KusunOKI, M., HARAdA, W. \& KAKUdO, M. (1984): Structure and possible catalytic residues of Taka-amylase A. J. Biochem. 95(3), 697-702.

Moore, T., Zhang, Y., Fenley, M. O. \& Li, H. (2004): Molecular basis of boc C/D RNA-protein interactions; cocrystal structure of archaeal L7Ae and box C/D RNA. Structure 12(5), 807-818. 
NAKAJIMA, R., IMANAKA, T. \& AIBA, S. (1986): Comparison of amino acid sequence of eleven different $\alpha$-amylases. Appl. Microbiol. Biotechnol. 23, 355-360.

Nesterenko, M. V., Tilley, M. \& Upton, J. S. (1994): A simple modification of Blum's silver stain method allows for 30 minute detection of proteins in polyacrylamide gels. J. Biochem. Biophys. Methods 28, 239-242.

Ni, J., TIEN, A. L. \& FOURNIER, M. J. (1997): Small nucleolar RNAs direct site-specific synthesis of pseudouridine in ribosomal RNA. Cell 89, 565-573.

Nottrott, S., Hartmuth, K., Fabrizio, P., Urlaub, H., Vidovic, I., Ficner, R. \& LÜHRMANN, R. (1999): Functional interaction of a novel 15.5kD [U4/U6.U5] tri-snRNP protein with the 5' stem-loop of the U4 snRNA. EMBO J. 18(21), 6119-6133.

Omer, A. D., Lowe, T. M., Russell, A. G., Ebhardt, H., Eddy, S. R. \& Dennis, P. P. (2000): Homologs of small nucleolar RNAs in Archaea. Science 288, 517-522.

OMer, A. D., ZiEsche, S., EBhARDT, H. \& DenNis, P. P. (2002): In vitro reconstitution and activity of a C/D box methylation guide ribonucleoprotein complex. Proc. Natl. Acad. Sci. USA 99(8), 5289-5294.

OTTWINOWsKi, Z. \& MinOR, W. (1997): Processing of X-ray diffraction data collected in oscillation mode. Methods Enzymol. 276, 307-326

PARK, K. H., KiM, T. J., CheOnG, T. K., KIM, J. W., OH, B. H. \& SvenSSON, B. (2000): Structure, specificity and function of cyclomaltodextrinase, a multispecific enzyme of the alpha-amylase family. Biochim. Biophys. Acta 1478, 165-185.

Pickett, S. D., Saqi, M.. A. \& Sternberg, M. J. (1992): Evaluation of the sequence template method for protein structure prediction. Discrimination of the $(\beta / \alpha)_{8}$-barrel fold. J. Mol. Biol. 228(1), 170-187. 
PÖHLING, H. \& NeuhofF, V. (1981): Visualization of proteins with silver stain: a critical analysis. Electrophoresis 2, 141-147.

Przylas, I., Terada, Y., Fuji, K., Takaha, T., Saenger, W. \& Sträter, N. (2000): $\mathrm{X}$-ray structure of acarbose bound to amylomaltase from Thermus aquaticus. Eur. J. Biochem. 267(23), 6903-6913.

PUJADAS, G. \& PALAU, J. (2001): Evolution of $\alpha$-amylases: Architectural features an key residues in the stabilization of the $(\beta / \alpha)_{8}$ scaffold. Mol. Biol. Evol. 18(1), 38-54.

QIAN, M., HASER, R \& PAYAN, F. (1993): Structure and molecular model refinement of pig pancreatic $\alpha$-amylase a $2.1 \AA$ resolution. J. Mol. Biol. 231(3), 785-799.

QiAn, M., HASER, R., Buisson, G., DuÉE,E. \& PAyAn, F. (1994): The active center of a mammalian $\alpha$-amylase. Structure of the complex of a pancreatic $\alpha$-amylase with a carbohydrate inhibitor refined at $2.2 \AA$ resolution. Biochemistry 33(20), 6284-6394.

REDDY, R. \& BUSCH, H. (1988): Small nucleolar RNAs: RNA sequences, structure, and modifications. In BIRnSTIEL, M. L. (ed.): Structure and Function of Major and Minor Small Nuclear Ribonucleoprotein Particles. Springer Verlag, Berlin, Deutschland.

Rogers, J. C. (1985): Two barley $\alpha$-amylase gene families are regulated differently in aleurone cells. J. Biol. Chem. 260(6), 3731-3738.

Rossmann, M. G. \& BlOw, D. M. (1962): The detection of sub-units within the crystallographic asymmetric unit. Acta Cryst. 15, 24-31.

Roujeinikova, A., RaAsch, C., Sedelnikova, S., Liebl, W. \& Rice, D. W. (2002): Crystal structure of Thermotoga maritima 4- $\alpha$-glucanotransferase and its Acarbose complex: implications of substrate specificity and catalysis. J. Mol. Biol. 321(1), 149162. 
SAmbrook, J., Fritsch, E. F. \& Maniatis, T. (eds.) (1989): Molecular cloning: A laboratory manual, second edition. Cold Spring Harbour Laboratory Press, Plainview, New York.

SCHENBORN E. T. \& MiERENDORF, R. C. (1985): A novel transcription property of SP6 and T7 RNA polymerases: dependence on template structure. Nucleic Acids Res. 13, 6223-6236.

SøgaARd, M., Kadziola, A., HASER, R. SvensSOn, B. (1993): Site-directed mutagenesis of histidine 93, aspartic acid 180, glutamic acid 205, histidine 290, and aspartic acid 291 at the active site and tryptophan 279 at the raw starch binding site in barley $\alpha$-amylase 1. J. Biol. Chem. 268(30), 22480-22484.

Strokopytov, B., Penninga, D., Rozeboom, H. J., Kalk, K. H. \& Dijkstra, B. W. (1995): X-Ray structure of cyclodextrin glycosyltransferase complexed with acarbose. Implications for the catalytic mechanism of glycosidases. Biochemistry 34(7), 22342240 .

SuZUKi, Y., Oishi, K., NAKANO, H. \& Nagayama, T. (1987): A strong correlation between the increase in number of proline residues and the rise in thermostability of five Bacillus oligo-1,6-glucosidases. Appl. Microbiol. Biotechnol. 26, 546-551.

SUZUKI, Y. (1989): A general principle of increasing protein thermostability. Proc. Jpn. Acad. 65B, 146-148.

SVENSSON, B. (1994): Protein engineering in the alpha-amylase family: catalytic mechanism, substrate specificity and stability. Plant Mol. Biol. 25, 141-157.

Thompson, J. D., Higgins, D. G. \& Gibson T. J. (1994): CLUSTAL W: improving the sensitivity of progressive multiple sequence alignment through sequence weighting, positions specific gap penalties and weight matrix choice. Nucl. Acids Res. 22, 46734680 . 
Tollervey, D., Lehtonen, H., Jansen, R., Kern, H. \& Hurt, E. C. (1993): Temperature-sensitive mutations demonstrate roles for yeast fibrillarin in pre-rRNA processing, pre-rRNA methylation, and ribosome assembly. Cell 72(3), 443-457.

Tycowski, K. T., Smith, C. M., ShU, M.-D. \& Steitz, J. A. (1996): A small nucleolar RNA requirement for site-specific ribose methylation of rRNA in Xenopus. Proc. Natl. Acad. Sci. USA 93(25), 14480-14485.

Tycowski, K. T., You, Z.-H., GRAhaM, P. J. \& STEITZ, J. A. (1998): Modification of U6 spliceosomal RNA is guided by other small RNAs. Mol. Cell 2, 629-638.

Vidovic, I., NotTrott, S., HARTMUth, K., LÜHRMAnN, R. \& Ficner, R. (2000): Crystal structure of the spliceosomal $15.5 \mathrm{kD}$ protein bound to a U4 snRNA fragment. Mol. Cell 6, 1331-1342.

Voet, D \& Voet, J. G. (1994): Biochemie. VCH, Weinheim, Deutschland.

WANG, H., BoISvERT, D., KIM, K. K., KIM, R. \& KIM, S.-H. (2000): Crystal structure of a fibrillarin homologue from Methanococcus jannaschii, a hyperthermophile, at $1.6 \AA$ resolution. EMBO J. 19(3), 317-323.

Watanabe, K., Chishiro, K., Kitamura, K. \& Suzuki, Y. (1991): Proline residues responsible for thermostability occur with high frequency in the loop regions of an extremely thermostable oligo-1,6-glucosidase from Bacillus thermoglucosidasius KP1006. J. Biol. Chem. 266(36), 24287-24294.

Watanabe, K., Masuda, T., Ohashi, H., Mihara, H. \& Suzuki, Y. (1994): Multiple proline substitutions cumulatively thermostabilize Bacillus cereus ATCC7064 oligo1,6-glucosidase. Irrefragable proof supporting the proline rule. Eur. J. Biochem. 226(2), 277-283. 
Watanabe, K., Kitamura, K. \& Suzuki, Y. (1996): Analysis of the critical sites for protein thermostabilization by proline substitution in oligo-1,6-glucosidase from Bacillus coagulans ATCC 7050 and the evolutionary consideration of proline residues. Appl. Environ. Microbiol. 62(6), 2066-2073.

Watkins, N. J., SéGault, V., Charpentier, B., Nottrott, S., Fabrizio, P., Bachi, A., Wilm, M., Rosbash, M., Branlant, C. \& LÜhrmann, R. (2000): A common core RNP structure shared between the small nucleolar box C/D RNPs and the spliceosomal U4 snRNP. Cell 103, 457-466.

Weinstein, L.B. \& STEITZ, J.A. (1999): Guided tours: from precursor snoRNA to functional snoRNP. Curr. Opin. Cell Biol. 11, 378-384.

Zebarjadian, Y., King, T., Fournier, M. J., Clarke, L. \& Carbon, J. (1999): Point mutations in yeast CBF5 can abolish in vivo pseudouridinylation of rRNA. Mol. Cell Biol. 19(11), 7461-7472. 
ANHANG

A.1 ABKÜRZUNGSVERZEICHNIS

$\begin{array}{ll}\text { A } & \text { Adenin } \\ \text { AmyB } & \text { Amylase B } \\ \text { APS } & \text { Ammoniumpersulfat } \\ \text { ATP } & \text { Adenosintriphosphat } \\ \text { Bis-Tris } & \text { Bis(2-hydroxyethyl)iminotris(hydroxymethyl)methan } \\ \text { C } & \text { Cytosin } \\ \text { CTP } & \text { Cytosintriphosphat } \\ \text { DNA } & \text { desoxyribonucleic acid (Desoxyribonukleinsäure) } \\ \text { DTT } & \text { Dithiothreitol } \\ \text { E. coli } & \text { Escherichia coli } \\ \text { EDTA } & \text { Ethylendiamintetraessigsäure } \\ \text { FPLC } & \text { Fast Protein Liquid Chromatographie } \\ \text { G } & \text { Guanin } \\ \text { GHF } & \text { Glykosyl-Hydrolase Familie } \\ \text { GH-H } & \text { Glykosyl-Hydrolase Familie Stamm H } \\ \text { GTP } & \text { Guanintriphosphat } \\ \text { h } & \text { Stunde } \\ \text { H }{ }_{2} \mathrm{O}_{\text {bidest }} & \text { doppelt entsalztes Wasser } \\ \text { HR } & \text { High Resolution } \\ \text { IPTG } & \text { Isopropyl- } \beta \text {-D-thiogalaktopyranosid } \\ \text { K } & \text { Kelvin } \\ \text { kb } & \text { Kilo-Basenpaare } \\ \text { kDa } & \text { Kilo-Dalton } \\ \text { LB } & \text { Luria Bertani } \\ \text { M } & \text { Molar } \\ \text { Mega Elektronenvolt }\end{array}$




\begin{tabular}{|c|c|}
\hline $\min$ & Minute \\
\hline $\mathrm{mM}$ & Millimolar \\
\hline MPD & 2-Methyl-2,4-pentandiol \\
\hline mRNA & messenger ribonucleic acid (Boten-Ribonukleinsäure) \\
\hline MRP & Mitochondrial RNA Processing \\
\hline MW & Molekulargewicht \\
\hline Nop & nucleolar protein (nukleoläres Protein) \\
\hline OD & optische Dichte \\
\hline PAA & Polyacrylamid \\
\hline PDB & Protein Datenbank \\
\hline PEG & Polyethylenglykol \\
\hline $\mathrm{pET}$ & Plasmid zur Expression in T7 \\
\hline prä-RNA & precursor ribonucleic acid (Vorläufer Ribonukleinsäure) \\
\hline prä-rRNA & $\begin{array}{l}\text { precursor ribosomal ribonucleic acid (Vorläufer-ribosomale Ribonuklein- } \\
\text { säure) }\end{array}$ \\
\hline RNA & ribonucleic acid (Ribonukleinsäure) \\
\hline RNase & Ribonuklease \\
\hline rRNA & ribosomal ribonucleic acid (ribosomale Ribonukleinsäure) \\
\hline RT & Raumtemperatur \\
\hline S & Sekunde \\
\hline SDS & Natriumdodecylsulfat \\
\hline SDS-PAGE & Natriumdodecylsulfat-Polyacrylamid-Gelelektrophorese \\
\hline snRNA & small nuklear ribonucleic acid (kleine nukleäre Ribonukleinsäure) \\
\hline snoRNA & small nucleolar ribonucleic acid (kleine nukleoläre Ribonukleinsäure) \\
\hline snoRNP & $\begin{array}{l}\text { small nucleolar ribonucleic particle (kleiner nukleolärer Ribonukleo- } \\
\text { protein Partikel) }\end{array}$ \\
\hline sRNA & small ribonucleic acid (kleine Ribonukleinsäure) \\
\hline sRNP & small ribonucleic particle (kleiner Ribonukleoprotein Partikel) \\
\hline TAE & Tris-Acetat- Ethylendiamintetraessigsäure \\
\hline TEMED & $\mathrm{N}, \mathrm{N}, \mathrm{N}^{\prime}, \mathrm{N}^{\prime}-$ Tetramethylendiamin \\
\hline TIM & Triosephosphatisomerase \\
\hline Tris & Tris-(hydroxymethyl) aminomethan \\
\hline tRNA & transfer ribonucleic acid (Transfer-Ribonukleinsäure) \\
\hline
\end{tabular}




$\begin{array}{ll}\text { U } & \text { Uridin } \\ \text { UTP } & \text { Uridintriphosphat } \\ \text { v/v } & \text { Volumenprozent } \\ \text { w/v } & \text { Gewichtsvolumenprozent }\end{array}$

\section{A.2 AMINOSÄUREN}

Aminosäure

Alanin

Arginin

Asparagin

Asparaginsäure/Aspartat

Cystein

Glutamin

Glutaminsäure/Glutamat

Glycin

Histidin

Isoleucin

Leucin

Lysin

Methionin

Phenylalanin

Prolin

Serin

Threonin

Tryptophan

Tyrosin

Valin
Drei-Buchstabencode

\section{Ein-Buchstabencode}

$\begin{array}{cc}\text { Ala } & \text { A } \\ \text { Arg } & \text { R } \\ \text { Asn } & \text { N } \\ \text { Asp } & \text { D } \\ \text { Cys } & \text { C } \\ \text { Gln } & \text { Q } \\ \text { Glu } & \text { E } \\ \text { Gly } & \text { G } \\ \text { His } & \text { H } \\ \text { Ile } & \text { I } \\ \text { Leu } & \text { L } \\ \text { Lys } & \text { K } \\ \text { Met } & \text { M } \\ \text { Phe } & \text { F } \\ \text { Pro } & \text { P } \\ \text { Ser } & \text { S } \\ \text { Thr } & \text { T } \\ \text { Trp } & \text { W } \\ \text { Tyr } & \text { Y } \\ \text { Val } & \text { V }\end{array}$




\section{A.3 Protein-SEQUENZALIGNMENT: AmyB-1UFA}

amybxx 0 $1 \mathrm{UFAxx} 1$

amybxx 0 $1 \mathrm{UFAxx} 1$

amybxx0 $1 \mathrm{UFAxx} 1$

amybxx0 $1 \mathrm{UFAxx} 1$

amybxx 0 $1 \mathrm{UFAxx} 1$

amybxx 0 $1 \mathrm{UFAxx} 1$ Prim.cons.

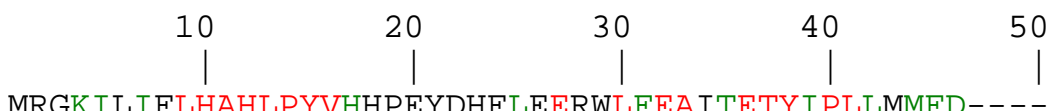

MRGKILIF LHAHLPYVHHP EYDHF LEERWLFEA ITETYIP LLMMFD----XARFALVLHAHLPYVRAHGX-WP FGEETLYEAXAETYLPLIRVLERLRA
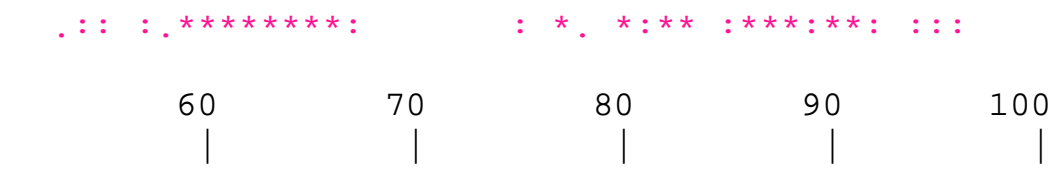
EIEDFRLTMSITPP LMEMLSSRDLQEKYERHMEKLIELANKEVERTKKEH EGVEAPFTLGITP ILAEQLADARIKEGFWAYAKDRLERAQGDYQRYR--G

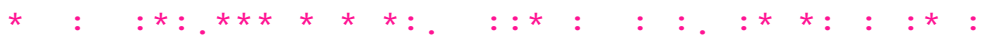

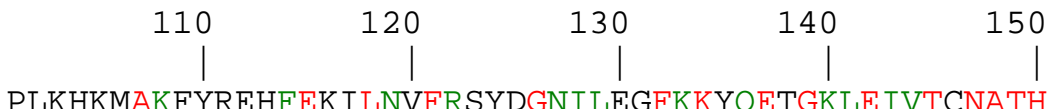
TALEASARHQVAFWELTLDHFQRLSGDLVAAFRKAEEGGQVELITSNATH
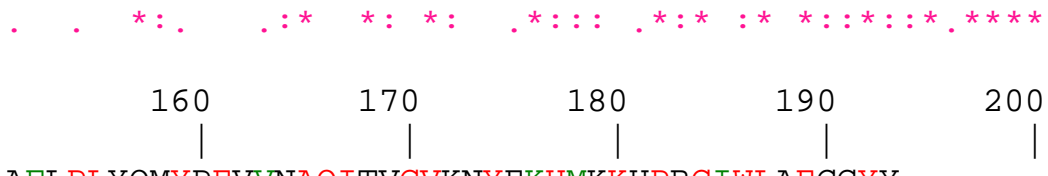
AFLPLYQMYPEVVNAQITVGVKNYEKHMKKHPRGIWLAECGYY------GYSPLLG-YDEALWAQIKTGVSTYRRHFAKDP TGFWLPEXAYRPKGPWKP

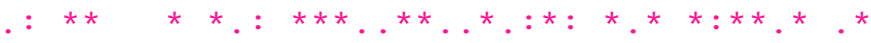

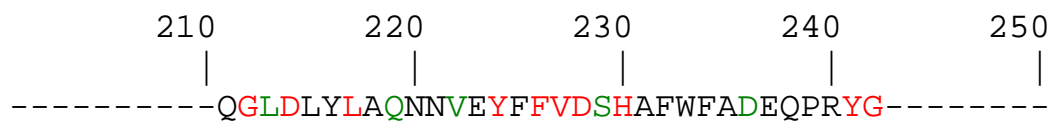
PVEGPPEGVRPGVDELLXRAGIRYTFVDAHLVQGGEP LSPYGEAALGPVE

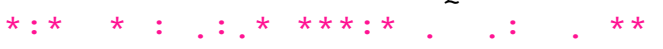

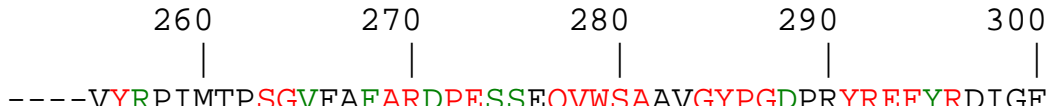
SQEATYHVHELESGLRVLARNPETTLQVWSADYGYP GEGLYREFHRKD--

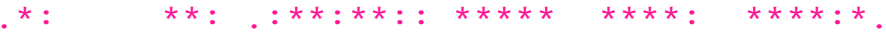
SQEA2Y222222SG2 222AR2PE222QVWSA22GYPG222YREF2R22GF

Abbildung A.1: Protein-Sequenz Alignment von AmyB und 1UFA

Alignment data : Alignment length : 561

Identity (*) : 168 is $29.95 \%$

Strongly similar (:) : 103 is $18.36 \%$

Weakly similar (.) : 54 is $9.63 \%$

Different : 236 is $42.07 \%$

Sequence 0001 : amybxx0 ( 528 residues)

Sequence 0002 : 1UFAxx1 ( 520 residues) 
amybxx 0

$1 \mathrm{UFAxx} 1$

amybxx 0

$1 \mathrm{UFAxx} 1$

amybxx 0 $1 \mathrm{UFAxx} 1$

amybxx 0 $1 \mathrm{UFAxx} 1$

amybxx 0

$1 \mathrm{UFAxx} 1$

amybxx 0

$1 \mathrm{UFAxx} 1$

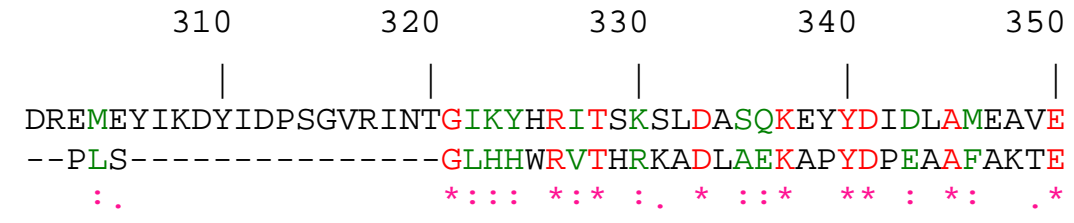

370

380

390

400

EHARDF LHKKESQARRLMD IMGVEPVIVAP FDAELF GHWWFEGVFFLKRF EHARHFVGLLERLAGRHP----EG-VILSPYDAELF GHWWYEGVAWLEAV $\star * * * * * * * * \quad * *:: *: * * * * * * * * *: * * *: *:$.

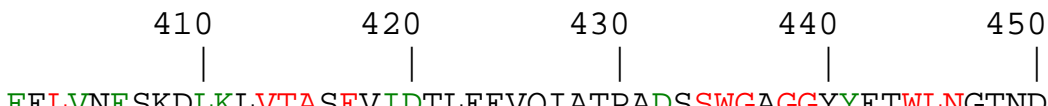
LRLLAQNPKVRPVTAREAVQGPAVRTALP--EGSWGRGGDHRVWLNEKTL $\therefore *:$ : . : : ****.: :

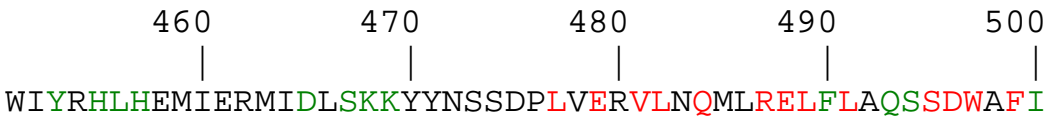
DYWEKVYRAEGAXREAARR-----GVLPEGVLRQAXRELLLLEASDWPFL

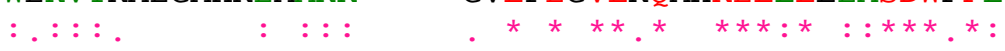<smiles>[Se]O[Se][Se]</smiles>
MTTRTSVQYAENRTKLHIKRF LNLYDQLVSGRIDEEMLRYYEWTDAIFPE XETGQAEAYARERYEEHARAFFHLLKGASP-----EELRALEERDNPFPE

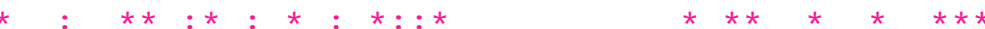

560

INFRVMARDVI

ADPRLYLFREA

: *:

Abbildung A.1: Fortsetzung: Protein-Sequenz Alignment von AmyB und 1UFA 


\section{A.4 ProteinsequenZen Der SRNP Proteine aL7, aNop56 UND aFib}

\section{A.4.1 aL7 (GenBank Nr. S75397)}

1 mnamskasyv kfevpqdlad kvleavrkak esgkikkgtn ettkavergq aklviiaedv

61 qpeeivahlp llcdekkipy vyvsskkalg eacglqvata saailepgea kdlvdeiikr 121 vneikgktss

\section{A.4.2 aNop56 (GenBank Nr. AAK41215)}

1 mmkiyliehv igavaydeng nivdyitnpr dlgkiteell nnekgipfsa tvellkkvnp

61 qevvveneae vpklqalgyr vsyepyskvs rifreslpkv aidikfasne edyynflhel

121 sleytrrklr saaqkrdlla iqavramddi dktinlfser lrewysihfp eldkliedhe

181 eyativsrfg drgfltidsl kelgfneqri nrildaakks igadiseddl samrmianti

241 ldlynirrnl nnylegvmke vapnvtalvg palgarllsi agsldelakm pastiqvlga

301 ekalfralrs ggrppkhgii fqypaihtsp rwqrgkiara laaklaiaar vdafsgrfig

361 dqlneqlkkr ideikekfaq pppkkpqqqk pqqpqkqqak gkkggkrrgk rk

\section{A.4.3 aFib (GenBank Nr. AAK41216)}

1 msevitvkqt nmeniyecef ndgsfrlctr nlvpnfnvyg erlikyegve yrewnafrsk

61 lagailkglk tnpirkgtkv lylgaasgtt ishvsdiiel ngkaygvefs prvvrelllv

121 aqrrpnifpl ladarfpqsy ksvvenvdvl yvdiaqpdqt diaiynakff lkvngdmllv

181 ikarsidvtk dpkeiyktev eklensnfet iqiinldpyd kdhaivlsky kg 


\section{DANKSAGUNG}

Herrn Prof. Dr. Ralf Ficner möchte ich sowohl für die Bereitstellung des Themas und die hervorragenden Arbeitsbedingungen als auch für den steten Gedankenaustausch danken.

Herrn Prof. Dr. Oliver Einsle danke ich für die Bereitschaft, meine Doktorarbeit als Zweitgutachter zu bewerten.

Für wertvolle Tips und Hilfestellungen mit Linux und den Programmen zur Strukturaufklärung gehört mein ganzer Dank Markus und Oliver. Für wichtige Kniffe im WetLab-Alltag danke ich besonders Annette und Achim.

Angela, Annette, Christina, Christos und Peter Thomas danke ich für die lustigsten und diskussionsfreudigsten Momente im Labor und der Freizeit (P.S.: Wir könnten schon lange reich und berühmt sein!).

Für die wertvolle technische Unterstützung bei der Aufreinigung der snoRNP-Proteine möchte ich Winfried danken.

Allen anderen, hier nicht namentlich erwähnten Labormitgliedern der AGs Ficner und Lührmann möchte ich ebenfalls für die schöne Zeit danken.

Danken möchte ich auch meinen Geschwistern, die soviel Geduld haben, noch immer auf ein Exemplar meiner Diplomarbeit zu warten. Ich gelobe Besserung und werde mich beeilen.

Thorsten, einfach fürs da sein.

Der größte Dank gilt aber meinen Eltern. Euer Verständnis gegenüber meinem „sturen“ Kopf, den daraus resultierenden Ereignissen und eure Unterstützung während der langen Ausbildungszeit kann ich in keiner Weise wiedergutmachen. 


\section{LEBENSLAUF}

Persönliche Daten

Name

Vorname

Geburtsdatum/-ort

Familienstand

Staatsangehörigkeit
Steinke

Carmen

27.11.1972 in Attendorn

ledig

deutsch

\section{Schulbildung}

08/1979-08/1983 Besuch der Grundschule Meinerzhagen-Valbert

08/1983-06/1993 Besuch des Ev. Gymnasiums Meinerzhagen

Juni 1993

Allgemeine Hochschulreife am Ev. Gymnasium Meinerzhagen

\section{Studium}

WS 1993/94

Immatrikulation an der Westfälischen-Wilhelms Universität Münster; Fachrichtung Chemie/Diplom

WS 1994/95

Immatrikulation an der Westfälischen-Wilhelms Universität Münster; Fachrichtung Biologie/Diplom

September 1996 Vordiplom im Fachbereich Biologie

Ende SS 1999 mündliche Diplomprüfungen im Fachbereich Biologie

10/1999-09/2000 Diplomarbeit in der Arbeitsgruppe Molekulare Zoophysiologie von Prof. Dr. Walter Stöcker an der Westfälischen-Wilhelms Universität Münster.

Titel der Arbeit: Molekulare Analyse zur Verbreitung der Zinkprotease Meprin im Tierreich

01/2001-09/2002 Anfertigung der vorliegenden Dissertation am MPI für Biophysikalische Chemie, Göttingen; Arbeitsgruppe Zelluläre Biochemie von Prof. Dr. Reinhard Lührmann, Untergruppe von Dr. Ralf Ficner

seit 09/2002 Fortsetzung der Dissertation in der Arbeitsgruppe Molekulare Strukturbiologie von Prof. Dr. Ralf Ficner an der Georg-AugustUniversität Göttingen. 

